\title{
The Factor Structure in Equity Options
}

Peter Christoffersen, Mathieu Fournier and Kris Jacobs

CREATES Research Paper 2013-47 


\title{
The Factor Structure in Equity Options*
}

\author{
Peter Christoffersen \\ University of Toronto University of Toronto \\ CBS and CREATES \\ Mathieu Fournier
}

June 27, 2013

\author{
Kris Jacobs \\ University of Houston \\ and Tilburg University
}

\begin{abstract}
Principal component analysis of equity options on Dow-Jones firms reveals a strong factor structure. The first principal component explains $77 \%$ of the variation in the equity volatility level, $77 \%$ of the variation in the equity option skew, and $60 \%$ of the implied volatility term structure across equities. Furthermore, the first principal component has a $92 \%$ correlation with S\&P500 index option volatility, a $64 \%$ correlation with the index option skew, and a $80 \%$ correlation with the index option term structure. We develop an equity option valuation model that captures this factor structure. The model allows for stochastic volatility in the market return and also in the idiosyncratic part of firm returns. The model predicts that firms with higher betas have higher implied volatilities, and steeper moneyness and term structure slopes. We provide a tractable approach for estimating the model on a large set of index and equity option data on which the model provides a good fit. The equity option data support the cross-sectional implications of the estimated model.
\end{abstract}

JEL Classification: G10; G12; G13.

Keywords: Factor models; equity options; implied volatility; option-implied beta.

${ }^{*}$ For helpful comments we thank Yakov Amihud, Menachem Brenner, George Constantinides, Redouane Elkamhi, Rob Engle, Bruno Feunou, Jean-Sebastien Fontaine, Jose Fajardo, Joel Hasbrouck, Jens Jackwerth, Bryan Kelly, Ralph Koijen, Markus Leippold, Dilip Madan, Matthew Richardson, Stijn Van Nieuwerburgh, Jason Wei, Alan White, Robert Whitelaw, Dacheng Xiu, and seminar participants at New York University (Stern), University of Chicago (Booth), University of Houston (Bauer), University of Toronto (Rotman), University of Zurich, as well as conference participants at IFM2, IFSID, NFA, OptionMetrics, and SoFiE. Christoffersen gratefully acknowledges financial support from the Bank of Canada and SSHRC. Correspondence to: Peter Christoffersen, Rotman School of Management, 105 St. George Street Toronto, Ontario, Canada M5S 3E6. E-mail: peter.christoffersen@rotman.utoronto.ca. 


\section{Introduction}

In their path-breaking study, Black and Scholes (1973) show that when valuing equity options in a constant volatility CAPM setting, the beta of the stock does not matter. Consequently, standard equity option valuation models make no attempt at modeling a factor structure in the underlying equities. Typically, a stochastic process is assumed for each underlying equity price and the option is priced on this stochastic process, ignoring any links the underlying equity price may have with other equity prices through common factors. Seminal papers in this vein include Wiggins (1987), Hull and White (1987), and Heston (1993), Bakshi, Cao and Chen (1997), and Bates (2000, 2008). We show that in a CAPM setting with stochastic volatility, the beta does indeed matter for equity option prices. We find strong support for this factor structure in a large-scale empirical investigation using equity option prices.

When considering a single stock option, ignoring an underlying factor structure may be relatively harmless. However, in portfolio applications it is crucial to understand links between the underlying stocks. Risk managers need to understand the total exposure to the underlying risk factors in a portfolio of stocks and stock options. Equity portfolio managers who use equity options to hedge large downside moves in individual stocks need to know their overall market exposure. Dispersion traders who sell (expensive) index options and buy (cheaper) equity options need to understand the market exposure of individual equity options. See for example Driessen, Maenhout, and Vilkov (2009) for evidence on the market exposure of equity options.

Our empirical analysis of more than three quarters of a million index option prices and 11 million equity option prices reveals a very strong factor structure. We study three characteristics of option prices: short-term implied volatility (IV) levels, the slope of IV curves across option moneyness, and the slope of IV curves across option maturity.

First, we compute the daily time series of implied volatility levels (IV) on the stocks in the Dow Jones Industrials Average and extract their principal components. The first common component explains $77 \%$ of the cross-sectional variation in IV levels and the common component has an $92 \%$ correlation with the short-term implied volatility constructed from S\&P 500 index options. Shortterm equity option IV appears to be characterized by a common factor.

Second, a principal component analysis of equity option IV moneyness, known as the option skew, reveals a significant common component as well. $77 \%$ of the variation in the skew across equities is captured by the first principal component. Furthermore, this common component has a correlation of $64 \%$ with the skew of market index options. Third, $60 \%$ of the variation in the term structure of equity IV is explained by the first principal component. This component has a correlation of $80 \%$ with the IV term slope from S\&P 500 index options. 
We use the findings from the principal component analysis as guidance to develop a structural model of equity option prices that incorporates a market factor structure. In line with well-known empirical facts in the literature on index options (see for example Bakshi, Cao and Chen, 1997; Heston and Nandi, 2000; Bates, 2000; and Jones, 2003), the model allows for mean-reverting stochastic volatility and correlated shocks to returns and volatility. Motivated by the principal component analysis, we allow for idiosyncratic shocks to equity returns which also have mean-reverting stochastic volatility and a separate leverage effect.

Individual equity returns are linked to the market index using a standard linear factor model with a constant factor loading. The model belongs to the affine class, which yields closed-form option pricing formulas. It can be extended to allow for market-wide and idiosyncratic jumps. ${ }^{1}$ The model has three important cross-sectional implications. First, it predicts that firms with higher betas have higher implied volatilities, consistent with the empirical findings in Duan and Wei (2009). Second, it predicts that firms with higher betas have steeper moneyness slopes. Third, higher beta firms are expected to have a greater positive (negative) slope when the market variance term-structure is upward (downward) sloping.

We develop a convenient approach to estimating the model using option data. When estimating the model on the firms in the Dow-Jones index, we find that it provides a good fit to observed equity option prices, and the cross-sectional implications of the model are supported by the data. While it is not the main focus of this paper, our model provides option-implied estimates of market betas, which is a topic of recent interest, studied by for example Chang, Christoffersen, Jacobs, and Vainberg (2012), and Buss and Vilkov (2012). Multiple applications in asset pricing and corporate finance require estimates of beta, such as cost of capital estimation, performance evaluation, portfolio selection, and abnormal return measurement.

Our paper is also related to the recent empirical literature on equity options. Dennis and Mayhew (2002) investigate the relationship between firm characteristics and risk-neutral skewness. Bakshi and Kapadia (2003) investigate the volatility risk premium for equity options. Bakshi, Kapadia, and Madan (2003) derive a skew law for individual stocks, decomposing individual return skewness into a systematic and idiosyncratic component. They find that individual firms display much less (negative) option-implied skewness than the market index. Bakshi, Cao, and Zhong (2012) investigate the performance of jump models for equity option valuation. Engle and Figlewski (2012) develop time series models of implied volatilities and study their correlation dynamics. Kelly, Lustig and Van Nieuwerburgh (2013) use the model in our paper to study the pricing of implicit government guarantees to the banking sector. Carr and Madan (2012) develop a Levy-based model

\footnotetext{
${ }^{1}$ Pan (2002), Broadie, Chernov, and Johannes (2007), and Bates (2008) among others have documented the importance of modeling jumps in index options.
} 
with factor structure but provide little empirical evidence. Perhaps most relevant for our work, Duan and Wei (2009) demonstrate empirically that systematic risk matters for the observed prices of equity options on the firm's stock. ${ }^{2}$

Our paper is also related to recent theoretical advances. Mo and Wu (2007) develop an international CAPM model which has features similar to our model. Elkamhi and Ornthanalai (2010) develop a bivariate discrete-time GARCH model to extract the market jump risk premia implicit in individual equity option prices. Finally, Serban, Lehoczky, and Seppi (2008) develop a non-affine model to investigate the relative pricing of index and equity options.

The reminder of the paper is organized as follows. In Section 2 we describe the data set and present the principal components analysis. In Section 3 we develop the theoretical model. Section 4 highlights a number of cross-sectional implications of the model. In Section 5 we estimate the model and investigate its fit to observed index and equity option prices. Section 6 concludes. The appendix contains the proofs of the propositions.

\section{Common Factors in Equity Option Prices}

In this section we first introduce the data set used in our study. We then look for evidence of commonality in three crucial features of the cross-section of equity options: Implied volatility levels, moneyness slopes (or skews), and volatility term structures. We rely on a principal component analysis (PCA) of the firm-specific levels of short-term at-the-money implied volatility (IV), the slope of IV with respect to option moneyness, and the slope of IV with respect to option maturity. The results from this model-free investigation will help identify desirable features of a factor model of equity option prices.

\subsection{Data}

We rely on end-of-day implied volatility surface data from OptionMetrics starting on January 4, 1996 and ending on October 29, 2010. We use the S\&P 500 index to proxy for the market factor. For our sample of individual equities, we choose the firms in the Dow Jones Industrial Average index at the end of the sample. Of the 30 firms in the index we excluded Kraft Foods for which data are not available throughout the sample.

The implied volatility surfaces contain options with more than 30 days and less than 365 days to maturity (DTM). We filter out options that have moneyness (spot price over strike price) less than

\footnotetext{
${ }^{2}$ See also Goyal and Saretto (2009), Vasquez (2011), and Jones and Wang (2012) for recent empirical work on equity option returns.
} 
0.7 and larger than 1.3, those that do not satisfy the usual arbitrage conditions, those with implied volatility less than $5 \%$ and greater than $150 \%$, and those for which the present value of dividends is larger than $4 \%$ of the stock price. For each option maturity, interest rates are estimated by linear interpolation using zero coupon Treasury yields. Dividends are obtained from OptionMetrics and are assumed to be known during the life of each option. For each option we discount future dividends from the current spot price.

The S\&P 500 index options are European, but the individual equity options are American style, and their prices may be influenced by early exercise premiums. OptionMetrics therefore uses binomial trees to compute implied volatility for equity options. Using these implied volatilities, we can treat all options as European-style in the analysis below.

Table 1 presents the number of option contracts, the number of calls and puts, the average days-to-maturity, and the average implied volatility. We have a total of 775,670 index options and on average 758, 976 equity options per firm. The average implied volatility for the market is $20.65 \%$ during the sample period. Cisco has the highest average implied volatility (40.68\%) while Johnson \& Johnson has the lowest average implied volatility (22.79\%). Table 1 also shows that the data set is balanced with respect to the number of calls and puts.

Table 2 reports the average, minimum, and maximum implied volatility, as well as the average option vega. Note that the index option vega is much higher than the equity vegas simply because the S\&P500 index values are much larger than the typical stock price.

Figure 1 plots the daily average short-term $(30<\mathrm{DTM}<60)$ at-the-money $(0.95<S / K<$ 1.05) implied volatility (IV) for six firms (black lines) as well as for the S\&P 500 index (grey lines). Figure 1 shows that the variation in the short-term at-the-money (ATM) equity volatility for each firm is highly related to S\&P 500 volatility.

\subsection{Methodology}

We want to assess the extent to which the time-varying volatilities of equities share one or more common components. In order to gauge the degree of commonality in risk-neutral volatilities, we need daily estimates of the level and slope of the implied volatility curve, and of the slope of the term structure of implied volatility for all firms and the index. For each day $t$ we run the following regression for firm $j$,

$$
I V_{j, l, t}=a_{j, t}+b_{j, t} \cdot\left(S_{t}^{j} / K_{j, l}\right)+c_{j, t} \cdot\left(D T M_{j, l}\right)+\epsilon_{j, l, t}
$$

where $l$ denotes an option available for firm $j$ on day $t$. The regressors are standardized each day by subtracting the mean and dividing by the standard deviation. We run the same regression on 
index option IVs. We interpret $a_{j, t}$ as a measure of the level of implied volatilities of firm $j$ on day $t$. Similarly, $b_{j, t}$ captures the slope of implied volatility curve while $c_{j, t}$ proxies for the slope of the term structure of implied volatility.

Once the regression coefficients have been estimated on each day and for each firm, we run a PCA analysis on each of the matrices $\left\{a_{j, t}\right\},\left\{b_{j, t}\right\}$, and $\left\{c_{j, t}\right\}$. Tables $3-5$ contain the results from the PCA analysis and Figures 2-4 plot the first principal component as well as the time series of the corresponding index option coefficients, $a_{I, t}, b_{I, t}$, and $c_{I, t}$.

\subsubsection{Common Factors in the Level of Implied Equity Volatility}

Table 3 contains the results for implied volatility levels. We report the loading of each equity IV on the first three components. At the bottom of the table we show the average, minimum, and maximum loading across firms for each component. We also report the total variation captured as well as the correlation of each component with S\&P 500 IV. The results in Table 3 are quite striking. The first component captures $77 \%$ of the total cross-sectional variation in the level of IV and it has a $92 \%$ correlation with the S\&P 500 index IV. This suggests that the equity IVs have a very strong common component highly correlated with index option IVs. Note that the loadings on the first component are positive for all 29 firms, illustrating the pervasive nature of the common factor.

The top panel of Figure 2 shows the time series of IV levels for index options. The bottom panel plots the time series of the first PCA component of equity IV. The strong relationship between the two series is readily apparent.

The second PCA component in Table 3 explains $13 \%$ of the total variation and the third component explains $2 \%$. The average loadings on these two components are close to zero and the loadings take on a wide range of positive and negative values. The sizeable second PCA component and the wide range of the loadings suggest the need for a second, firm-specific, source of variation in equity volatility.

\subsubsection{Common Factors in the Moneyness Slope}

Table 4 contains the results for IV moneyness slopes. The moneyness slopes contain a significant degree of co-movement. The first principal component explains $77 \%$ of cross-sectional variation in the moneyness slope. The second and third components explain $6 \%$ and $4 \%$ respectively. The first component has positive loadings on all 29 firms where as the second and third components have positive and negative loadings across firms, and average loadings very close to zero.

Table 4 also shows that the first principal component has a $64 \%$ correlation with the moneyness 
slope of S\&P 500 implied volatility. Equity moneyness slope dynamics clearly seem driven to a non-trivial extent by the market moneyness slope.

Figure 3 plots the S\&P 500 index IV moneyness slope in the top panel and the first principal component from the equity moneyness slopes in the bottom panel. The relationship between the first principal component and the market moneyness slope is readily apparent, but not as strong as for the volatility level in Figure 2.

\subsubsection{Common Factors in the Term Structure Slope}

Table 5 contains the results for IV term structure slopes. The variation in the term structure slope captured by the first principal component is $60 \%$, which is lower than for spot volatility (Table 3 ) and the moneyness slope (Table 4). The loadings on the first component are positive for all 29 firms. The correlation between the first component and the term slope of S\&P 500 index option IV is $80 \%$, which is higher than for the moneyness slope in Table 4 but lower than for the variance level in Table 3. The second and third components capture $14 \%$ and $5 \%$ of the variation respectively and the wide range of loadings on this factor suggest a scope for firm-specific variation in the IV term structure for equity options.

Figure 4 plots the S\&P 500 index IV term structure slope in the top panel and the first principal component from the equity term slopes in the bottom panel. Most of the spikes in the S\&P 500 term structure slope are clearly evident in the first principal component as well.

We conclude that the market volatility term structure captures a substantial share of the variation in equity volatility term structures.

\subsection{Other Stylized Facts in the Cross-Section of Equity Option Prices}

The literature on equity options has documented a number of important cross-sectional stylized facts. Bakshi, Kapadia, and Madan (2003) derive a skew law for individual stocks, decomposing individual return skewness into a systematic and idiosyncratic component. They theoretically investigate and empirically document the relationship between risk-neutral market and equity skewness, which affects the relationship between the moneyness slope for equity and index options. They find that the volatility smile for the market index is on average more negatively sloped than volatility smiles for individual firms. They also show that the more negatively skewed the risk-neutral distribution, the steeper the volatility smile. Finally, they find that the risk-neutral equity distributions are on average less skewed to the left than index distributions.

Other studies document cross-sectional relationships between betas, estimated using historical data, and characteristics of the equity IVs. Dennis and Mayhew (2002) find that option-implied 
skewness tends to be more negative for stocks with larger betas. Duan and Wei (2009) find that the level of implied equity volatility is related to the systematic risk of the firm and that the slope of the implied volatility curve is related to systematic risk as well. Finally, Driessen, Maenhout, and Vilkov (2009) find a large negative index variance risk premium, but find no evidence of a negative risk premium on individual variance risk.

These findings are at first blush not directly related to the findings of the PCA analysis above, which merely documents a strong factor structure of various aspects of implied equity volatilities. We next outline a structural equity option modeling approach with a factor structure that captures the results from the PCA analysis outlined above, but is also able to match the cross-sectional relationships between betas and implied volatilities documented by these studies.

\section{Equity Option Valuation Using a Single-Factor Structure}

We model an equity market consisting of $n$ firms driven by a single market factor, $I_{t}$. The individual stock prices are denoted by $S_{t}^{j}$, for $j=1,2, \ldots, n$. Investors also have access to a risk-free bond which pays a return of $r$.

The market factor evolves according to the process

$$
\frac{d I_{t}}{I_{t}}=\left(r+\mu_{I}\right) d t+\sigma_{I, t} d W_{t}^{(I, 1)}
$$

where $\mu_{I}$ is the instantaneous market risk premium and where volatility is stochastic and follows the standard square root process

$$
d \sigma_{I, t}^{2}=\kappa_{I}\left(\theta_{I}-\sigma_{I, t}^{2}\right) d t+\delta_{I} \sigma_{I, t} d W_{t}^{(I, 2)} .
$$

As in Heston (1993), $\theta_{I}$ denotes the long-run variance, $\kappa_{I}$ captures the speed of mean reversion of $\sigma_{I, t}^{2}$ to $\theta_{I}$, and $\delta_{I}$ measures volatility of volatility. The innovations to the market factor return and volatility are correlated with coefficient $\rho_{I}$. Conventional estimates of $\rho_{I}$ are negative and large capturing the so-called leverage effect in aggregate market returns.

Individual equity prices are driven by the market factor as well as an idiosyncratic term which also has stochastic volatility

$$
\begin{aligned}
\frac{d S_{t}^{j}}{S_{t}^{j}}-r d t & =\alpha_{j} d t+\beta_{j}\left(\frac{d I_{t}}{I_{t}}-r d t\right)+\sigma_{j, t} d W_{t}^{(j, 1)} \\
d \sigma_{j, t}^{2} & =\kappa_{j}\left(\theta_{j}-\sigma_{j, t}^{2}\right) d t+\delta_{j} \sigma_{j, t} d W_{t}^{(j, 2)}
\end{aligned}
$$


where $\alpha_{j}$ denotes the excess return and $\beta_{j}$ is the market beta of firm $j$.

The innovations to idiosyncratic returns and volatility are correlated with coefficient $\rho_{j}$. As suggested by the skew laws derived in Bakshi, Kapadia, and Madan (2003), asymmetry of the idiosyncratic return component is required to explain the differences in the price structure of individual equity and index options. Note that this model of the equity market has a total of $2(n+1)$ innovations.

\subsection{The Risk Neutral Distribution}

In order to use our model of the equity market to value derivatives we need to assume a change of measure from the physical $(P)$ distribution developed above to the risk-neutral $(Q)$ distribution. Following the literature, we assume a change-of-measure of the exponential form

$$
\frac{d Q}{d P}(t)=\exp \left(-\int_{0}^{t} \gamma_{u} d W_{u}-\frac{1}{2} \int_{0}^{t} \gamma_{u}^{\prime} d\left\langle W, W^{\prime}\right\rangle_{u} \gamma_{u}\right)
$$

where $W_{u} \equiv\left[W_{u}^{(1,1)}, W_{u}^{(1,2)}, . ., W_{u}^{(I, 1)}, W_{u}^{(I, 2)}\right]^{\prime}$ is a $2(n+1) \times 1$ vector containing the innovations, $\gamma_{u} \equiv\left[\gamma_{u}^{(1,1)}, \gamma_{u}^{(1,2)}, . ., \gamma_{u}^{(I, 1)}, \gamma_{u}^{(I, 2)}\right]^{\prime}$ is the vector of market prices of risk, and $d\langle.,$.$\rangle is the covariance$ operator.

In the spirit of Cox, Ingersoll, and Ross (1985) and Heston (1993) among others, we assume a price of market variance risk of the form $\lambda_{I} \sigma_{I, t}$. We also assume that idiosyncratic variance risk is not priced. These assumptions yield the following result.

Proposition 1 Given the change-of-measure in (3.5) the process governing the market factor under the Q-measure is given by

$$
\begin{aligned}
\frac{d I_{t}}{I_{t}} & =r d t+\sigma_{I, t} d \tilde{W}_{t}^{(I, 1)} \\
d \sigma_{I, t}^{2} & =\tilde{\kappa}_{I}\left(\tilde{\theta}_{I}-\sigma_{I, t}^{2}\right) d t+\delta_{I} \sigma_{I, t} d \tilde{W}_{t}^{(I, 2)} \\
\text { with } \tilde{\kappa}_{I} & =\kappa_{I}+\delta_{I} \lambda_{I}, \text { and } \tilde{\theta}_{I}=\frac{\kappa_{I} \theta_{I}}{\tilde{\kappa}_{I}},
\end{aligned}
$$

and the processes governing the individual equities under the Q-measure are given by

$$
\begin{aligned}
\frac{d S_{t}^{j}}{S_{t}^{j}} & =r d t+\beta_{j}\left(\frac{d I_{t}}{I_{t}}-r d t\right)+\sigma_{j, t} d \tilde{W}_{t}^{(j, 1)} \\
d \sigma_{j, t}^{2} & =\kappa_{j}\left(\theta_{j}-\sigma_{j, t}^{2}\right) d t+\delta_{j} \sigma_{j, t} d \tilde{W}_{t}^{(j, 2)}
\end{aligned}
$$


where $d \tilde{W}_{t}$ denotes the risk-neutral counterpart of $d W_{t}$ for which

$$
d \tilde{W}_{t}=d W_{t}+d\left\langle W, W^{\prime}\right\rangle_{t} \gamma_{t}
$$

where

$$
\begin{gathered}
\gamma_{t}^{(I, 1)}=\frac{\mu_{I}-\rho_{I} \lambda_{I} \sigma_{I, t}^{2}}{\sigma_{I, t}\left(1-\rho_{I}^{2}\right)} \text { and } \gamma_{t}^{(I, 2)}=\frac{\lambda_{I} \sigma_{I, t}^{2}-\rho_{I} \mu_{I}}{\sigma_{I, t}\left(1-\rho_{I}^{2}\right)} \\
\gamma_{t}^{(j, 1)}=\frac{\alpha_{j}}{\sigma_{j, t}\left(1-\rho_{j}^{2}\right)} \text { and } \gamma_{t}^{(j, 2)}=-\frac{\rho_{j} \alpha_{j}}{\sigma_{j, t}\left(1-\rho_{j}^{2}\right)} .
\end{gathered}
$$

Proof. See Appendix A.

This proposition provides several insights. Note that the market factor structure is preserved un$\operatorname{der} Q$. Consequently, the market beta is the same under the risk-neutral and physical distributions. This is consistent with Serban, Lehoczky, and Seppi (2008), who document that the risk-neutral and objective betas are economically and statistically close for most stocks. Note that this result makes betas estimated from option data appropriate for applications of the CAPM such as capital budgeting.

It is also important to note that in our modeling framework, higher moments and their premiums, as defined by the difference between the moment under $P$ and $Q$, are affected by the drift adjustment in the variance processes. We will discuss this further below.

\subsection{Closed-Form Option Valuation}

The model has been cast in an affine framework, which implies that the characteristic function for the logarithm of the index level and the logarithm of the equity price can both be derived analytically. The characteristic function for the index is identical to that in Heston (1993). Consider now individual equity options. We need the following proposition:

Proposition 2 The risk-neutral conditional characteristic function $\tilde{\phi}^{j}(\tau, u)$ for the equity price, $S_{T}^{j}$, is given by

$$
\begin{aligned}
\tilde{\phi}^{j}(\tau, u) & \equiv E_{t}^{Q}\left[\exp \left(i u \ln \left(S_{T}^{j}\right)\right)\right] \\
& =\left(S_{t}^{j}\right)^{i u} \exp \left(i u r \tau-(A(\tau, u)+B(\tau, u))-C(\tau, u) \sigma_{I, t}^{2}-D(\tau, u) \sigma_{j, t}^{2}\right)
\end{aligned}
$$

where $\tau=T-t$ and the expressions for $A(\tau, u), B(\tau, u), C(\tau, u)$, and $D(\tau, u)$ are provided in Appendix B. 


\section{Proof. See Appendix B.}

Given the characteristic function for the $\log$ spot price under $Q$, the price of a European equity call option with strike price $K$ and maturity $\tau=T-t$ is

$$
C_{t}^{j}\left(S_{t}^{j}, K, \tau\right)=S_{t}^{j} \Pi_{1}^{j}-K e^{-r \tau} \Pi_{2}^{j},
$$

where the risk-neutral probabilities $\Pi_{1}^{j}$ and $\Pi_{2}^{j}$ are defined by

$$
\begin{aligned}
\Pi_{1}^{j} & =\frac{1}{2}+\frac{e^{-r \tau}}{\pi S_{t}^{j}} \int_{0}^{\infty} \operatorname{Re}\left[\frac{e^{-i u \ln K \tilde{\phi}^{j}(\tau, u-i)}}{i u}\right] d u \\
\Pi_{2}^{j} & =\frac{1}{2}+\frac{1}{\pi} \int_{0}^{\infty} \operatorname{Re}\left[\frac{e^{-i u \ln K} \tilde{\phi}^{j}(\tau, u)}{i u}\right] d u .
\end{aligned}
$$

While these integrals must be evaluated numerically, they are well-behaved and can be computed quickly.

\section{Model Properties}

In this section we derive a number of important cross-sectional implications from the model and investigate if the model captures the stylized facts documented in Section 2. We will also draw some key implications of the model for option risk management and for equity option expected returns. For convenience we assume that beta is positive for all firms below. This is not required by the model but it simplifies the interpretation of certain expressions.

\subsection{The Level of Equity Option Volatility}

Duan and Wei (2009) show empirically that firms with higher systematic risk have a higher level of risk-neutral variance. We now investigate if our model is consistent with this empirical finding.

First, define total spot variance for firm $j$ at time $t$

$$
V_{j, t} \equiv \beta_{j}^{2} \sigma_{I, t}^{2}+\sigma_{j, t}^{2},
$$

and define the expectations under $P$ and $Q$ of the corresponding integrated variance by

$$
E_{t}^{P}\left[V_{j, t: T}\right] \equiv E_{t}^{P}\left[\int_{t}^{T} V_{j, s} d s\right] \quad \text { and } \quad E_{t}^{Q}\left[V_{j, t: T}\right] \equiv E_{t}^{Q}\left[\int_{t}^{T} V_{j, s} d s\right] .
$$


By decomposing the $P$-expectation into integrated market variance and idiosyncratic variance, we have

$$
E_{t}^{P}\left[V_{j, t: T}\right]=\beta_{j}^{2} E_{t}^{P}\left[\sigma_{I, t: T}^{2}\right]+E_{t}^{P}\left[\sigma_{j, t: T}^{2}\right],
$$

where $\sigma_{I, t: T}^{2}$, and $\sigma_{j, t: T}^{2}$ correspond to the integrated variances from $t$ to $T$.

Given our model, the expectation of the integrated total variance for equity $j$ under $Q$ is

$$
E_{t}^{Q}\left[V_{j, t: T}\right]=\beta_{j}^{2} E_{t}^{Q}\left[\sigma_{I, t: T}^{2}\right]+E_{t}^{Q}\left[\sigma_{j, t: T}^{2}\right]=\beta_{j}^{2} E_{t}^{Q}\left[\sigma_{I, t: T}^{2}\right]+E_{t}^{P}\left[\sigma_{j, t: T}^{2}\right] .
$$

Note that the second equation holds when idiosyncratic risk is not priced so that $E_{t}^{P}\left[\sigma_{j, t: T}^{2}\right]=$ $E_{t}^{Q}\left[\sigma_{j, t: T}^{2}\right]$.

For any two firms having the same level of expected total variance under the $P$-measure $\left(E_{t}^{P}\left[V_{1, t: T}\right]=E_{t}^{P}\left[V_{2, t: T}\right]\right)$ we have

$$
E_{t}^{P}\left[\sigma_{1, t: T}^{2}\right]-E_{t}^{P}\left[\sigma_{2, t: T}^{2}\right]=-\left(\beta_{1}^{2}-\beta_{2}^{2}\right) E_{t}^{P}\left[\sigma_{I, t: T}^{2}\right] .
$$

Therefore

$$
\begin{aligned}
E_{t}^{Q}\left[V_{1, t: T}\right]-E_{t}^{Q}\left[V_{2, t: T}\right] & =\left(\beta_{1}^{2}-\beta_{2}^{2}\right) E_{t}^{Q}\left[\sigma_{I, t: T}^{2}\right]+\left(E_{t}^{Q}\left[\sigma_{1, t: T}^{2}\right]-E_{t}^{Q}\left[\sigma_{2, t: T}^{2}\right]\right) \\
& =\left(\beta_{1}^{2}-\beta_{2}^{2}\right) E_{t}^{Q}\left[\sigma_{I, t: T}^{2}\right]+\left(E_{t}^{P}\left[\sigma_{1, t: T}^{2}\right]-E_{t}^{P}\left[\sigma_{2, t: T}^{2}\right]\right) \\
& =\left(\beta_{1}^{2}-\beta_{2}^{2}\right)\left(E_{t}^{Q}\left[\sigma_{I, t: T}^{2}\right]-E_{t}^{P}\left[\sigma_{I, t: T}^{2}\right]\right) .
\end{aligned}
$$

When the market variance premium is negative, we have $\tilde{\theta}_{I}>\theta_{I}$ which implies that $E_{t}^{Q}\left[\sigma_{I, t: T}^{2}\right]>$ $E_{t}^{P}\left[\sigma_{I, t: T}^{2}\right]$. We therefore have that

$$
\beta_{1}>\beta_{2} \Leftrightarrow E_{t}^{Q}\left[V_{1, t: T}\right]>E_{t}^{Q}\left[V_{2, t: T}\right]
$$

We conclude that our model is consistent with the finding in Duan and Wei (2009) that firms with high betas tend to have a high level of risk-neutral variance.

\subsection{Equity Option Skews}

To understand the slope of equity option implied volatility moneyness curves, we need to understand how beta influences the skewness of the risk-neutral equity return distribution. The next proposition is key to understanding how beta, systematic risk, and index skewness impact equity skewness.

Proposition 3 The conditional total skewness of the integrated returns of firm $j$ under $P$, denoted 
by $T S k_{j}^{P}$, is given by

$$
T S k_{j, t: T}^{P} \equiv S k^{P}\left(\int_{t}^{T} \frac{d S_{u}^{j}}{S_{u}^{j}}\right)=S k_{I}^{P} \cdot\left(A_{j, t: T}^{P}\right)^{3 / 2}+S k_{j}^{P} \cdot\left(1-A_{j, t: T}^{P}\right)^{3 / 2} .
$$

The conditional total skewness of the integrated returns of firm $j$ under $Q$, denoted by $T S k_{j}^{Q}$, is given by

$$
T S k_{j, t: T}^{Q} \equiv S k^{Q}\left(\int_{t}^{T} \frac{d S_{u}^{j}}{S_{u}^{j}}\right)=S k_{I}^{Q} \cdot\left(A_{j, t: T}^{Q}\right)^{3 / 2}+S k_{j}^{Q} \cdot\left(1-A_{j, t: T}^{Q}\right)^{3 / 2},
$$

where

$$
A_{j, t: T}^{P} \equiv \frac{E_{t}^{P}\left[\beta_{j}^{2} \sigma_{I, t: T}^{2}\right]}{E_{t}^{P}\left[V_{j, t: T}\right]} \text { and } A_{j, t: T}^{Q} \equiv \frac{E_{t}^{Q}\left[\beta_{j}^{2} \sigma_{I, t: T}^{2}\right]}{E_{t}^{Q}\left[V_{j, t: T}\right]}
$$

are the proportion of systematic risk of firm $j$ under $P$ and $Q$, and where $S k_{I}=S k\left(\int_{t}^{T} \frac{d I_{s}}{I_{s}}\right)$ and $S k_{j}=S k\left(\int_{t}^{T} \sigma_{j, s} d W_{s}^{(j, 1)}\right)$ is the market and idiosyncratic skewness, respectively.

Proof. See Appendix C.

This result shows that $\beta_{j}$ matters for determining firm $j$ 's conditional total skewness. Equation (4.2) shows that under the risk neutral measure, $\beta_{j}$ affects the slope of the equity implied volatility curve through $T S k_{j, t: T}^{Q}$ by influencing the systematic risk proportion, $A_{j, t: T}^{Q}$. A higher $A_{j, t: T}^{Q}$ implies a higher loading on the market risk-neutral skewness $S k_{I}^{Q}$. Consider two firms with the same expected total variance under $Q$ and $\beta_{1}>\beta_{2}$, which implies $A_{1, t: T}^{Q}>A_{2, t: T}^{Q}$. Firm 1 has a greater loading on index risk-neutral skewness than firm 2 . When the index $Q$-distribution is more negatively skewed than the idiosyncratic equity distribution, as found empirically in Bakshi, Kapadia, and Madan (2003), we have the following cross-sectional prediction: Higher-beta firms will have more negatively skewed $Q$-distributions. Note that this prediction is in line with the cross-sectional empirical findings of Duan and Wei (2009) and Dennis and Mayhew (2002).

Figure 5 plots the implied Black-Scholes volatility from model option prices. Each line has a different beta but the same amount of unconditional total equity variance defined by $\tilde{V}_{j} \equiv \beta_{j}^{2} \tilde{\theta}_{I}+\theta_{j}=$ 0.1 . We set the current spot variance to $\sigma_{I, t}^{2}=0.01$ and $V_{j, t}=0.05$, and define the idiosyncratic variance as the residual $\sigma_{j, t}^{2}=V_{j, t}-\beta_{j}^{2} \sigma_{I, t}^{2}$. The market index parameters are $\tilde{\kappa}_{I}=5, \tilde{\theta}_{I}=0.04, \delta_{I}=$ $0.5, \rho_{I}=-0.8$, and the individual equity parameters are $\kappa_{j}=1, \delta_{j}=0.4$, and $\rho_{j}=0$. The risk-free rate is $4 \%$ per year and option maturity is 3 months. Figure 5 shows that beta has a substantial impact on the moneyness slope of equity IV even when keeping the total variance constant: The higher the beta, the larger the moneyness slope. 
The factor structure in the model also has implications for the relative importance of systematic risk under the two measures. The model implies

$$
E_{t}^{Q}\left[\sigma_{I, t: T}^{2}\right]>E_{t}^{P}\left[\sigma_{I, t: T}^{2}\right] \Leftrightarrow A_{j, t: T}^{Q}>A_{j, t: T}^{P}
$$

A negative market variance premium implies a greater importance of systematic risk under the $Q$ measure than under the $P$ measure. This suggests that systematic risk will be of even greater importance for pricing options than for explaining historical returns. Systematic risk may therefore be helpful in explaining the co-movements in the implied volatility moneyness slopes for equity options documented in Section 2.

\subsection{The Term Structure of Equity Volatility}

Our model implies the following two-component term-structure of equity variance

$$
E_{t}^{Q}\left[V_{j, t: T}\right]=\left(\beta_{j}^{2} \tilde{\theta}_{I}+\theta_{j}\right)+\beta_{j}^{2}\left(\sigma_{I, t}^{2}-\tilde{\theta}_{I}\right) e^{-\tilde{\kappa}_{I}(T-t)}+\left(\sigma_{j, t}^{2}-\theta_{j}\right) e^{-\kappa_{j}(T-t)}
$$

This expression shows how the term structure of market variance affects the term structure of variance for firm $j$. Given different systematic and idiosyncratic mean reverting speeds $\left(\tilde{\kappa}_{I} \neq \kappa_{j}\right)$, $\beta_{j}$ has important implications for the term-structure of volatilities. In the empirical work below, we find that the idiosyncratic variance process is more persistent than the market variance. When the idiosyncratic variance process is more persistent $\left(\tilde{\kappa}_{I}>\kappa_{j}\right)$, higher values of beta imply a faster reversion toward the unconditional total variance $\left(\tilde{V}_{j}=\beta_{j}^{2} \tilde{\theta}_{I}+\theta_{j}\right)$. As a result, when the market variance process is less persistent than the idiosyncratic variance, firms with higher betas are likely to have steeper volatility term-structures. In other words, higher beta firms are expected to have a greater positive (negative) slope when the market variance term-structure is upward (downward) sloping.

Figure 6 plots the implied Black-Scholes volatility from model prices against option maturity. Each line has a different beta but the same amount of unconditional total equity variance $\tilde{V}_{j}=$ $\beta_{j}^{2} \tilde{\theta}_{I}+\theta_{j}=0.1$. We set the current spot variance to $\sigma_{I, t}^{2}=0.01$ and $V_{j, t}=0.05$, and define the idiosyncratic variance as the residual $\sigma_{j, t}^{2}=V_{j, t}-\beta_{j}^{2} \sigma_{I, t}^{2}$. The parameter values are as in Figure 5 . Figure 6 shows that beta has a non-trivial effect on the IV term structure: The higher the beta, the steeper the term structure when the term structure is upward sloping.

In summary, our model suggests that-ceteris paribus-firms with higher betas should have higher levels of volatility, steeper moneyness slopes, and higher absolute maturity slopes. 


\subsection{Equity Option Risk Management}

In classic equity option valuation models, partial derivatives are used to assess the sensitivity of the option price to the underlying stock price (delta) and equity variance (vega). In our model the equity option price additionally is exposed to changes in the market level and market variance. Portfolio managers with diversified equity option holdings need to know the sensitivity of the equity option price to these market level variables in order to properly manage risk. The following proposition provides the model's implications for the sensitivity to the market level and market variance.

Proposition 4 For a derivative contract $f^{j}$ written on the stock price, $S_{t}^{j}$, the sensitivity of $f^{j}$ with respect to the index level, $I_{t}$ (the market delta), is given by

$$
\frac{\partial f^{j}}{\partial I_{t}}=\frac{\partial f^{j}}{\partial S_{t}^{j}} \frac{S_{t}^{j}}{I_{t}} \beta_{j}
$$

The sensitivity of $f^{j}$ with respect to the market variance (the market vega) is given by

$$
\frac{\partial f^{j}}{\partial \sigma_{I, t}^{2}}=\frac{\partial f^{j}}{\partial V_{j, t}} \beta_{j}^{2} .
$$

Proof. See Appendix D.

This proposition shows that the beta of the firm in a straightforward way provides the link between the usual stock price delta $\frac{\partial f^{j}}{\partial S_{t}^{j}}$ and the market delta, $\frac{\partial f^{j}}{\partial I_{t}}$, as well as the link between the usual equity vega, $\frac{\partial f^{j}}{\partial V_{j, t}}$, and the market vega $\frac{\partial f^{j}}{\partial \sigma_{I, t}^{2}}$.

This result allows market participants with portfolios of equity options on different firms to measure and manage their total exposure to the index level and to the market variance. It also allows investors engaged in dispersion trading, who sell index options and buy equity options, to measure and manage their overall exposure to market risk and market variance risk.

In Figure 7 we use the parameter values from Figure 5 , and additionally set $S_{t}^{j} / I_{t}=0.1$. We plot the market delta (top panel) and the market vega (bottom panel) against moneyness for firms with different betas. The top panel of Figure 7 shows that the differences in market deltas across firms with different betas can be substantial for ATM and ITM call options. The bottom panel of Figure 7 shows that the differences in market vega is also substantial- particularly for ATM calls where the option exposure to total variance is the largest. 


\subsection{Expected Returns on Equity Options}

So far we have focused on option prices. In applications such as the management of option portfolios, option returns are of interest as well. The following proposition provides an expression for the expected ( $P$-measure) equity option return as a function of the expected market return. ${ }^{3}$

Proposition 5 For a derivative $f^{j}$ written on the stock price, $S_{t}^{j}$, the expected excess return on the derivative contract is given by:

$$
\frac{1}{d t} E_{t}^{P}\left[\frac{d f^{j}}{f^{j}}-r d t\right]=\frac{\partial f^{j}}{\partial S_{t}^{j}} \frac{S_{t}^{j}}{f^{j}}\left(\alpha_{j}+\beta_{j} \mu_{I}\right)=\frac{\partial f^{j}}{\partial S_{t}^{j}} \frac{S_{t}^{j}}{f^{j}} \alpha_{j}+\frac{\partial f^{j}}{\partial I_{t}} \frac{I_{t}}{f^{j}} \mu_{I},
$$

where $\frac{\partial f^{j}}{\partial I_{t}}$ is given by Proposition 4 .

Proof. See Appendix E.

The model thus decomposes the excess return on the option into two parts: The delta of the equity option and the beta of the stock. Put differently, equity options provide investors with two sources of leverage: First, the beta with respect to the market, and second, the elasticity of the option price with respect to changes in the stock price.

In Figure 8 we use the parameter values from Figure 5 and additionally set the equity market risk premium, $\mu_{I}=0.075$. We plot the expected excess return on equity call options (top panel) and on put options (bottom panel) in percent per day against moneyness for firms with different betas. The top panel of Figure 8 shows that the differences in expected call returns across firms with different betas can be substantial for OTM calls where option leverage in general is highest. The bottom panel of Figure 8 shows that put option expected excess returns (which are always negative) also vary most across firms with different betas, when the put options are OTM. In general the differences in expected excess returns across betas are smaller for put options (bottom panel) than for call options (top panel).

\section{$5 \quad$ Estimation and Fit}

In this section, we first describe our estimation methodology. Subsequently we report on parameter estimates and model fit. Finally we relate the estimated betas to patterns in observed equity option IVs.

\footnotetext{
${ }^{3}$ Recent empirical work on equity and index option returns includes Broadie, Chernov, and Johannes (2009), Goyal and Saretto (2009), Constantinides, Czerwonko, Jackwerth, and Perrakis (2011), Vasquez (2011), and Jones and Wang (2012).
} 


\section{$5.1 \quad$ Estimation Methodology}

Several approaches have been proposed in the literature for estimating stochastic volatility models. Jacquier, Polson, and Rossi (1994) use Markov Chain Monte Carlo to estimate a discrete-time stochastic volatility model. Pan (2002) uses GMM to estimate the objective and risk neutral parameters from returns and option prices. Serban, Lehoczky, and Seppi's (2008) estimation strategy is based on simulated maximum likelihood using the EM algorithm and a particle filter.

Another approach treats the latent volatility states as parameters to be estimated and thus avoids filtering the latent volatility factor. This strategy has been adopted by Bates (2000) and Santa-Clara and Yan (2010) among others. We follow this strand of literature.

Recall that we need to estimate two vectors of latent variables $\left\{\sigma_{I, t}^{2}, \sigma_{j, t}^{2}\right\}$ and two sets of structural parameters $\left\{\Theta_{I}, \Theta_{j}\right\}$, where $\Theta_{I} \equiv\left\{\tilde{\kappa}_{I}, \tilde{\theta}_{I}, \delta_{I}, \rho_{I}\right\}$ and $\Theta_{j} \equiv\left\{\kappa_{j}, \theta_{j}, \delta_{j}, \rho_{j}, \beta_{j}\right\}$. Our methodology involves two main steps.

In the first step, we estimate the market index dynamic $\left\{\Theta_{I}, \sigma_{I, t}^{2}\right\}$ based on S\&P 500 option prices alone. In the second step, we use equity options for firm $j$ only, we take the market index

dynamic as given, and we estimate the firm-specific dynamics $\left\{\Theta_{j}, \sigma_{j, t}^{2}\right\}$ for each firm conditional on estimates of $\left\{\Theta_{I}, \sigma_{I, t}^{2}\right\}$. This step-wise estimation procedure is not fully econometrically efficient but it enables us to estimate our model for 29 equities while ensuring that the same dynamic is imposed for the market-wide index for each of the 29 firms. We have confirmed that this estimating technique has good finite sample properties in a Monte Carlo study which is available from the authors upon request.

Each of the two main steps contains an iterative procedure which we now describe in detail.

\section{Step 1: Parameter Estimation for the Index}

Given a set of starting values, $\Theta_{I}^{0}$, for the structural parameters characterizing the index, we first estimate the spot market variance each day by solving

$$
\hat{\sigma}_{I, t}^{2}=\arg \min _{\sigma_{I, t}^{2}} \sum_{m=1}^{N_{I, t}}\left(C_{I, t, m}-C_{m}\left(\Theta_{I}^{0}, \sigma_{I, t}^{2}\right)\right)^{2} / V e g a_{I, t, m}^{2}, \text { for } t=1,2, \ldots, T,
$$

where $C_{I, t, m}$ is the market price of index option contract $m$ on day $t, C_{m}\left(\Theta_{I}, \sigma_{I, t}^{2}\right)$ is the model index option price, $N_{I, t}$ is the number of index contracts available on day $t$, and $V e g a_{I, t, m}$ is the Black-Scholes sensitivity of the index option price with respect to volatility evaluated at the implied volatility. These vega-weighted dollar price errors are a good approximation to implied volatility 
errors and the computational cost involved is much lower. ${ }^{4}$

Once the set of $T$ market spot variances is obtained, we solve for the set of parameters characterizing the index dynamic as follows

$$
\hat{\Theta}_{I}=\arg \min _{\Theta_{I}} \sum_{m, t}^{N_{I}}\left(C_{I, t, m}-C_{m}\left(\Theta_{I}, \hat{\sigma}_{I, t}^{2}\right)\right)^{2} / V e g a_{I, t, m}^{2}
$$

where $N_{I} \equiv \sum_{t}^{T} N_{I, t}$ represents the total number of index option contracts available.

We iterate between (5.1) and (5.2) until the improvement in fit is negligible, which typically requires 5-10 iterations.

\section{Step 2: Parameter Estimation for Individual Equities}

Given an initial value $\Theta_{j}^{0}$ and the estimated $\hat{\sigma}_{I, t}^{2}$ and $\hat{\Theta}_{I}$ we can estimate the spot equity variance each day by solving

$$
\hat{\sigma}_{j, t}^{2}=\arg \min _{\sigma_{j, t}^{2}} \sum_{m=1}^{N_{j, t}}\left(C_{j, t, m}-C_{m}\left(\Theta_{j}^{0}, \hat{\Theta}_{I}, \hat{\sigma}_{I, t}^{2}, \sigma_{j, t}^{2}\right)\right)^{2} / V e g a_{j, t, m}^{2}, \text { for } t=1,2, \ldots T,
$$

where $C_{j, t, m}$ is the price of equity option $m$ for firm $j$ with price $t, C_{m}\left(\Theta_{j}, \Theta_{I}, \sigma_{I, t}^{2}, \sigma_{j, t}^{2}\right)$ is the model equity option price, $N_{j, t}$ is the number of equity contracts available on day $t$, and $V e g a_{j, t, m}$ is the Black-Scholes Vega of the equity option.

Once the set of $T$ market spot variances is obtained, we solve for the set of parameters characterizing the equity dynamic as follows

$$
\hat{\Theta}_{j}=\arg \min _{\Theta_{j}} \sum_{m, t}^{N_{j}}\left(C_{j, t, m}-C_{m}\left(\Theta_{j}, \hat{\Theta}_{I}, \hat{\sigma}_{I, t}^{2}, \hat{\sigma}_{j, t}^{2}\right)\right) / V e g a_{j, t, m}^{2}
$$

where $N_{j} \equiv \sum_{t}^{T} N_{j, t}$ is the total number of contracts available for security $j$.

We again iterate between (5.3) and (5.4) until the improvement in fit is negligible. We repeat this estimation procedure for each of the 29 firms in our data set.

\subsection{Parameter Estimates}

This section presents estimation results for the market index and the 29 firms for the 1996-2010 period. In order to speed up estimation, we restrict attention to put options with moneyness in the

\footnotetext{
${ }^{4}$ This approximation has been used in Carr and Wu (2007) and Trolle and Schwartz (2009) among others.
} 
range $0.9 \leq S / K \leq 1.1$ and maturities of 2,4 , and 6 months. We estimate the structural parameters in the model on a panel data set consisting of the collection of the first Wednesday of each month. We end up using a total of 150,455 equity options and 6,147 index options when estimating the structural parameters. We estimate the spot variances on each trading day thus using more than 3.1 million equity options and 128, 532 index options.

Table 6 reports estimates of the structural parameters that characterize the dynamics of the systematic variance and the idiosyncratic variance, as well as estimates of the betas. The top row shows estimates for the S\&P 500 index.

The unconditional risk-neutral market index variance $\tilde{\theta}_{I}=0.0610$ corresponds to $24.70 \%$ volatility per year. Based on the average index spot variance path for the sample, $\frac{1}{T} \sum_{t=1}^{T} \sigma_{I, t}^{2}$, we obtain a volatility of $22.23 \%$. The idiosyncratic $\theta_{j}$ estimates range from 0.0018 for American Express to 0.0586 for Cisco.

The estimate of the mean-reversion parameter for the market index variance $\tilde{\kappa}_{I}$ is equal to 1.13 , which corresponds to a daily variance persistence of $1-1.13 / 365=0.9969$ which is very high, consistent with the existing literature. The idiosyncratic $\kappa_{j}$ range from 0.15 for Bank of America to 1.29 for Merck, indicating that idiosyncratic volatility is highly persistent as well. Only five firms in the sample (JP Morgan, Hewlett-Packard, Intel, IBM, and Merck) have an idiosyncratic variance process that is less persistent than the market variance.

The estimate of $\rho_{I}$ is strongly negative $(-0.855)$, capturing the so-called leverage effect in the index. The idiosyncratic $\rho_{j}$ are also generally negative, ranging from -0.724 for Bank of America to +0.2970 for Exxon Mobil. The estimates of beta are reasonable and vary from 0.70 for Johnson \& Johnson to 1.24 for American Express. The average beta across the 29 firms is 0.99 .

The average total spot volatility (ATSV) for firm $j$ is computed as

$$
\operatorname{ATSV}=\sqrt{\frac{1}{T} \sum_{t=1}^{T} V_{j, t}}=\sqrt{\frac{1}{T} \sum_{t=1}^{T}\left(\beta_{j}^{2} \sigma_{I, t}^{2}+\sigma_{j, t}^{2}\right)}
$$

Comparing the beta column with the ATSV column in Table 6 shows that ATSV is generally high when beta is high.

The final column of Table 6 reports the systematic risk ratio (SSR) for each firm. It is computed from the spot variances as follows

$$
\mathrm{SSR}=\frac{\sum_{t=1}^{T} \beta_{j}^{2} \sigma_{I, t}^{2}}{\sum_{t=1}^{T}\left(\beta_{j}^{2} \sigma_{I, t}^{2}+\sigma_{j, t}^{2}\right)} .
$$

Table 6 shows that the systematic risk ratio varies from close to $32 \%$ for Hewlett-Packard to above 
$70 \%$ for Exxon Mobile. The systematic risk ratio is $46 \%$ on average, indicating that the estimated factor structure is strongly present in the equity option data. Comparison of the beta column with the SSR column in Table 6 shows that firms with similar betas can have radically different SSR and, vice versa, firms with very different betas can have roughly similar SSRs. This finding of course suggests a key role for the idiosyncratic variance dynamic in the model.

\subsection{Model Fit}

We measure model fit using the root mean squared error (RMSE) based on the vegas, which is consistent with the criterion function used in estimation

$$
\text { Vega RMSE } \equiv \sqrt{\frac{1}{N} \sum_{m, t}^{N}\left(C_{m, t}-C_{m, t}(\Theta)\right)^{2} / V e g a_{m, t}^{2}}
$$

We also report the implied volatility RMSE defined as

$$
\operatorname{IVRMSE} \equiv \sqrt{\frac{1}{N} \sum_{m, t}^{N}\left(I V_{m, t}-I V\left(C_{m, t}(\Theta)\right)\right)^{2}},
$$

where $I V_{m, t}$ denotes market IV for option $m$ on day $t$ and $I V\left(C_{m, t}(\Theta)\right)$ denotes model IV. We use Black-Scholes to compute IV for both model and market prices.

Table 7 reports model fit for the market index and for each of the 29 firms. We report results for all contracts, as well as separate results for in- and out-of-the-money puts, and for 2-month and 6-months at-the-money (ATM) contracts. We also report the IVRMSE divided by the average market IV in order to assess relative IV fit. Several interesting findings emerge from Table 7.

- First, the Vega RMSE approximates the IVMRSE closely for the index and for all firms. This suggests that using Vega RMSE in estimation does not bias the IVRMSE results.

- Second, the average IVRMSE across firms is $1.20 \%$ and the relative IV (IVRMSE / Average IV) is $4.05 \%$ on average. The fit does not vary much across firms. Overall the fit of the model is thus quite good across firms. The best pricing performance for equity options is obtained for Coca Cola with an IVRMSE of $0.95 \%$. The worst fit is for General Electric with an IVRMSE of $1.64 \%$. Based on the relative IVRMSE, the best fit is for Intel with $2.90 \%$ and the worst is again for GE with $5.66 \%$.

- Third, the average IVRMSE fit across firms for ITM puts is $1.17 \%$ and for OTM puts it is $1.23 \%$. Using this metric the model fits ITM and OTM puts roughly equally well. 
- Fourth, the average IVRMSE fit across firms for 2-month ATM options is $1.10 \%$ and for 6month ATM options it is $1.08 \%$. The model thus fits 2-month and 6-month ATM options equally well on average.

Figure 9 reports the market IV (solid) and model IV (dashed) averaged over time for different moneyness categories for each firm. The black lines (left axis) show the average on days with above-average IV and the grey lines (right axis) show the average for days with below-average IV. Moneyness is on the horizontal axis, measured by $S / K$, so that and ITM puts are shown on the left side and OTM puts are shown on the right side. Figure 9.A reports on the first 15 firms and Figure 9.B reports on the remaining 14 firms as well as the index. Note that in order to properly see the different patterns across firms, the vertical axis scale differs in each subplot, but the range of implied volatility values is kept fixed at $10 \%$ across firms to facilitate comparisons.

Figure 9 shows that the smiles computed using market prices vary considerably across firms, both in terms of level and shape. It is noteworthy that for many of these large firms, the smile looks more like an asymmetric smirk-especially on low-volatility days (grey lines). The smirk is of course a strong stylized fact for index options and it is evident in the bottom-right panel of Figure 9.B. The IV bias by moneyness are small in general across firms and no large outliers are apparent. The model tends to slightly underprice OTM equity puts when volatility is high (black lines). This is not the case when volatility is low (grey lines).

The bottom right panel in Figure 9.B confirms the finding in Bakshi, Kapadia and Madan (2003) that the market index is generally more (negatively) skewed than individual firms. The bottom right panel also shows that the model requires additional negative skewness to fit the relatively expensive OTM puts trading on the market index. This can be achieved by including jumps in returns (Bates, 2000). Note that when allowing for a large negative $\rho_{I}$ the Heston (1993) model is able to fit OTM index put options quite well.

Figure 10 reports for each firm the average (over time) implied volatility as a function of time to maturity (in years). We split the data set into two groups: Days with upward-sloping IV term structure and days with downward-sloping IV term structure. We then compute the median slope on the upward-sloping days and the median slope on the downward-sloping days. In Figure 10 we report the average market IVs (solid lines) as well as the average model IVs (dashed lines) on the days with higher-than-median upward-sloping term structure (grey lines) and on the days with lower-than-median downward-sloping term structure (black lines). This is done because on many days the term structure is roughly flat and so uninteresting. The downward-sloping black lines use the left axis and the upward-sloping grey lines use the right axis. In order to facilitate comparison between model and market IVs the level of IVs differ between the left and right axis and they differ 
across firms. For ease of comparison between term structures the difference between the minimum and maximum on each axis is fixed at $10 \%$ across all firms.

Figure 10 shows that the term structure of IV differs considerably across firms. Some firms such as Hewlett-Packard tends to mean-revert rather quickly, whereas other firms such as 3M have much more persistent term structures. Generally, across firms, the downward sloping black lines appear to be steeper than the upward sloping grey lines. This pattern is matched by the model. It is also worth noting that the model is able to capture the strong persistence in IV quite well: Figure 10 does not reveal any systematic model biases in the term structure of IVs. The two-factor stochastic volatility structure of our equity model is clearly helpful in this regard.

We conclude from Table 7 and Figures 9 and 10 that the model fits the observed equity option data quite well. Encouraged by this finding, we next analyze in some detail how the estimated betas are related to observed patterns in equity option IVs.

\subsection{Equity Betas and Equity Option IVs}

The three main cross-sectional predictions of our model, as discussed in Section 4, are as follows:

1. Firms with higher betas have higher risk-neutral variance.

2. Firms with higher betas have steeper moneyness slopes. This is equivalent to stating that firms with higher betas are characterized by more negative skewness.

3. Firms with higher betas have steeper positive volatility term structures when the term structure is upward sloping, and steeper negative volatility term structures when the term structure is downward sloping.

We now document if these theoretical model implications are supported by the estimates for the 29 Dow-Jones firms. Consider first the level of option-implied volatility. In the top panel of Figure 11, we scatter plot the time-averaged intercepts from the implied volatility regression in (2.1), $\frac{1}{T} \sum_{t=1}^{T} a_{j, t}$ against the beta estimate from Table 6 for each firm $j$. We then run a regression on the 29 points in the scatter and assess the significance and fit. The slope has a t-statistic of 6.81 and the regression fit $\left(R^{2}\right)$ is quite high at $63 \%$. The regression line shows the positive relationship between the estimated betas and the average implied volatility observed in the market prices of equity options.

In the middle panel of Figure 11, we scatter plot the moneyness slope coefficients from the

IV regression in (2.1), $\frac{1}{T} \sum_{t=1}^{T} b_{j, t}$ against the beta estimate from Table 6 for each firm $j$. In the moneyness slope regression, the sensitivity to beta has a t-statistic of 4.66 and an $R^{2}$ of $45 \%$. The 
middle panel of Figure 11 clearly shows that higher beta estimates are associated with steeper slopes of the IV moneyness smile.

Finally, in the bottom panel of Figure 11 we scatter plot the absolute value of the term structure slope coefficients from (2.1), $\frac{1}{T} \sum_{t=1}^{T} c_{j, t}$ against the beta estimate from Table 6 for each firm. In the term slope regression, the sensitivity to beta has a t-statistic of 4.90 and the $R^{2}$ is $47 \%$. Panel $\mathrm{C}$ shows that higher betas are associated with higher absolute slopes of the term structure in equity IVs: Firms with high betas will tend to have a term structure of implied volatility curve that decays more quickly to the unconditional level of volatility compared with firms with low betas.

We conclude that our estimates of beta are related to the model-free measures of IV level, slope, and term structure in a way that is consistent with the three main model predictions from Section 4 .

\subsection{Option-Implied and Historical Betas}

As discussed in section 5.2, the estimated betas seem reasonable. They vary from 0.70 for Johnson \& Johnson to 1.24 for American Express and the average beta across the 29 firms is 0.99. To provide additional perspective we also compute historical betas for the same 29 firms. To be consistent with the option-based estimate, we estimate a constant beta using daily return data for the entire sample from 1996 to 2010. The historical beta is 0.97 on average across firms.

Figure 12 provides a scatter plot of the option-implied betas versus historical betas. It also shows the results of a regression of the historical on the option-implied betas. A number of important conclusions obtain. First, the option-implied betas are positively correlated with the historical betas. In fact, the relation between the two beta estimates is very strong, which is evidenced by the high R-square of the regression (84\%) and the fact that Figure 12 contains very few outliers. Second, option-implied betas have a smaller dispersion (15\%) than historical betas (31\%). This is interesting in light of the well-known statistical biases in estimating historical betas, and the common practice of shrinking the betas toward one to account for this bias. Note that this larger dispersion of the historical betas yields a regression slope larger than one and a negative regression intercept when regressing historical beta on option implied beta.

We conclude that overall the relationship between historical and option-implied beta is surprisingly strong. It may prove interesting to see if this relationship also holds for betas computed over shorter windows. We leave that for future work. 


\subsection{The Cross-Section of Idiosyncratic Risk}

A number of recent studies investigate co-movements between firm-level volatilities. Engle and Figlewski (2012) model the dynamics of correlations between implied volatilities, and investigate the role of VIX as a factor in explaining firm-level implied volatilities. Schürhoff and Ziegler (2010) study the relative pricing of equity and index variance swaps. Kelly, Lustig, and Van Nieuwerburgh (2012) show that there is a strong factor structure in firm-level historical volatility, distinct from the common variation in returns. Surprisingly, they find that idiosyncratic volatility contains a factor structure that is similar to total volatility.

Motivated by these findings, Table 8 presents the correlation matrix between the idiosyncratic variances for the 29 firms estimated from the model. Clearly, Table 8 confirms the results of Kelly, Lustig, and Van Nieuwerburgh (2012), which are obtained using historical returns data. While Table 8 may be interpreted as suggesting the need for a richer factor model, note that the results of Kelly, Lustig, and Van Nieuwerburgh (2012) are robust to the inclusion of additional factors.

\section{Summary and Conclusions}

Principal component analysis reveals a strong factor structure in equity options. The first common component explains $77 \%$ of the cross-sectional variation in IV and the common component has a $92 \%$ correlation with the short-term implied volatility constructed from S\&P 500 index options. Furthermore, $77 \%$ of the variation in the equity skew is captured by the first principal component. This common component has a correlation of $64 \%$ with the skew of market index options. Also, $60 \%$ of the variation in the term structure of equity IV is explained by the first principal component.

This component has a correlation of $80 \%$ with the term slope of the option IV from S\&P500 index options.

Motivated by the findings from the principal component analysis, we develop a structural model of equity option prices that incorporates a market factor. The model allows for mean-reverting stochastic volatility and correlated shocks to returns and volatility. Motivated by the principal components analysis, we allow for idiosyncratic shocks to equity prices which also have meanreverting stochastic volatility and a separate leverage effect. Individual equity returns are linked to the market index using a standard linear factor model with a constant beta factor loading. We derive closed-form option pricing formulas as well as results for option hedging and option expected returns.

We develop a convenient estimation method for estimation and filtering based on option prices. When estimating the model on the firms in the Dow-Jones index, we find that it provides a good fit 
to observed equity option prices. Moreover, we show that the estimates strongly confirm the three main cross-sectional model implications.

Several issues are left for future research. First, it would be interesting to empirically study the implications of our models for option price sensitivities and option returns. Second, it may be useful to extend the model, for instance by allowing for two stochastic volatility factors in the market price process, as in Bates (2000), or by allowing for jumps in the market price (Bates, 2008; Bollerslev and Todorov, 2011). Third, combining option information with high-frequency returns (Patton and Verardo, 2012; Hansen, Lunde, and Voev, 2012) may lead to better estimates of betas. Finally, characterizing the time-variation in option-implied betas would be of significant interest.

\section{Appendix}

This appendix collects proofs of the propositions.

\section{A. Proof of Proposition 1}

First, define the stochastic exponential $\xi($.

$$
\xi\left(\int_{0}^{t} \omega_{u}^{\prime} d W_{u}\right) \equiv \exp \left(\int_{0}^{t} \omega_{u}^{\prime} d W_{u}-\frac{1}{2} \int_{0}^{t} \omega_{u}^{\prime} d\left\langle W, W^{\prime}\right\rangle_{u} \omega_{u}\right)
$$

where $\omega_{u}$ is a $2(n+1)$ real or complex valued vector adapted to the Brownian filtration (see Protter (1990) p. 85). Given (3.3), (3.5), and the definition of $\xi($.$) , we can write$

$$
\frac{S_{t}^{j}}{S_{0}^{j}}=\xi\left(\int_{0}^{t} \beta_{j} \sigma_{I, u} d W_{u}^{(I, 1)}+\int_{0}^{t} \sigma_{j, u} d W_{u}^{(j, 1)}\right) \exp \left(\left(r+\alpha_{j}+\beta_{j} \mu_{I}\right) t\right) \text { and } \frac{d Q}{d P}(t)=\xi\left(-\int_{0}^{t} \gamma_{u}^{\prime} d W_{u}\right)
$$

By imposing the no-arbitrage condition on the individual equity $S_{t}^{j}$, we must have

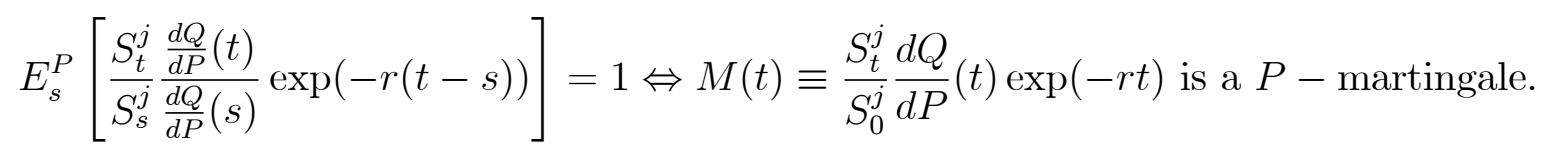


Therefore, equity $j$ 's no-arbitrage condition restrains the process $M(t)$ to be a $P$-martingale. Given (6.2), $M(t)$ can be orthogonalized in the following manner $M(t)=F(t) G(t)$ where

$$
\begin{aligned}
F(t) \equiv & \exp \left(\left(\alpha_{j}+\beta_{j} \mu_{I}\right) t\right) \xi\left(\int_{0}^{t} \beta_{j} \sigma_{I, u} d W_{u}^{(I, 1)}\right) \xi\left(-\int_{0}^{t} \gamma_{u}^{(I, 1)} d W_{u}^{(I, 1)}-\int_{0}^{t} \gamma_{u}^{(I, 2)} d W_{u}^{(I, 2)}\right) \\
& \xi\left(\int_{0}^{t} \sigma_{j, u} d W_{u}^{(j, 1)}\right) \xi\left(-\int_{0}^{t} \gamma_{u}^{(j, 1)} d W_{u}^{(j, 1)}-\int_{0}^{t} \gamma_{u}^{(j, 2)} d W_{u}^{(j, 2)}\right),
\end{aligned}
$$

and

$$
G(t) \equiv \xi\left(-\sum_{k \notin j, I}\left(\int_{0}^{t} \gamma_{u}^{(k, 1)} d W_{u}^{(k, 1)}+\int_{0}^{t} \gamma_{u}^{(k, 2)} d W_{u}^{(k, 2)}\right)\right)
$$

where in order to decompose $\frac{d Q}{d P}(t)$ and $S_{t}^{j} / S_{0}^{j}$ we have used $\xi\left(X_{t}+Y_{t}\right)=\xi\left(X_{t}\right) \xi\left(Y_{t}\right)$ for orthogonal processes. By properties of stochastic exponentials, we know that $\xi($.$) are P$-martingales which implies that $G(t)$ is a $P$-martingale. Since $F(t)$ and $G(t)$ are independent, $M(t)$ will be a $P$-martingale if and only if $F(t)$ is a $P$-martingale. Using the result $\xi\left(X_{t}\right) \xi\left(Y_{t}\right)=\xi\left(X_{t}+\right.$ $\left.Y_{t}\right) \exp \left(\langle X, Y\rangle_{t}\right)$ to rewrite $(6.3)$, we have

$$
\begin{aligned}
& \xi\left(\int_{0}^{t} \beta_{j} \sigma_{I, u} d W_{u}^{(I, 1)}\right) \xi\left(-\int_{0}^{t} \gamma_{u}^{(I, 1)} d W_{u}^{(I, 1)}-\int_{0}^{t} \gamma_{u}^{(I, 2)} d W_{u}^{(I, 2)}\right) \\
= & \xi\left(\int_{0}^{t}\left(\beta_{j} \sigma_{I, u}-\gamma_{u}^{(I, 1)}\right) d W_{u}^{(I, 1)}-\int_{0}^{t} \gamma_{u}^{(I, 2)} d W_{u}^{(I, 2)}\right) \exp \left(-\int_{0}^{t} \beta_{j} \sigma_{I, u}\left(\gamma_{u}^{(I, 1)}+\rho_{I} \gamma_{u}^{(I, 2)}\right) d u\right),
\end{aligned}
$$

and

$$
\begin{aligned}
& \xi\left(\int_{0}^{t} \sigma_{j, u} d W_{u}^{(j, 1)}\right) \xi\left(-\int_{0}^{t} \gamma_{u}^{(j, 1)} d W_{u}^{(j, 1)}-\int_{0}^{t} \gamma_{u}^{(j, 2)} d W_{u}^{(j, 2)}\right) \\
= & \xi\left(\int_{0}^{t}\left(\sigma_{j, u}-\gamma_{u}^{(j, 1)}\right) d W_{u}^{(j, 1)}-\int_{0}^{t} \gamma_{u}^{(j, 2)} d W_{u}^{(j, 2)}\right) \exp \left(-\int_{0}^{t} \sigma_{j, u}\left(\gamma_{u}^{(j, 1)}+\rho_{j} \gamma_{u}^{(j, 2)}\right) d u\right) .
\end{aligned}
$$

Combining the previous expressions with (6.3), we see that $F(t)$ will be a $P$-martingale whenever

$$
\exp \left(-\int_{0}^{t} \beta_{j} \sigma_{I, u}\left(\gamma_{u}^{(I, 1)}+\rho_{I} \gamma_{u}^{(I, 2)}\right) d u\right) \exp \left(-\int_{0}^{t} \sigma_{j, u}\left(\gamma_{u}^{(j, 1)}+\rho_{j} \gamma_{u}^{(j, 2)}\right) d u\right) \exp \left(\left(\alpha_{j}+\beta_{j} \mu_{I}\right) t\right)=1
$$

which is satisfied when

$$
\begin{aligned}
& \mu_{I}-\sigma_{I, t}\left(\gamma_{t}^{(I, 1)}+\rho_{I} \gamma_{t}^{(I, 2)}\right)=0 \quad d P \otimes d t \quad \text { a.s. } \\
& \alpha_{j}-\sigma_{j, t}\left(\gamma_{t}^{(j, 1)}+\rho_{j} \gamma_{t}^{(j, 2)}\right)=0 \quad d P \otimes d t \quad \text { a.s. }
\end{aligned}
$$


where (6.4) is the no-arbitrage condition for the market index. Following for example Heston (1993), we assume that the market price of variance risks are proportional to their spot variances $\sigma_{I, t}$ and $\sigma_{j, t}$, that is

$$
\begin{aligned}
& \gamma_{t}^{(I, 2)}+\rho_{I} \gamma_{t}^{(I, 1)}=\lambda_{I} \sigma_{I, t} \\
& \gamma_{t}^{(j, 2)}+\rho_{j} \gamma_{t}^{(j, 1)}=\lambda_{j} \sigma_{j, t} .
\end{aligned}
$$

Solving (6.4), (6.5), (6.6), and (6.7) restricting attention to the subset of solutions satisfying $\lambda_{j}=0$, where idiosyncratic variance risk is not priced, we have

$$
\begin{gathered}
\gamma_{t}^{(I, 1)}=\frac{\mu_{I}-\rho_{I} \lambda_{I} \sigma_{I, t}^{2}}{\sigma_{I, t}\left(1-\rho_{I}^{2}\right)} \quad \text { and } \quad \gamma_{t}^{(I, 2)}=\frac{\lambda_{I} \sigma_{I, t}^{2}-\rho_{I} \mu_{I}}{\sigma_{I, t}\left(1-\rho_{I}^{2}\right)} \\
\gamma_{t}^{(j, 1)}=\frac{\alpha_{j}}{\sigma_{j, t}\left(1-\rho_{j}^{2}\right)} \quad \text { and } \quad \gamma_{t}^{(j, 2)}=-\frac{\rho_{j} \alpha_{j}}{\sigma_{j, t}\left(1-\rho_{j}^{2}\right)} .
\end{gathered}
$$

Combining (6.8) and (6.9) with $d \tilde{W}_{t}=d W_{t}+d\left\langle W, W^{\prime}\right\rangle_{t} \gamma_{t}$ delivers the risk-neutral processes (3.1), $(3.2),(3.3)$, and (3.4).

\section{B. Proof of Proposition 2}

For ease of notation, we define $\tilde{W}_{\sigma_{k, t: T}}^{1} \equiv \int_{t}^{T} \sigma_{k, u} d \tilde{W}_{u}^{(k, 1)}$ for $k \in\{I, j\}$. Given the $Q$-processes, one can apply Ito's lemma to $\ln \left(S_{t}^{j}\right)$ and obtain (after integration) the following expression for individual equity log-returns

$$
\ln \left(\frac{S_{T}^{j}}{S_{t}^{j}}\right)=r \tau-\frac{1}{2}\left(\sigma_{j, t: T}^{2}+\beta_{j}^{2} \sigma_{I, t: T}^{2}\right)+\tilde{W}_{\sigma_{j, t: T}}^{1}+\beta_{j} \tilde{W}_{\sigma_{I, t: T}}^{1}
$$

where $\tau=T-t$. Therefore, the conditional characteristic function of the risk-neutral log-returns takes the form

$$
\tilde{\phi}^{L R}(\tau, u)=E_{t}^{Q}\left[\exp \left(i u\left(r \tau-\frac{1}{2}\left(\sigma_{j, t: T}^{2}+\beta_{j}^{2} \sigma_{I, t: T}^{2}\right)+\tilde{W}_{\sigma_{j, t: T}}^{1}+\beta_{j} \tilde{W}_{\sigma_{I, t: T}}^{1}\right)\right)\right] .
$$

Using the definition of the stochastic exponential $\xi(\cdot)$ in $(6.1)$, we have

$$
\xi\left(\eta \tilde{W}_{\sigma_{k, t: T}}^{1}\right)=\exp \left(\eta \tilde{W}_{\sigma_{k, t: T}}^{1}-\frac{(\eta)^{2}}{2}\left\langle\tilde{W}_{\sigma_{k}}^{1}, \tilde{W}_{\sigma_{k}}^{1}\right\rangle_{t: T}\right)=\exp \left(\eta \tilde{W}_{\sigma_{k, t: T}}^{1}-\frac{1}{2} \eta^{2} \sigma_{k, t: T}^{2}\right), \text { for } k \in\{j, I\}
$$


which allows us to write $(6.11)$ as

$$
\tilde{\phi}^{L R}(\tau, u)=\exp (i u r \tau) E_{t}^{Q}\left[\xi\left(i u \beta_{i} \tilde{W}_{\sigma_{I, t: T}}^{1}\right) \xi\left(i u \tilde{W}_{\sigma_{j, t: T}}^{1}\right) \exp \left(-\left(g_{1} \sigma_{I, t: T}^{2}+g_{2} \sigma_{j, t: T}^{2}\right)\right)\right]
$$

where $g_{1}=\frac{i u}{2} \beta_{j}^{2}(1-i u)$ and $g_{2}=\frac{i u}{2}(1-i u)$. Following Carr and Wu (2004) and Detemple and Rindisbacher (2010), we define the following change-of-measure

$$
\frac{d C}{d Q}(t) \equiv \xi\left(i u \beta_{j} \tilde{W}_{\sigma_{I, 0: t}}^{1}\right) \xi\left(i u \tilde{W}_{\sigma_{j, 0: t}}^{1}\right)
$$

Combining (6.13) with the change of measure (6.14), we can write

$$
\begin{aligned}
\tilde{\phi}^{L R}(\tau, u) & =\exp (i u r \tau) E_{t}^{Q}\left[\frac{\frac{d C}{d Q}(T)}{\frac{d C}{d Q}(t)} \exp \left(-\left(g_{1} \sigma_{I, t: T}^{2}+g_{2} \sigma_{j, t: T}^{2}\right)\right)\right] \\
\Rightarrow & \tilde{\phi}^{L R}(\tau, u)=\exp (\text { iur } \tau) E_{t}^{C}\left[\exp \left(-g_{1} \sigma_{I, t: T}^{2}\right)\right] E_{t}^{C}\left[\exp \left(-g_{2} \sigma_{j, t: T}^{2}\right)\right] .
\end{aligned}
$$

Given an extension of the Girsanov theorem to the complex plane, under the $C$-measure we have

$$
\begin{gathered}
d W_{t}^{C,(I, 2)}=d \tilde{W}_{t}^{(I, 2)}-\left(i u \rho_{I} \beta_{j} \sigma_{I, t}\right) d t \\
d W_{t}^{C,(j, 2)}=d \tilde{W}_{t}^{(j, 2)}-\left(i u \rho_{j} \sigma_{j, t}\right) d t .
\end{gathered}
$$

As a result,

$$
d \sigma_{k, t}^{2}=\kappa_{k}^{C}\left(\theta_{k}^{C}-\sigma_{k, t}^{2}\right) d t+\delta_{k} \sigma_{k, t} d W_{t}^{C,(k, 2)}
$$

where

$$
\kappa_{I}^{C}=\tilde{\kappa}_{I}-i u \rho_{I} \beta_{j} \delta_{I}, \quad \theta_{I}^{C}=\frac{\tilde{\kappa}_{I} \tilde{\theta}_{I}}{\kappa_{I}^{C}}, \kappa_{j}^{C}=\kappa_{j}-i u \rho_{j} \delta_{j}, \text { and } \theta_{j}^{C}=\frac{\kappa_{j} \theta_{j}}{\kappa_{j}^{C}} .
$$

We can now make use of the closed-form solution for the moment generating function of $E_{t}^{C}\left[\exp \left(-g \sigma_{t: T}^{2}\right)\right]$ to obtain the following expression for $\tilde{\phi}^{L R}(\cdot)$,

$$
\tilde{\phi}^{L R}(\tau, u)=\exp \left(i u r \tau-(A(\tau, u)+B(\tau, u))-C(\tau, u) \sigma_{I, t}^{2}-D(\tau, u) \sigma_{j, t}^{2}\right)
$$

with

$$
\begin{aligned}
& A(\tau, u)=\frac{\tilde{\kappa}_{I} \tilde{\theta}_{I}}{\delta_{I}^{2}}\left\{2 \ln \left(\left(1-\frac{\left(\Psi_{1}-\kappa_{I}^{C}\right)}{2 \Psi_{1}}\left(1-e^{-\Psi_{1} \tau}\right)\right)+\left(\Psi_{1}-\kappa_{I}^{C}\right) \tau\right\}\right. \\
& B(\tau, u)=\frac{\kappa_{j} \theta_{j}}{\delta_{j}^{2}}\left\{2 \ln \left(1-\frac{\left(\Psi_{2}-\kappa_{j}^{C}\right)}{2 \Psi_{2}}\left(1-e^{-\Psi_{2} \tau}\right)\right)+\left(\Psi_{2}-\kappa_{j}^{C}\right) \tau\right\}
\end{aligned}
$$




$$
\begin{aligned}
& C(\tau, u)=\frac{2 g_{1}\left(1-e^{-\Psi_{1} \tau}\right)}{2 \Psi_{1}-\left(\Psi_{1}-\kappa_{I}^{C}\right)\left(1-e^{-\Psi_{1} \tau}\right)} \\
& D(\tau, u)=\frac{2 g_{2}\left(1-e^{-\Psi_{2} \tau}\right)}{2 \Psi_{2}-\left(\Psi_{2}-\kappa_{j}^{C}\right)\left(1-e^{-\Psi_{2} \tau}\right)}
\end{aligned}
$$

and where

$$
\Psi_{1}=\sqrt{\left(\kappa_{I}^{C}\right)^{2}+2 \delta_{I}^{2} g_{1}} \text { and } \Psi_{2}=\sqrt{\left(\kappa_{j}^{C}\right)^{2}+2 \delta_{j}^{2} g_{2}}
$$

with

$$
g_{1}=\frac{i u}{2} \beta_{j}^{2}(1-i u) \text { and } g_{2}=\frac{i u}{2}(1-i u)
$$

and

$$
\kappa_{I}^{C}=\tilde{\kappa}_{I}-i u \rho_{I} \beta_{j} \delta_{I} \text { and } \kappa_{j}^{C}=\kappa_{j}-i u \rho_{j} \delta_{j}
$$

Using the fact that $\tilde{\phi}^{j}(\tau, u)=e^{i u \ln \left(S_{t}^{j}\right)} \tilde{\phi}^{L R}(\tau, u)$, the previous equations can be used to compute the price of a European call option written on $S^{j}$.

\section{Proof of Proposition 3}

The following argument is derived under the $P$ measure; however, a similar argument can be developed under the $Q$ measure. Given the definition of skewness, the total (conditional) skewness of the integrated return of firm $j$ is

$$
S k^{P}\left(\int_{t}^{T} \frac{d S_{u}^{j}}{S_{u}^{j}}\right) \equiv E_{t}^{P}\left[\left(\int_{t}^{T} \frac{d S_{u}^{j}}{S_{u}^{j}}-E_{t}^{P}\left[\int_{t}^{T} \frac{d S_{u}^{j}}{S_{u}^{j}}\right]\right)^{3}\right] /\left(E_{t}^{P}\left[\left(\int_{t}^{T} \frac{d S_{u}^{j}}{S_{u}^{j}}-E_{t}^{P}\left[\int_{t}^{T} \frac{d S_{u}^{j}}{S_{u}^{j}}\right]\right)^{2}\right]\right)^{3 / 2} .
$$

Given that

$$
\int_{t}^{T} \frac{d S_{u}^{j}}{S_{u}^{j}}-E_{t}^{P}\left[\int_{t}^{T} \frac{d S_{u}^{j}}{S_{u}^{j}}\right]=\beta_{j} W_{\sigma_{I, t: T}}^{1}+W_{\sigma_{j, t: T}}^{1},
$$

equation (6.22) can be simplified to

$$
S k^{P}\left(\int_{t}^{T} \frac{d S_{u}^{j}}{S_{u}^{j}}\right)=\frac{E_{t}^{P}\left[\left(\beta_{j} W_{\sigma_{I, t: T}}^{1}+W_{\sigma_{j, t: T}}^{1}\right)^{3}\right]}{\left(E_{t}^{P}\left[\left(\beta_{j} W_{\sigma_{I, t: T}}^{1}+W_{\sigma_{j, t: T}}^{1}\right)^{2}\right]\right)^{3 / 2}} .
$$

By the properties of Ito integrals and the independence of $W^{(I, 1)}$ and $W^{(j, 1)}$, we have

$$
E_{t}^{P}\left[\left(\beta_{j} W_{\sigma_{I, t: T}}^{1}+W_{\sigma_{j, t: T}}^{1}\right)^{2}\right]=E_{t}^{P}\left[\beta_{j}^{2} \sigma_{I, t: T}^{2}\right]+E_{t}^{P}\left[\sigma_{j, t: T}^{2}\right]=E_{t}^{P}\left[V_{j, t: T}\right],
$$


and

$$
E_{t}^{P}\left[\left(\beta_{j} W_{\sigma_{I, t: T}}^{1}+W_{\sigma_{j, t: T}}^{1}\right)^{3}\right]=E_{t}^{P}\left[\left(\beta_{j} W_{\sigma_{I, t: T}}^{1}\right)^{3}\right]+E_{t}^{P}\left[\left(W_{\sigma_{j, t: T}}^{1}\right)^{3}\right] .
$$

Consequently, the total (conditional) skewness of the integrated return of firm $j$ takes the form

$$
\begin{aligned}
S k^{P}\left(\int_{t}^{T} \frac{d S_{u}^{j}}{S_{u}^{j}}\right)= & \frac{E_{t}^{P}\left[\left(\beta_{j} W_{\sigma_{I, t: T}}^{1}\right)^{3}\right]}{\left(E_{t}^{P}\left[V_{j, t: T}\right]\right)^{3 / 2}}+\frac{E_{t}^{P}\left[\left(W_{\sigma_{j, t: T}}^{1}\right)^{3}\right]}{\left(E_{t}^{P}\left[V_{j, t: T}\right]\right)^{3 / 2}} \\
= & \frac{E_{t}^{P}\left[\left(W_{\sigma_{I, t: T}}^{1}\right)^{3}\right]}{\left(E_{t}^{P}\left[\sigma_{I, t: T}^{2}\right]\right)^{3 / 2}} \cdot\left(\frac{E_{t}^{P}\left[\beta_{j}^{2} \sigma_{I, t: T}^{2}\right]}{E_{t}^{P}\left[V_{j, t: T}\right]}\right)^{3 / 2} \cdot \operatorname{sign}\left(\beta_{j}\right) \\
& +\frac{E_{t}^{P}\left[\left(W_{\sigma_{j, t: T}}^{1}\right)^{3}\right]}{\left(E_{t}^{P}\left[\sigma_{j, t: T}^{2}\right]\right)^{3 / 2}} \cdot\left(\frac{E_{t}^{P}\left[\sigma_{j, t: T}^{2}\right]}{E_{t}^{P}\left[V_{j, t: T}\right]}\right)^{3 / 2} .
\end{aligned}
$$

Defining $A_{j, t: T}^{P} \equiv E_{t}^{P}\left[\beta_{j}^{2} \sigma_{I, t: T}^{2}\right] / E_{t}^{P}\left[V_{j, t: T}\right]$, we obtain for positive beta firms

$$
S k^{P}\left(\int_{t}^{T} \frac{d S_{u}^{j}}{S_{u}^{j}}\right)=S k_{I}^{P} \cdot\left(A_{j, t: T}^{P}\right)^{3 / 2}+S k_{j}^{P} \cdot\left(1-A_{j, t: T}^{P}\right)^{3 / 2},
$$

where

$$
S k_{I}^{P}=S k^{P}\left(\int_{t}^{T} \frac{d I_{s}}{I_{s}}\right) \text { and } S k_{j}^{P}=S k^{P}\left(\int_{t}^{T} \sigma_{j, s} d W_{s}^{(j, 1)}\right)
$$

are the market and idiosyncratic skewness, respectively.

\section{Proof of Proposition 4}

Within our model, the index price $\left(I_{t}\right)$ takes the following form under the risk-neutral measure

$$
I_{t}=I_{0} \exp \left(r t-\frac{1}{2} \sigma_{I, 0: t}^{2}+\tilde{W}_{\sigma_{I, 0: t}}^{1}\right) .
$$

Taking the derivative of the index price $I_{t}$ with respect to $\beta_{j} \tilde{W}_{\sigma_{I, 0: t}}^{1}$ gives

$$
\frac{\partial I_{t}}{\partial \beta_{j} \tilde{W}_{\sigma_{I, 0: t}}^{1}}=\frac{\partial I_{t}}{\partial \tilde{W}_{\sigma_{I, 0: t}}^{1}} \frac{\partial \tilde{W}_{\sigma_{I, 0: t}}^{1}}{\partial \beta_{j} \tilde{W}_{\sigma_{I, 0: t}}^{1}}=\frac{\partial I_{t}}{\partial \tilde{W}_{\sigma_{I, 0: t}}^{1}}\left(\frac{\partial \beta_{j} \tilde{W}_{\sigma_{I, 0: t}}^{1}}{\partial \tilde{W}_{\sigma_{I, 0: t}}^{1}}\right)^{-1}=\frac{I_{t}}{\beta_{j}},
$$


where the second equality makes use of the inverse function theorem which holds as long as $\beta_{j} \neq 0$. Moreover, as long as $I_{t} \neq 0$ the inverse function theorem also implies that

$$
\frac{\partial \beta_{j} \tilde{W}_{\sigma_{I, 0: t}}^{1}}{\partial I_{t}}=\left(\frac{\partial I_{t}}{\partial \beta_{j} \tilde{W}_{\sigma_{I, 0: t}}^{1}}\right)^{-1}=\frac{\beta_{j}}{I_{t}}
$$

Furthermore, within our model the equity price is given by

$$
S_{t}^{j}=S_{0}^{j} \exp \left(r t-\frac{1}{2}\left(\sigma_{j, 0: t}^{2}+\beta_{j}^{2} \sigma_{I, 0: t}^{2}\right)+\tilde{W}_{\sigma_{j, 0: t}}^{1}+\beta_{j} \tilde{W}_{\sigma_{I, 0: t}}^{1}\right)
$$

which implies

$$
\frac{\partial S_{t}^{j}}{\partial \beta_{j} \tilde{W}_{\sigma_{I, 0: t}}^{1}}=S_{t}^{j}
$$

Combining (6.24) and (6.25) implies

$$
\frac{\partial S_{t}^{j}}{\partial I_{t}}=\frac{\partial S_{t}^{j}}{\partial \beta_{j} \tilde{W}_{\sigma_{I, 0: t}}^{1}} \frac{\partial \beta_{j} \tilde{W}_{\sigma_{I, 0: t}}^{1}}{\partial I_{t}}=\frac{S_{t}^{j}}{I_{t}} \beta_{j}
$$

Therefore, for any derivative $f^{j}$ written on $S^{j}$ the sensitivity of $f^{j}$ with respect to market value, $I_{t}$ (market delta), is

$$
\frac{\partial f^{j}}{\partial I_{t}}=\frac{\partial f^{j}}{\partial S_{t}^{j}} \frac{\partial S_{t}^{j}}{\partial I_{t}}=\frac{\partial f^{j}}{\partial S_{t}^{j}} \frac{S_{t}^{j}}{I_{t}} \beta_{j}
$$

For the sensitivity of $f^{j}$ with respect to market variance (market vega), we have

$$
\frac{\partial f^{j}}{\partial \sigma_{I, t}^{2}}=\frac{\partial f^{j}}{\partial V_{j, t}} \frac{\partial V_{j, t}}{\partial \sigma_{I, t}^{2}}=\frac{\partial f^{j}}{\partial V_{j, t}} \frac{\partial\left(\beta_{j}^{2} \sigma_{I, t}^{2}+\sigma_{j, t}^{2}\right)}{\partial \sigma_{I, t}^{2}}=\frac{\partial f^{j}}{\partial V_{j, t}} \beta_{j}^{2} .
$$

\section{E. Proof of Proposition 5}

The proof of this proposition is adapted from Broadie, Chernov, and Johannes (2009) to our set-up. By application of Ito's lemma to the derivative contract $f^{j}$ written on $S^{j}$, combined with the pricing PDE, allows us to write the dynamic of $d f^{j}$ under $P$ as

$$
\begin{aligned}
d f^{j}= & \left\{r f^{j}-f_{S}^{j} r S_{t}^{j}-f_{V_{j}}^{j} \beta_{j}^{2} \tilde{\kappa}_{I}\left(\tilde{\theta}_{I}-\sigma_{I, t}^{2}\right)+\tilde{\kappa}_{j}\left(\tilde{\theta}_{j}-\sigma_{j, t}^{2}\right)\right\} d t \\
& +f_{S}^{j} d S_{t}^{j}+f_{V_{j}}^{j} d V_{j, t}
\end{aligned}
$$




$$
\begin{aligned}
\Leftrightarrow \quad & d f^{j}=\left\{r f^{j}-f_{S}^{j} r S_{t}^{j}-f_{V_{j}}^{j} \beta_{j}^{2} \tilde{\kappa}_{I}\left(\tilde{\theta}_{I}-\sigma_{I, t}^{2}\right)+\kappa_{j}\left(\theta_{j}-\sigma_{j, t}^{2}\right)\right\} d t \\
& +f_{S}^{j} d S_{t}^{j}+f_{V_{j}}^{j} d V_{j, t} .
\end{aligned}
$$

where $f_{x}^{j}$ denotes the partial derivative of $f^{j}$ with respect to $x$. Note that in the previous equation, we have assumed that idiosyncratic risk is not priced, which is consistent with Proposition 1 (i.e. $\tilde{\theta}_{j}=\theta_{j}$ and $\tilde{\kappa}_{j}=\kappa_{j}$ ). Moreover,

$$
\begin{aligned}
& \frac{E_{t}^{P}\left[d S_{t}^{j}\right]}{d t}=\left(r+\alpha_{j}+\beta_{j} \mu_{I}\right) S_{t}^{j} \\
& \frac{E_{t}^{P}\left[d V_{j, t}\right]}{d t}=\beta_{j}^{2} \kappa_{I}\left(\theta_{I}-\sigma_{I, t}^{2}\right)+\kappa_{j}\left(\theta_{j}-\sigma_{j, t}^{2}\right) .
\end{aligned}
$$

Consequently, combining (6.26) and (6.27) leads to

$$
\begin{aligned}
\frac{1}{d t} E_{t}^{P}\left[\frac{d f^{j}}{f^{j}}-r d t\right]= & \frac{f_{S}^{j}}{f^{j}} E_{t}^{P}\left[d S_{t}^{j}-r S_{t}^{j} d t\right]+\frac{f_{V_{j}}^{j}}{f^{j}} \beta_{j}^{2} E_{t}^{P}\left[d \sigma_{I, t}^{2}-\tilde{\kappa}_{I}\left(\tilde{\theta}_{I}-\sigma_{I, t}^{2}\right) d t\right] \\
& +\frac{f_{V_{j}}^{j}}{f^{j}} E_{t}^{P}\left[d \sigma_{j, t}^{2}-\kappa_{j}\left(\theta_{j}-\sigma_{j, t}^{2}\right) d t\right]
\end{aligned}
$$

which simplifies to

$$
\frac{1}{d t} E_{t}^{P}\left[\frac{d f^{j}}{f^{j}}-r d t\right]=f_{S}^{j} \frac{S_{t}^{j}}{f^{j}}\left(\alpha_{j}+\beta_{j} \mu_{I}\right)+f_{V_{j}}^{j} \frac{\beta_{j}^{2}}{f^{j}}\left(\tilde{\kappa}_{I} \tilde{\theta}_{I}-\kappa_{I} \theta_{I}\right) .
$$

As in Heston (1993), our risk neutralization implies that $\tilde{\kappa}_{I} \tilde{\theta}_{I}=\kappa_{I} \theta_{I}$. Consequently, we obtain

$$
\frac{1}{d t} E_{t}^{P}\left[\frac{d f^{j}}{f^{j}}-r d t\right]=f_{S}^{j} \frac{S_{t}^{j}}{f^{j}}\left(\alpha_{j}+\beta_{j} \mu_{I}\right)=\frac{\partial f^{j}}{\partial S_{t}^{j}} \frac{S_{t}^{j}}{f^{j}} \alpha_{j}+\frac{\partial f^{j}}{\partial I_{t}} \frac{I_{t}}{f^{j}} \mu_{I}
$$

where the second equation uses the result in Proposition 4. 


\section{References}

[1] Bakshi, G., Cao, C., Chen, Z. (1997) Empirical performance of alternative option pricing models, Journal of Finance, 52, 2003-2050.

[2] Bakshi, G., Cao, C., Zhong, Z. (2012) Assessing models of individual equity option prices, Working Paper, University of Maryland

[3] Bakshi, G., Kapadia, N. (2003) Delta-hedged gains and the negative market volatility risk premium, Review of Financial Studies, 16, 527-566.

[4] Bakshi, G., Kapadia, N., Madan, D. (2003) Stock return characteristics, skew laws, and differential pricing of individual equity options, Review of Financial Studies, 10, 101-143.

[5] Bates, D. (2000) Post-'87 crash fears in the S\&P500 futures option market, Journal of Econometrics, 94, 181-238.

[6] Bates, D. (2008) The market for crash risk, Journal of Economic Dynamics and Control, 32, 2291-2321.

[7] Black, F., Scholes, M. (1973) Valuation of options and corporate liabilities, Journal of Political Economy, 81, 637-654.

[8] Bollerslev, T., Todorov, B. (2011), Tails, fears, and risk premia, Journal of Finance, 66, 21652211.

[9] Broadie, M., Chernov, M., Johannes, M. (2007) Model specification and risk premiums: Evidence from futures options, Journal of Finance, 62, 1453-1490.

[10] Broadie, M. Chernov, M., Johannes, M. (2009) Understanding index option returns, Review of Financial Studies, 22, 4493-4529.

[11] Buss, A., Vilkov, G., (2012) Measuring equity risk with option-implied correlations, Review of Financial Studies, 25, 3113-3140.

[12] Carr, P., Madan, D. (2012), Factor models for option pricing, Asia-Pacific Financial Markets, 19, 319-329.

[13] Carr, P., Wu, L. (2004) Time-changed Lévy processes and option pricing, Journal of Financial Economics, 71, 113-141. 
[14] Carr, P., Wu, L. (2007) Stochastic skew in currency options, Journal of Financial Economics, $86,213-247$.

[15] Chang, B.Y, Christoffersen, P., Jacobs, K., Vainberg, G. (2012) Option-implied measures of equity risk, Review of Finance, 16, 385-428.

[16] Constantinides, G., Czerwonko, M., Jackwerth, J., Perrakis, S. (2011), Are options on index futures profitable for risk averse investors? Empirical evidence, Journal of Finance, 66, 14071437.

[17] Cox, J., Ingersoll, J., Ross, S. (1985) A theory of the term structure of interest rates, Econometrica, 53, 385-408.

[18] Dennis, P., Mayhew, S. (2002) Risk-neutral skewness: Evidence from stock options, Journal of Financial and Quantitative Analysis, 37, 471-93.

[19] Detemple, J. B., Rindisbacher, M. (2010) Dynamic asset allocation: Portfolio decomposition formula and applications, Review of Financial Studies, 23, p 25-100.

[20] Driessen, J., Maenhout, P., Vilkov, G. (2009) The price of correlation risk: Evidence from equity options, Journal of Finance, 64, 1377-1406.

[21] Duan, J-C., Wei, J. (2009) Systematic risk and the price structure of individual equity options, Review of Financial Studies, 22, 1981-2006.

[22] Elkamhi, R., Ornthanalai, C. (2010) Market jump risk and the price structure of individual equity options, Working Paper, Rotman School, University of Toronto.

[23] Engle, R. and Figlewski, S. (2012) Modeling the dynamics of correlations among implied volatilities, Working Paper, Stern School, New York University.

[24] Goyal A., Saretto A. (2009) Cross-section of option returns and volatility. Journal of Financial Economics, 94, 310-326.

[25] Hansen, P., Lunde, A., Voev, V. (2012), Realized beta GARCH: A multivariate GARCH model with realized measures of volatility and co-volatility, Journal of Applied Econometrics, forthcoming.

[26] Heston, S. (1993) Closed-form solution for options with stochastic volatility, with application to bond and currency options, Review of Financial Studies, 6, 327-343. 
[27] Heston, S., Nandi, S. (2000) A closed-form GARCH option pricing model, Review of Financial Studies, 13, 585-626.

[28] Hull, J., White, A. (1987) The pricing of options on assets with stochastic volatilities, Journal of Finance, 42, 281-300.

[29] Jacquier, E., Polson, N.G., Rossi, P.E. (1994) Bayesian analysis of stochastic volatility models (with discussion), Journal of Business and Economic Statistics, 12, 371-417.

[30] Jones, C. (2003) The dynamics of stochastic volatility: Evidence from underlying and options markets, Journal of Econometrics, 116, 181-224.

[31] Jones, C., Wang, T. (2012), The term structure of equity option implied volatility, Working Paper, USC Marshall.

[32] Kelly, B., Lustig, H., Van Nieuwerburgh, S. (2013), Too-systemic-to-fail: What option markets imply about sector-wide government guarantees, Working Paper, NYU Stern.

[33] Kelly, B., Lustig, H., Van Nieuwerburgh, S. (2012), The volatility factor structure, Working Paper, NYU Stern.

[34] Mo, H., Wu, L. (2007) International capital asset pricing: Evidence from options, Journal of Empirical Finance, 14, 465-498.

[35] Pan, J. (2002) The jump risk premia implicit in options: Evidence from an integrated time series study, Journal of Financial Economics, 63, 3-50.

[36] Patton, A., Verardo, M. (2012), Does beta move with news? Firm-specific information flows and learning about profitability, Review of Financial Studies, 25, 2789-2839.

[37] Protter, P. (1990) Stochastic integration and differential equations, Springer-Verlag.

[38] Santa-Clara, P., Yan, S. (2010) Crashes, volatility, and the equity premium: Lessons from S\&P500 options, Review of Economics and Statistics, 92, 435-451.

[39] Schürhoff, N., Ziegler, A. (2010), The pricing of systematic and idiosyncratic variance risk, Working Paper, University of Zurich.

[40] Serban, M., Lehoczky, J., Seppi, D. (2008) Cross-sectional stock option pricing and factor models of returns, Working Paper, CMU. 
[41] Trolle, A., Schwartz, E. (2009) Unspanned stochastic volatility and the pricing of commodity derivatives, Review of Financial Studies, 22, 4423-4461.

[42] Vasquez, A. (2011), Volatility term structure and the cross-section of option returns, Working Paper, ITAM.

[43] Wiggins, J. (1987) Option values under stochastic volatility: Theory and empirical evidence, Journal of Financial Economics, 19, 351-372. 
Figure 1: At-the-Money Implied Volatility. Six Firms and the S\&P 500 Index
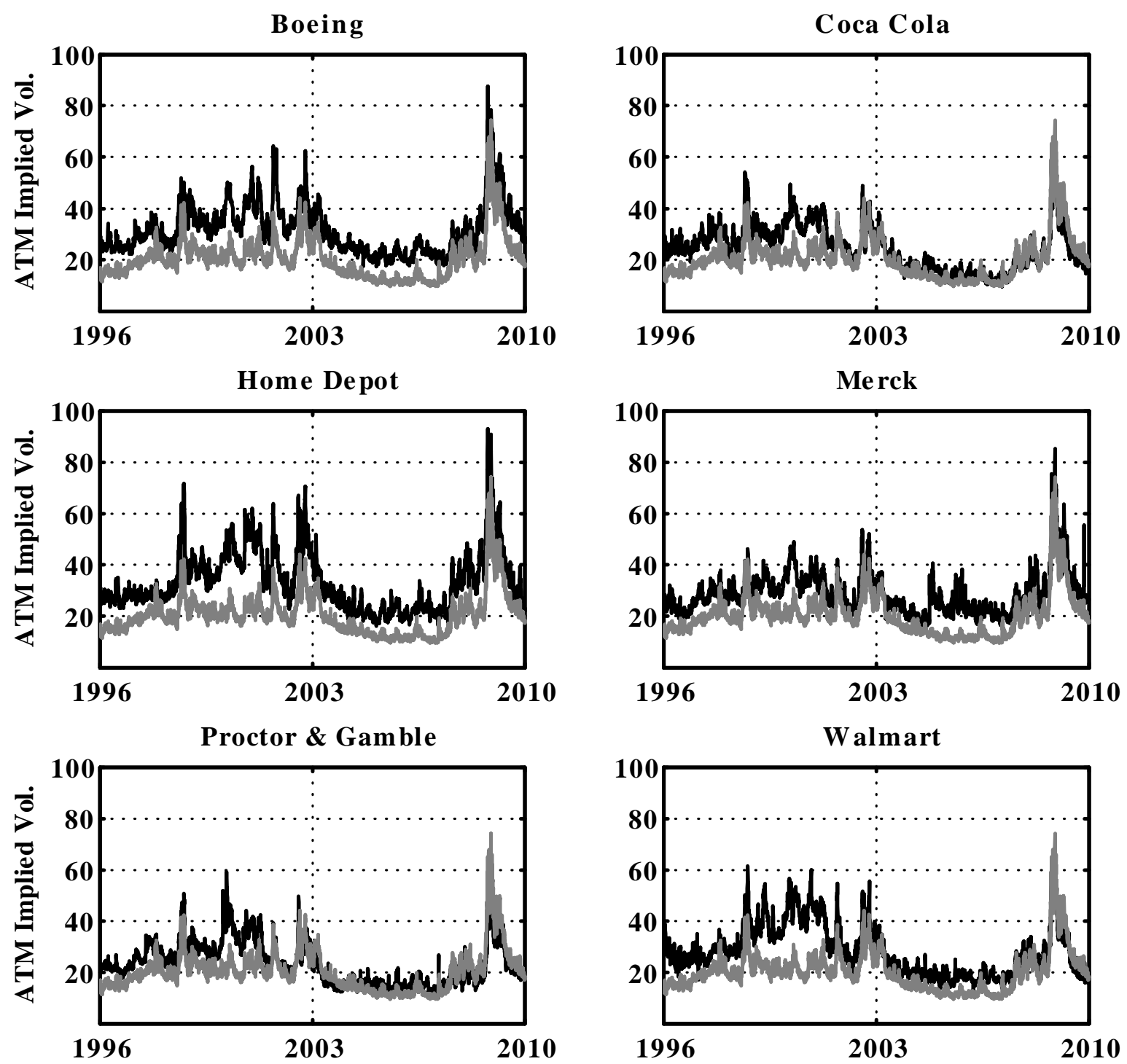

Notes to Figure: We plot the time series of implied volatility for six firms (black) and the S\&P 500 index (grey). On each day we use contracts with between 30 and 60 days to maturity and a moneyness $(S / K)$ between 0.95 and 1.05. For every trading day and every security, we average the available implied volatilities to obtain an estimate of at-the-money implied volatility. 
Figure 2: Implied Volatility Level.

S\&P 500 Index and the First Principal Component from 29 Firms
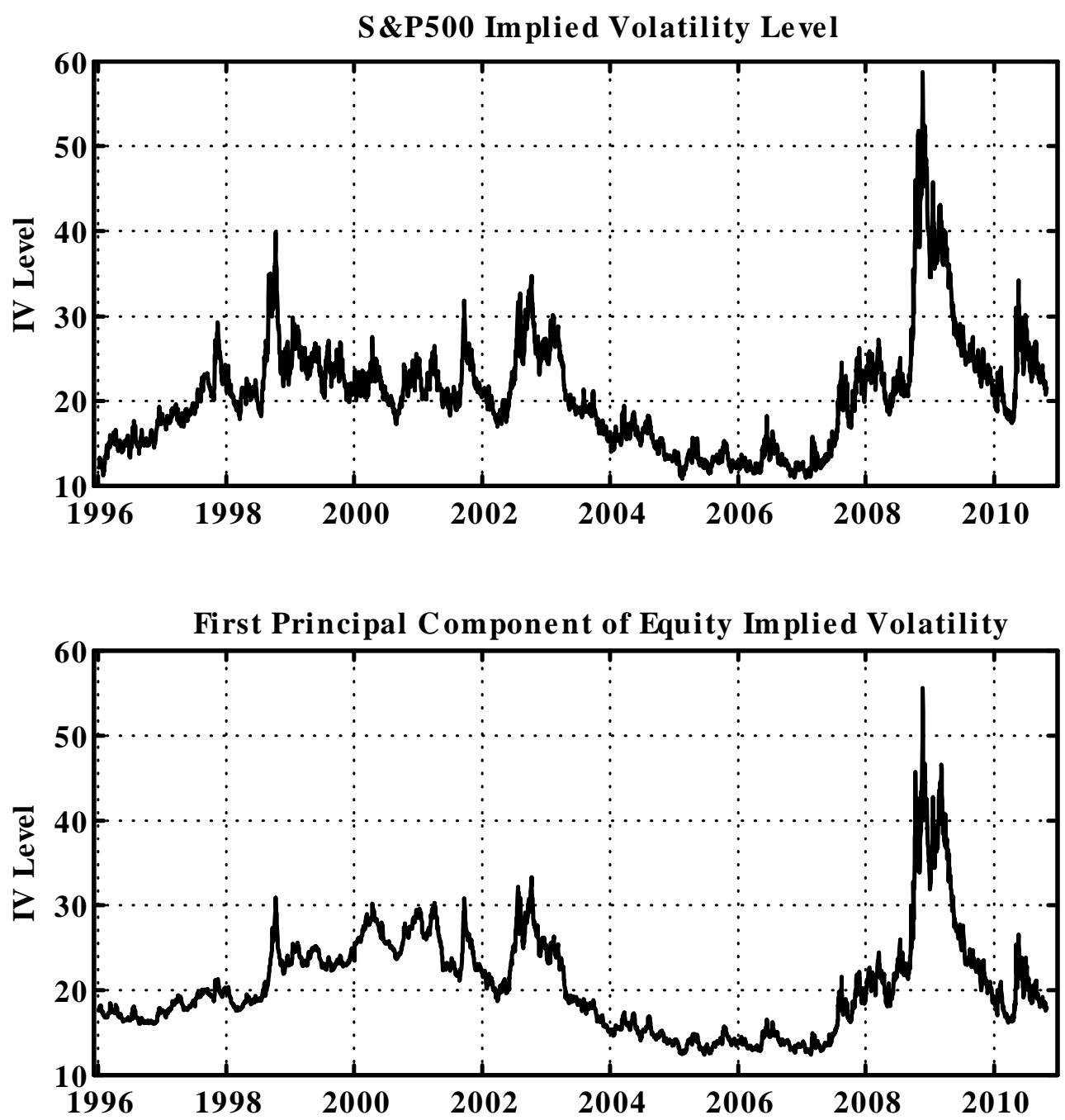

Notes to Figure: The top panel plots the implied volatility level from S\&P 500 index options. The bottom panel plots the first principal component of implied volatility levels from options on 29 equities in the Dow-Jones index. 
Figure 3: Implied Volatility Moneyness Slopes.

S\&P 500 Index and the First Principal Component from 29 Firms

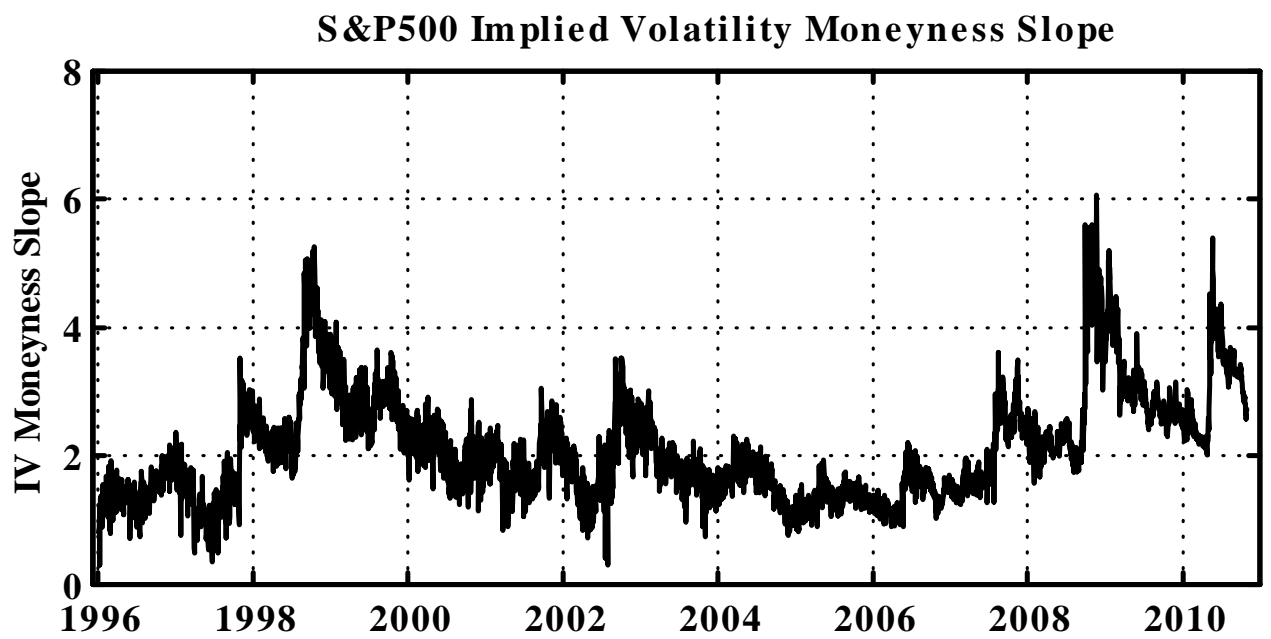

First Principal Component of Equity Implied Volatility Moneyness Slope

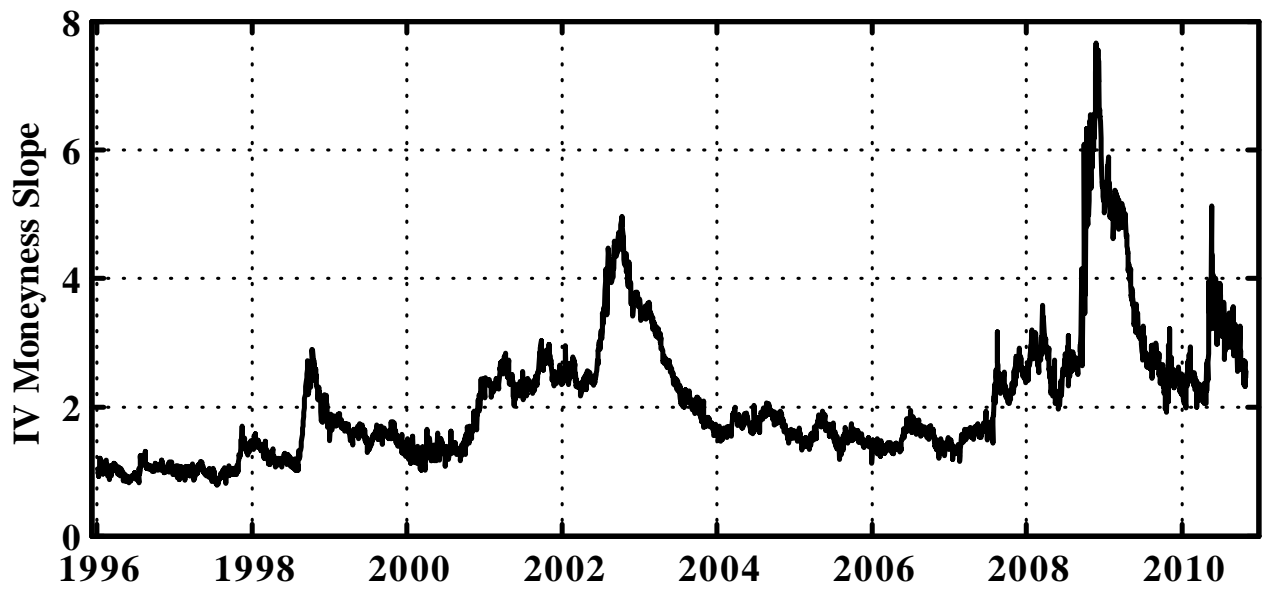

Notes to Figure: The top panel plots the slope of implied volatility with respect to moneyness from short-term S\&P 500 index options. The bottom panel plots the first principal component of the implied volatility moneyness slopes from options on 29 equities in the Dow-Jones index. 
Figure 4: Implied Volatility Term Structure Slopes.

S\&P 500 Index and the First Principal Component from 29 Firms

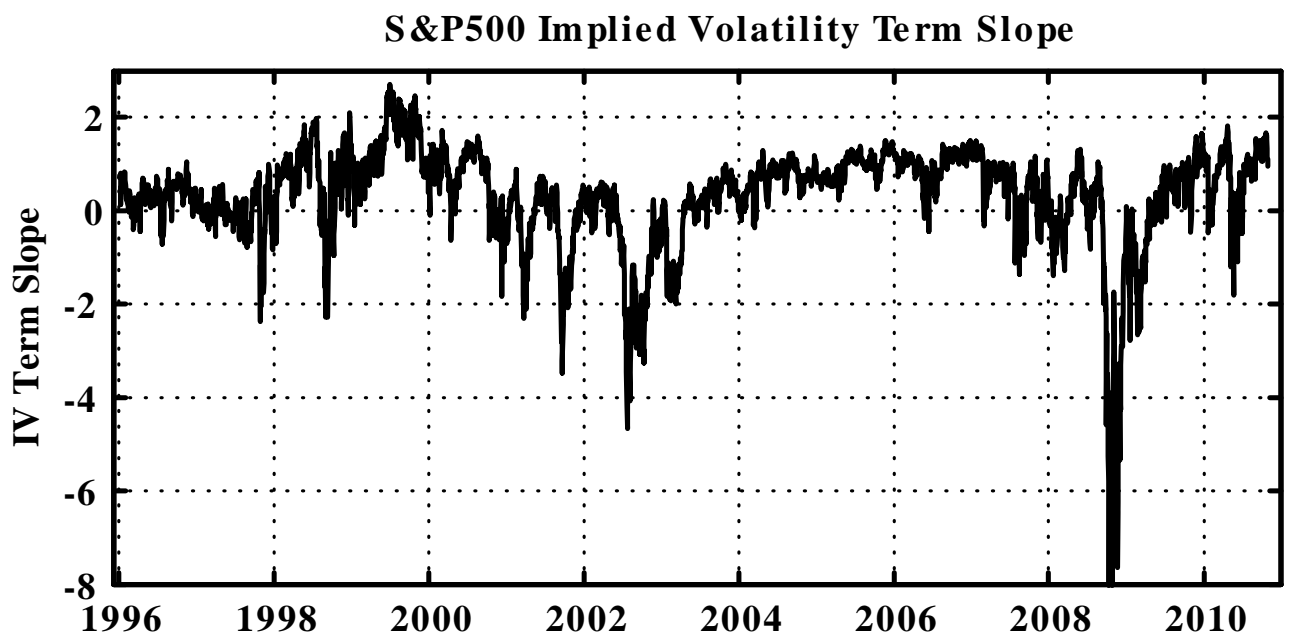

First Principal Component of Equity Implied Volatility Term Slope

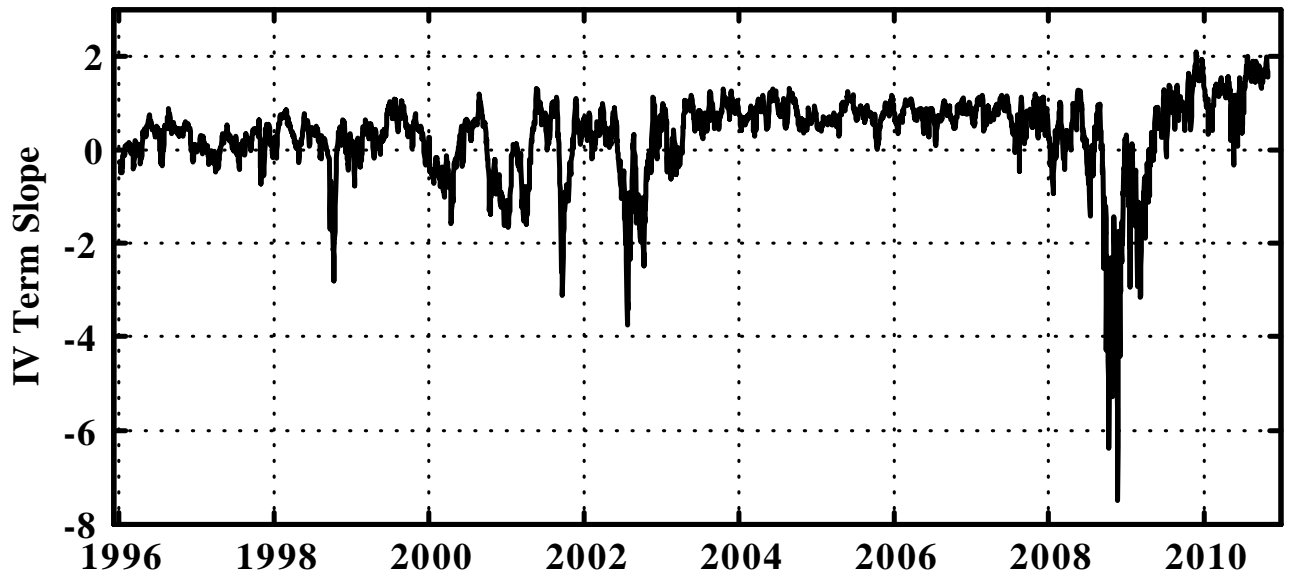

Notes to Figure: The top panel plots the slope of the implied volatility term structure from S\&P 500 index options. The bottom panel plots the first principal component of the implied volatility term structure from options on 29 equities in the Dow-Jones index. 
Figure 5: Beta and Implied Volatility Across Moneyness

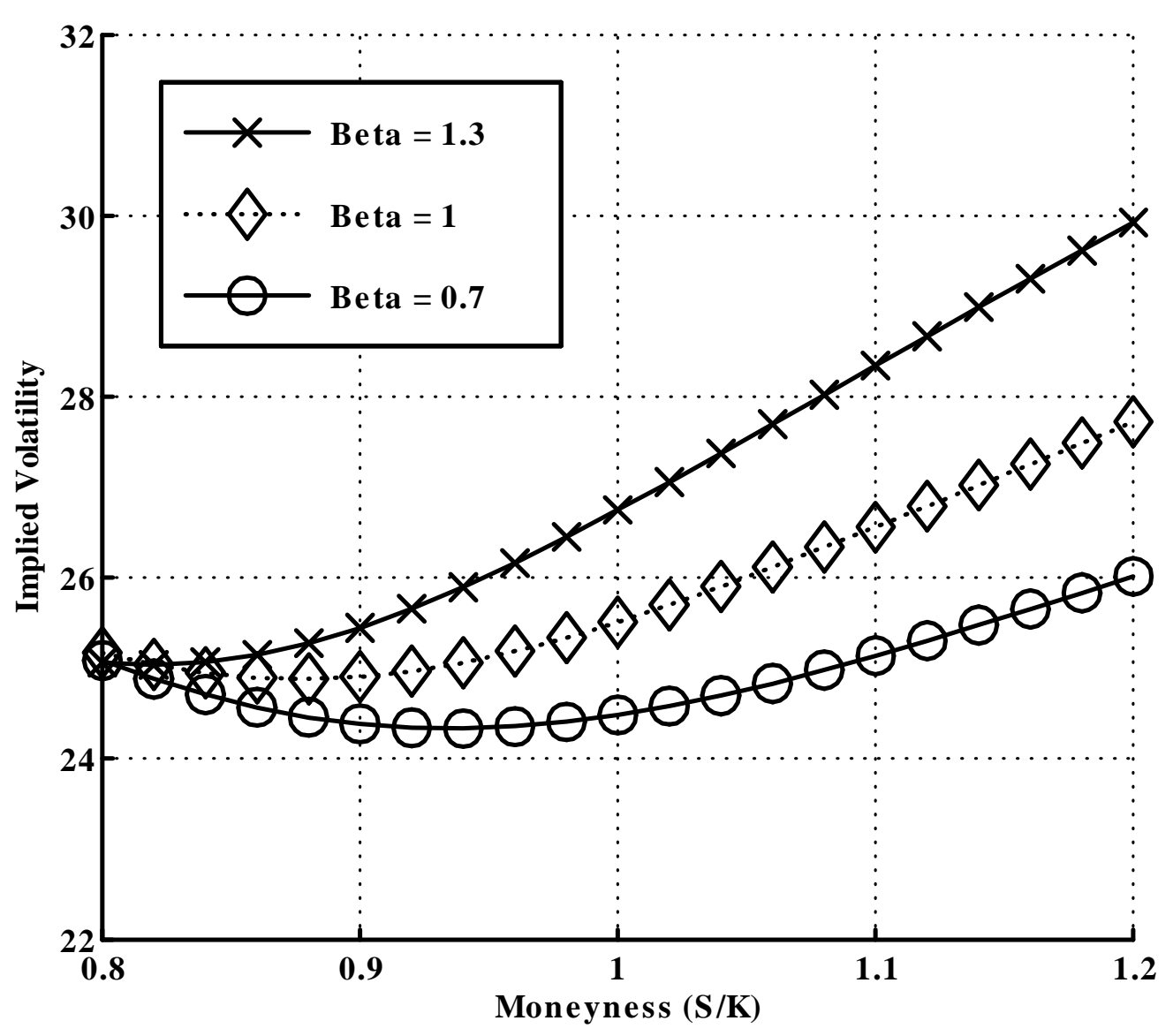

Notes to Figure: We plot implied Black-Scholes volatility from model prices. Each line has a different beta but the same amount of unconditional total equity variance $\tilde{V}_{j}=\beta_{j}^{2} \tilde{\theta}_{I}+\theta_{j}=0.1$. We set the current spot variance to $\sigma_{I, t}^{2}=0.01$ and $V_{j, t}=0.05$, and define the idiosyncratic variance as the residual $\sigma_{j, t}^{2}=V_{j, t}-\beta_{j}^{2} \sigma_{I, t}^{2}$. The market index parameters are $\tilde{\kappa}_{I}=5, \tilde{\theta}_{I}=0.04, \delta_{I}=0.5, \rho_{I}=$ -0.8 , and the individual equity parameters are $\kappa_{j}=1, \delta_{j}=0.4$, and $\rho_{j}=0$. The risk-free rate is $4 \%$ per year and option maturity is 3 months. 
Figure 6: Beta and the At-the-Money Implied Volatility Term Structure

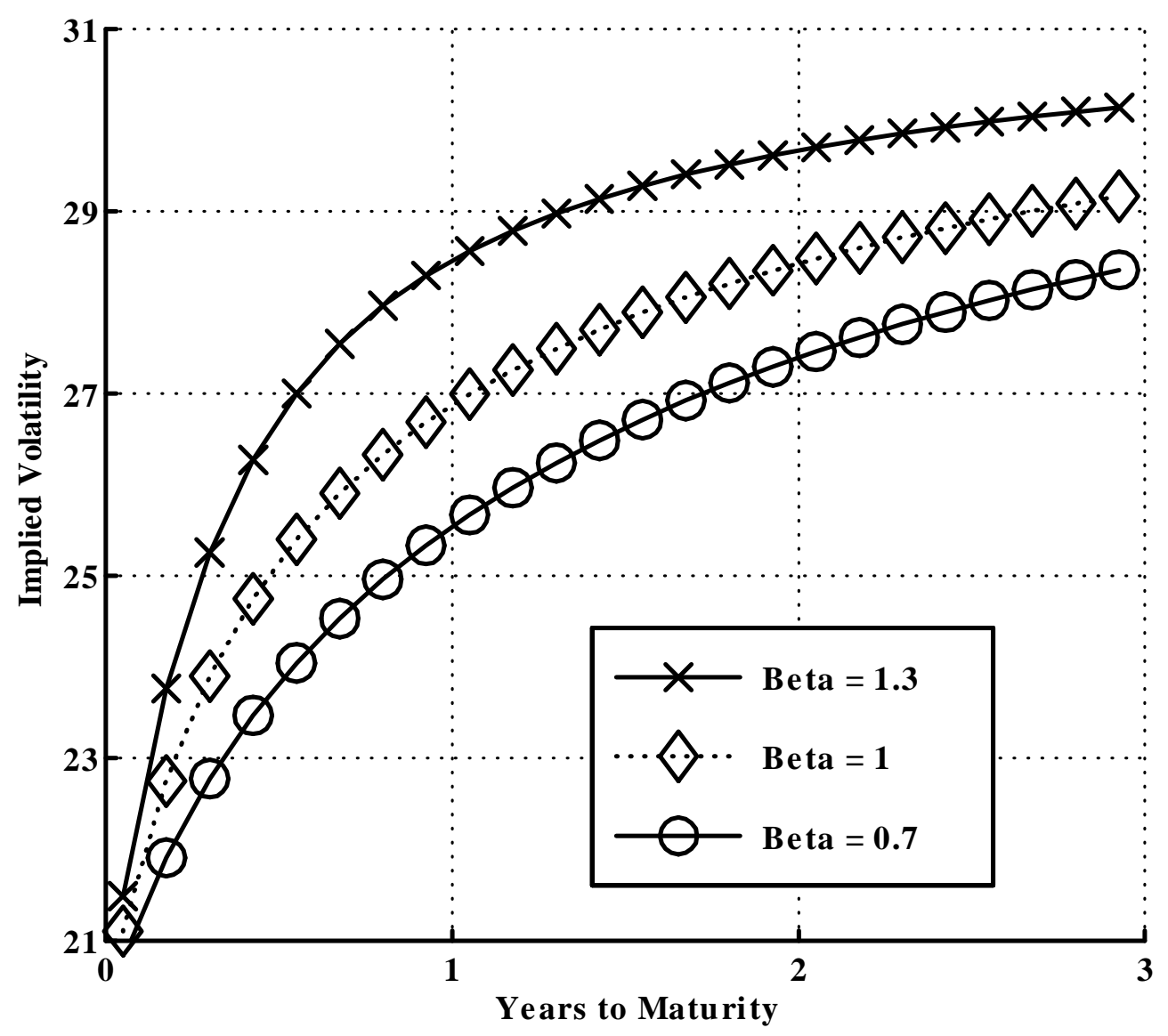

Notes to Figure: We plot implied Black-Scholes volatility from model prices. Each line has a different beta but the same amount of unconditional total equity variance $\tilde{V}_{j}=\beta_{j}^{2} \tilde{\theta}_{I}+\theta_{j}=0.1$. We set the current spot variance to $\sigma_{I, t}^{2}=0.01$ and $V_{j, t}=0.05$, and define the idiosyncratic variance as the residual $\sigma_{j, t}^{2}=V_{j, t}-\beta_{j}^{2} \sigma_{I, t}^{2}$. The market index parameters are $\tilde{\kappa}_{I}=5, \tilde{\theta}_{I}=0.04, \delta_{I}=0.5, \rho_{I}=$ -0.8 , and the individual equity parameters are $\kappa_{j}=1, \delta_{j}=0.4$, and $\rho_{j}=0$. The risk-free rate is $4 \%$ per year and $S_{t}^{j} / K=1$. 
Figure 7: Market Delta and Vega of Equity Call Options
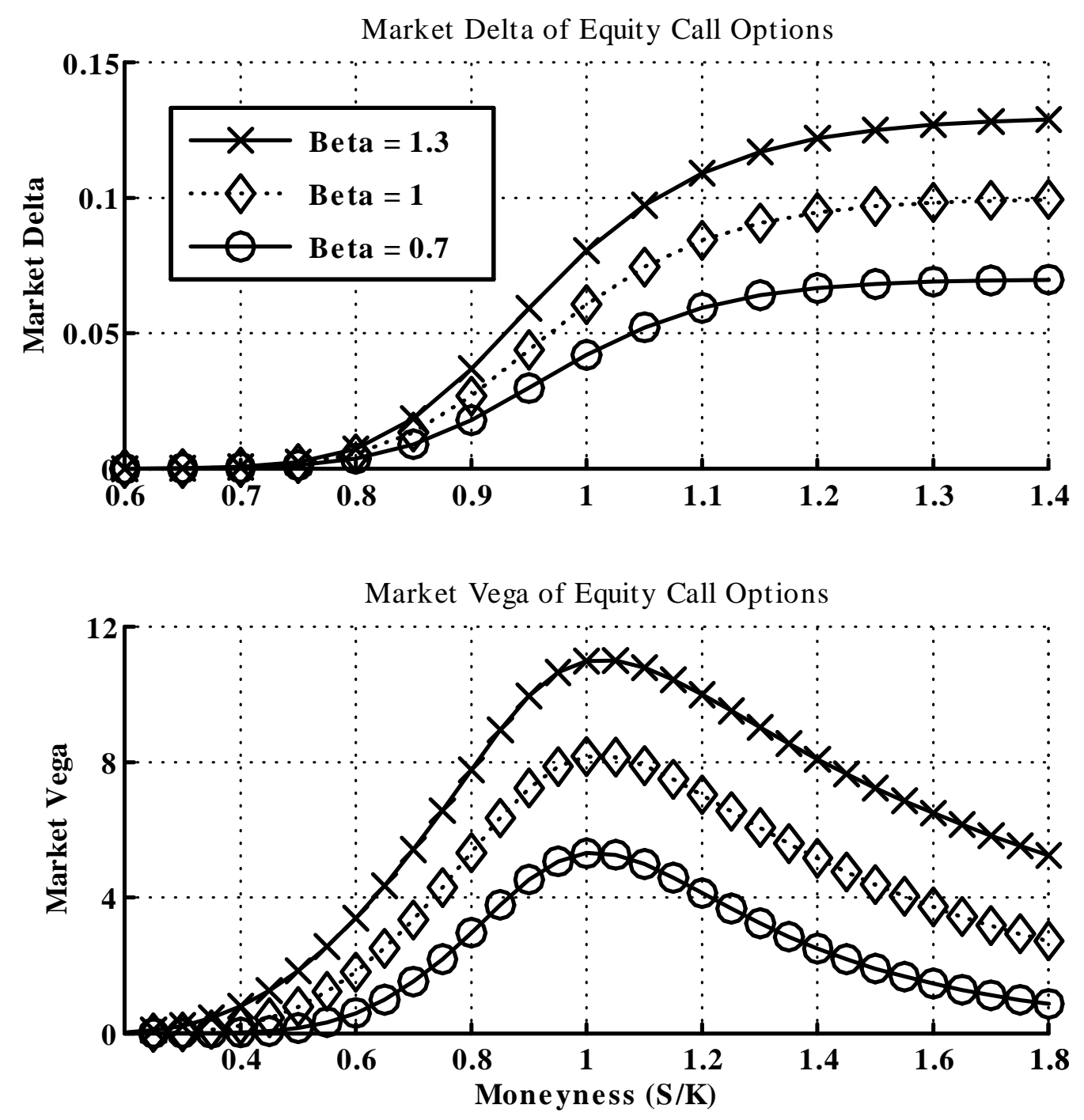

Notes to Figure: We plot the sensitivity of equity options to changes in market level (market delta) and market volatility (market vega). Each line has a different beta but the same amount of unconditional total equity variance $\tilde{V}_{j}=\beta_{j}^{2} \tilde{\theta}_{I}+\theta_{j}=0.1$. We set the current spot variance to $\sigma_{I, t}^{2}=0.01$ and $V_{j, t}=0.05$, and define the idiosyncratic variance as the residual $\sigma_{j, t}^{2}=V_{j, t}-\beta_{j}^{2} \sigma_{I, t}^{2}$. The market index parameters are $\tilde{\kappa}_{I}=5, \tilde{\theta}_{I}=0.04, \delta_{I}=0.5, \rho_{I}=-0.8$, and the individual equity parameters are $\kappa_{j}=1, \delta_{j}=0.4$, and $\rho_{j}=0$. The risk-free rate is $4 \%$ per year, option maturity is 3 months, and we set $S_{t}^{j} / I_{t}=0.1$. 
Figure 8: Expected Excess Returns on Equity Options

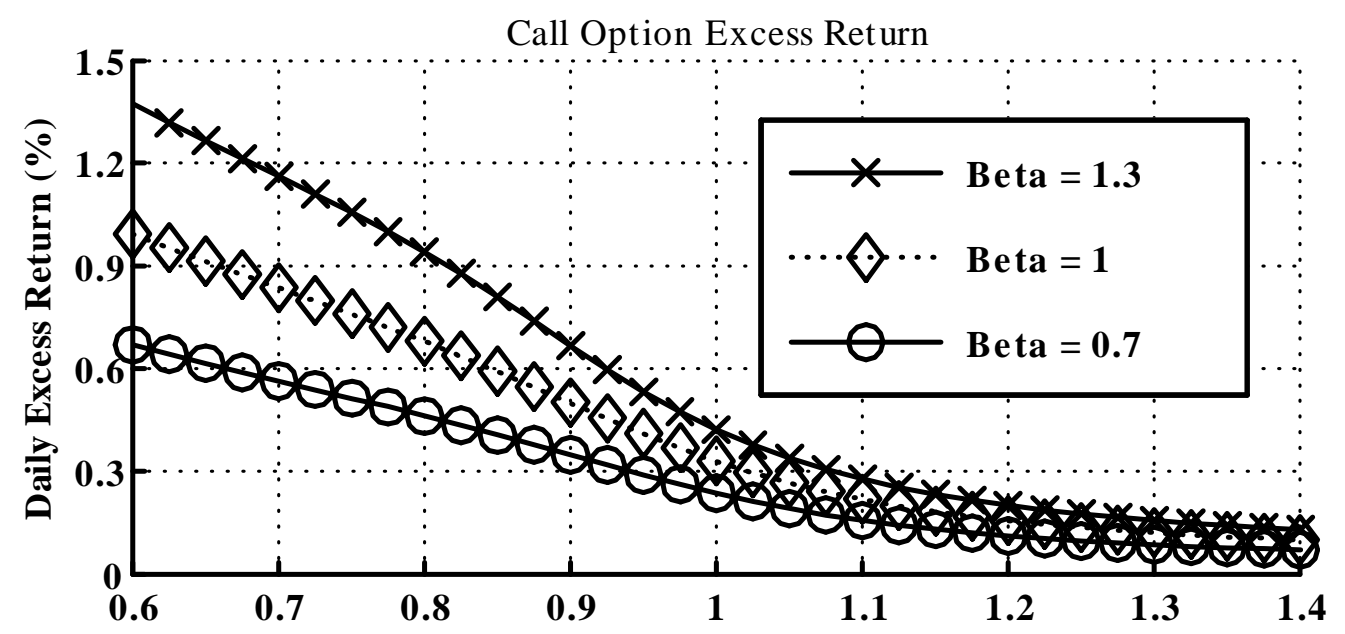

Put Option Excess Return

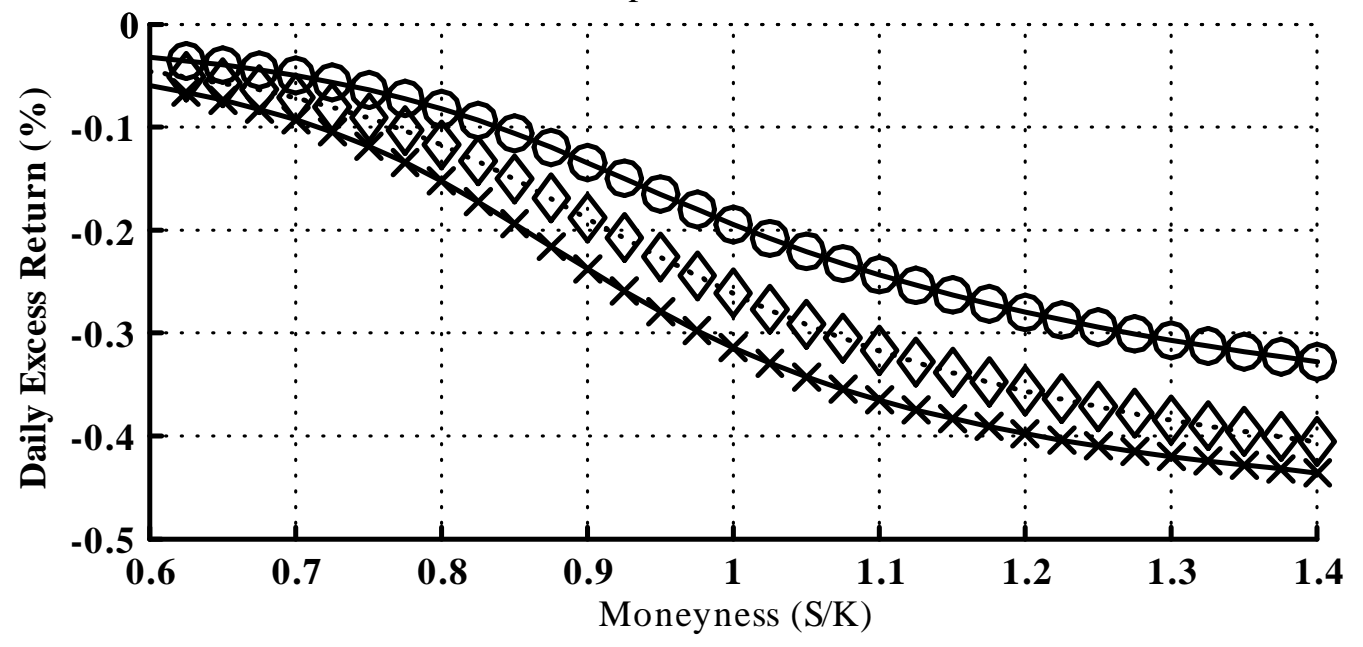

Notes to Figure: We plot expected excess returns in percent per day on call and put options using the model. Each line has a different beta but the same amount of unconditional total equity variance $\tilde{V}_{j}=\beta_{j}^{2} \tilde{\theta}_{I}+\theta_{j}=0.1$. We set the current spot variance to $\sigma_{I, t}^{2}=0.01$ and $V_{j, t}=0.05$, and define the idiosyncratic variance as the residual $\sigma_{j, t}^{2}=V_{j, t}-\beta_{j}^{2} \sigma_{I, t}^{2}$. The market index parameters are $\tilde{\kappa}_{I}=5, \tilde{\theta}_{I}=0.04, \delta_{I}=0.5, \rho_{I}=-0.8, \mu_{I}=0.075$, and the individual equity parameters are $\kappa_{j}=1, \delta_{j}=0.4, \rho_{j}=0$, and $\alpha_{j}=0$. The risk-free rate is $4 \%$ per year and option maturity is 3 months. 
Figure 9.A: Average Market- (solid) and Model-Implied (dashed) Volatility Smile. High Volatility (black) and Low Volatility (grey) Days

Alcoa
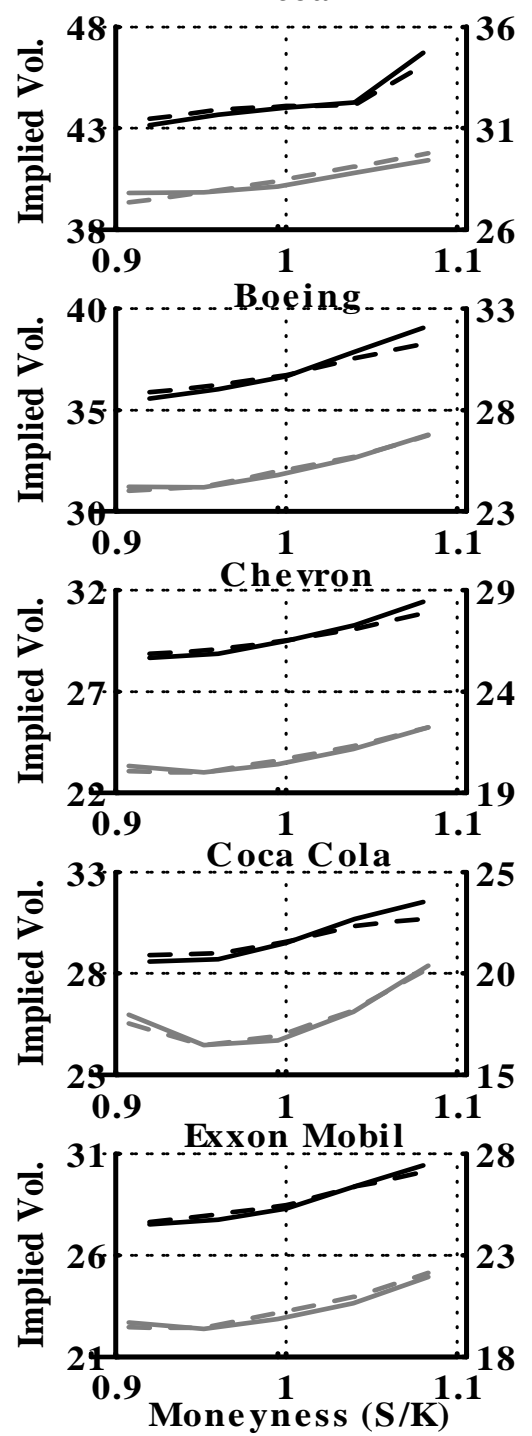

American Express
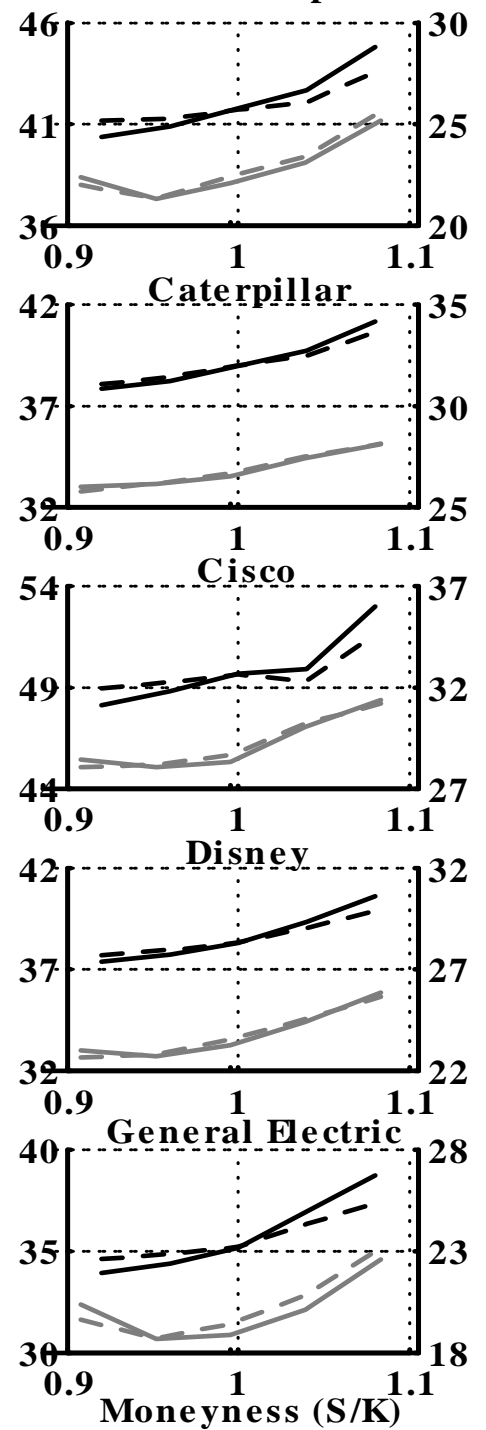

Bank of America
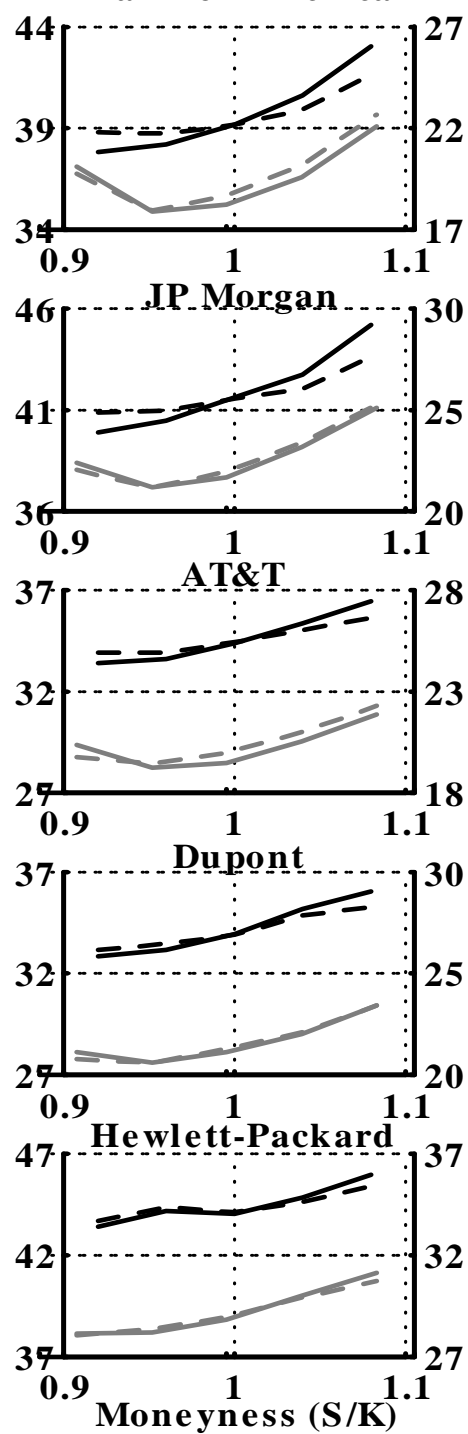

Notes to Figure: We plot the market IV (solid) and model IV (dashed) averaged over time for different moneyness categories for each firm. The black lines (left axis) show the average on days with above-average IV and the grey lines (right axis) show the average for days with below-average IV. Moneyness measured by $S / K$ is on the horizontal axis. 
Figure 9.B: Average Market- (solid) and Model-Implied (dashed) Volatility Smile. High Volatility (black) and Low Volatility (grey) Days
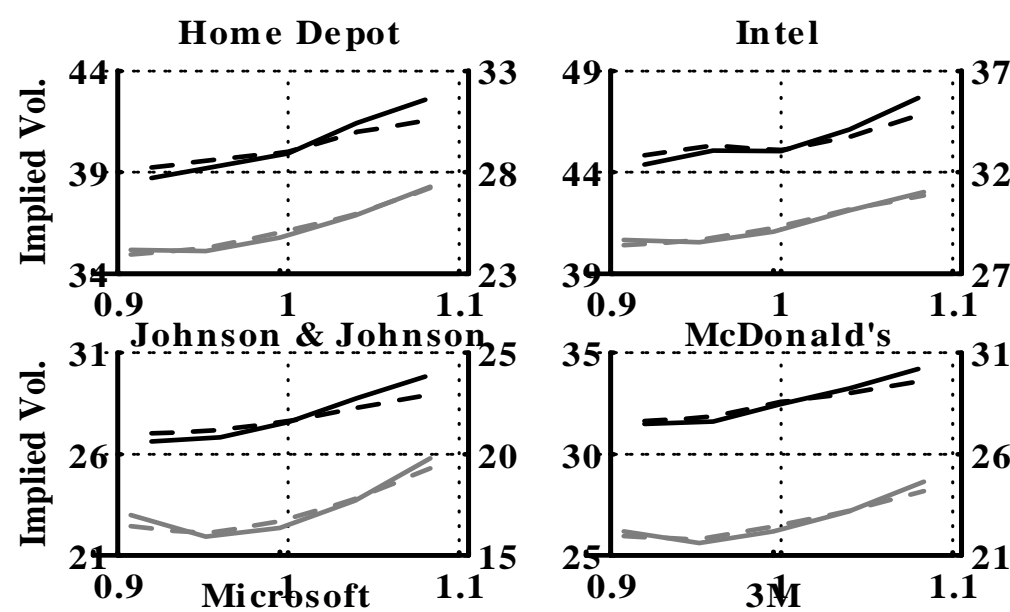

Intel
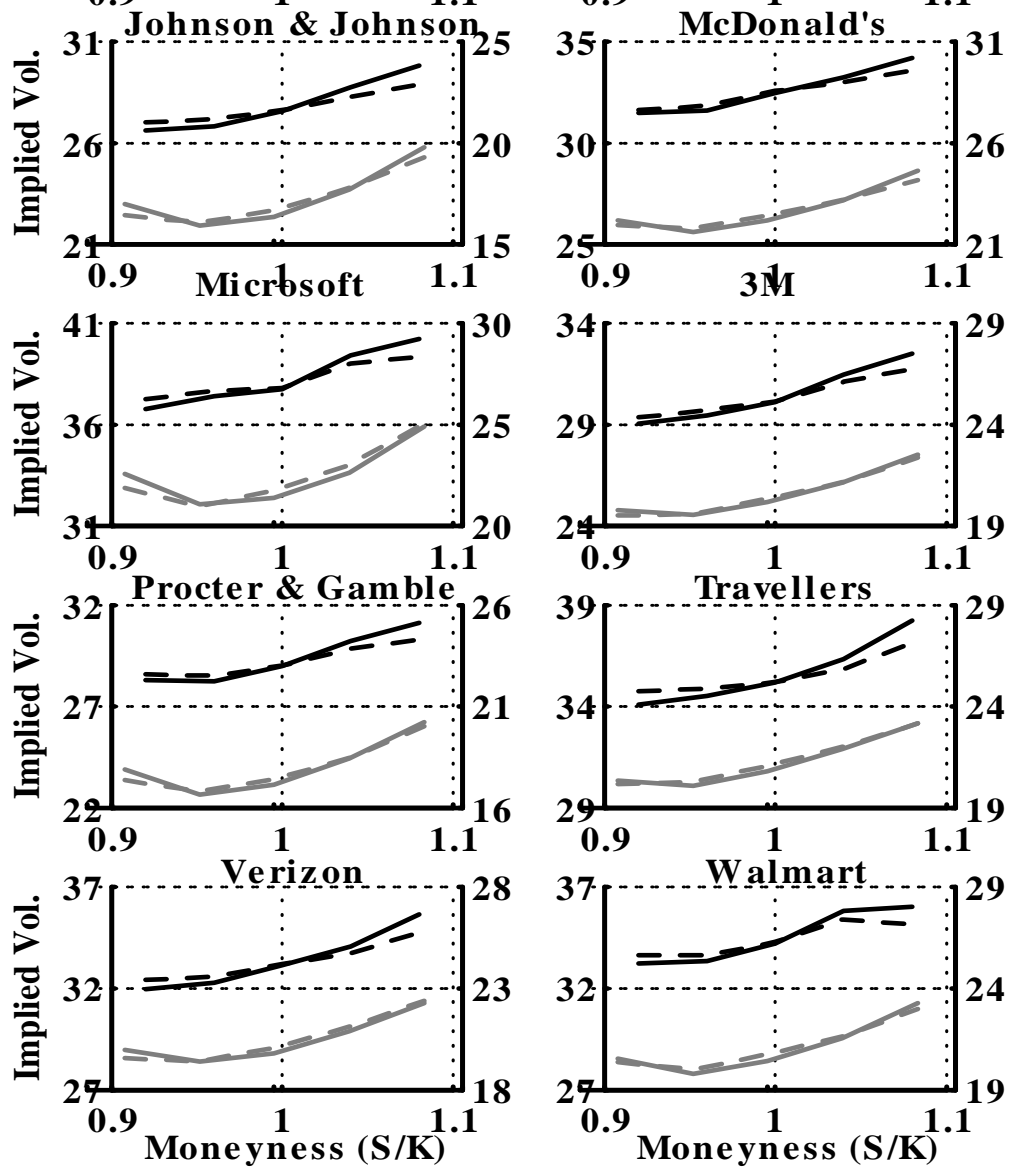
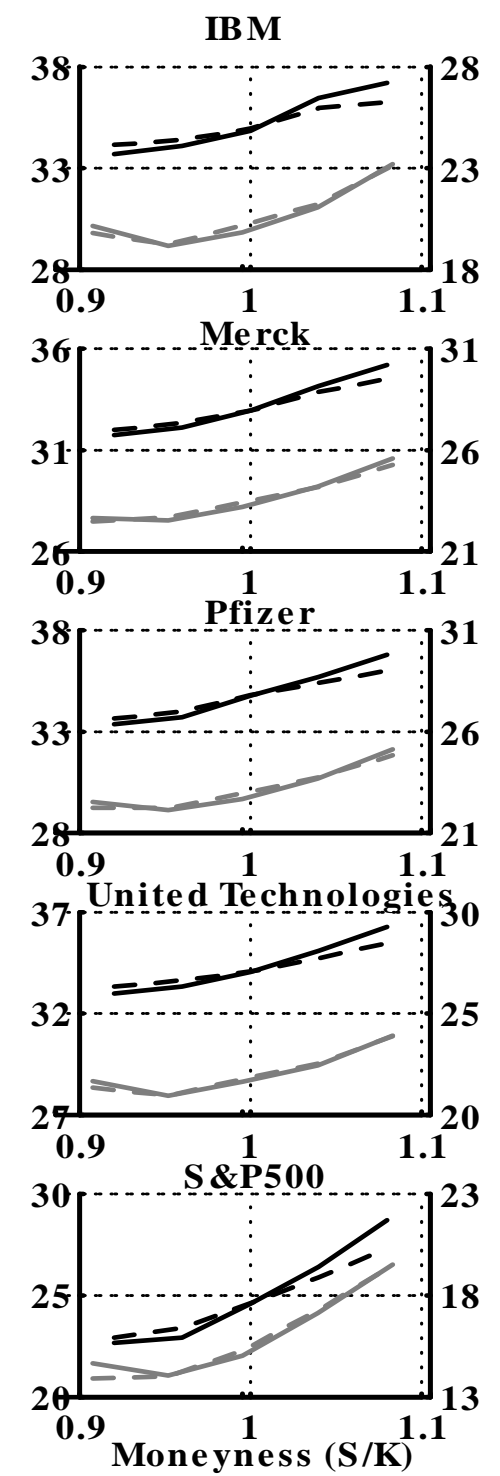

Notes to Figure: We plot the market IV (solid) and model IV (dashed) averaged over time for different moneyness categories for each firm. The black lines (left axis) show the average on days with above-average IV and the grey lines (right axis) show the average for days with below-average IV. Moneyness measured by $S / K$ is on the horizontal axis. 
Figure 10.A: Market- (solid) and Model-Implied (dashed) Term Structures for At-the-Money Implied Volatility. Upward-Sloping (grey) and Downward-Sloping (black) Days
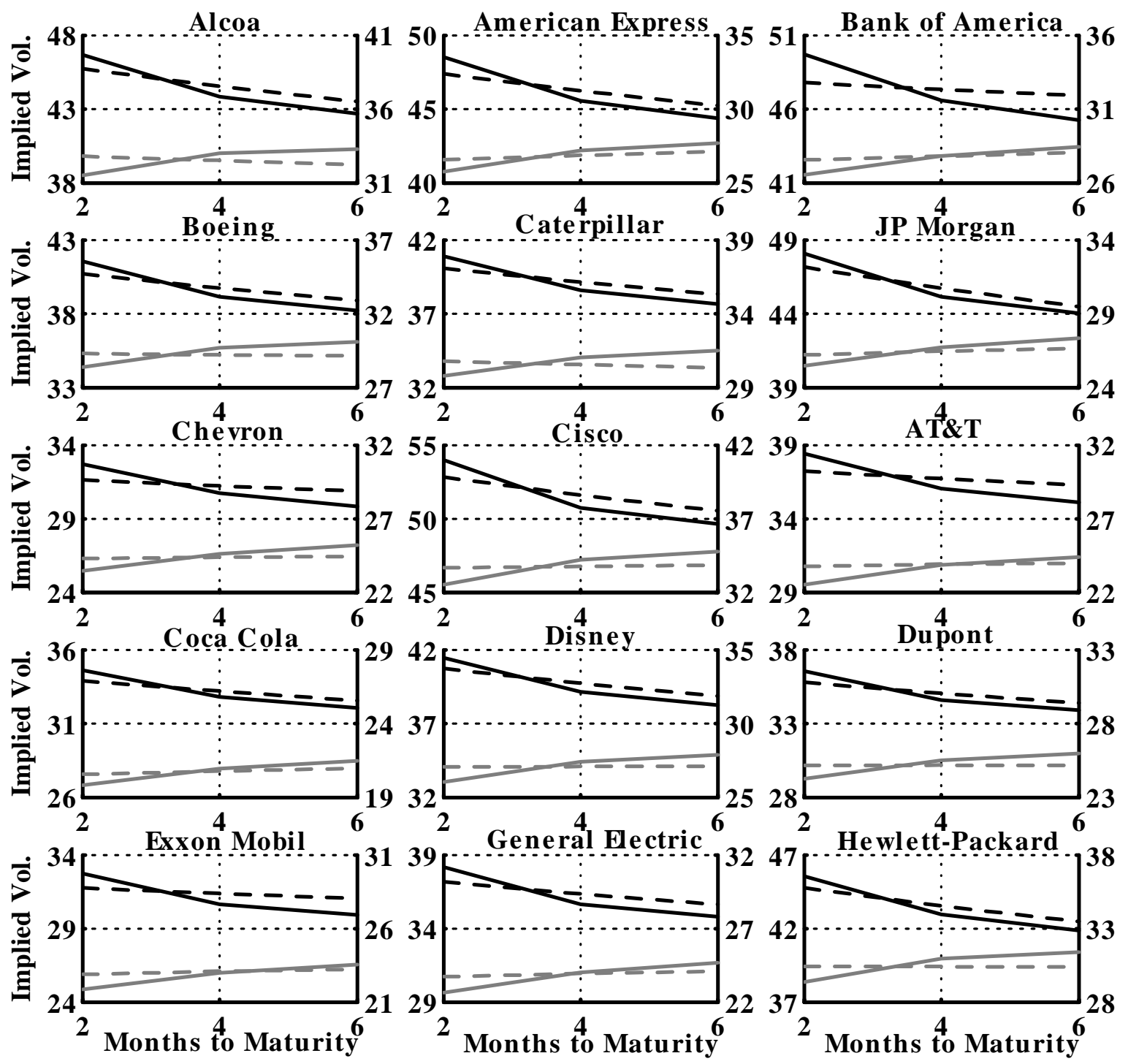

Notes to Figure: The solid black line (left axis) shows the average market IV on days with steeperthan-median downward-sloping term structures and the grey line (right axis) shows the average market IV on days with steeper-than-median upward-sloping term structures. The dashed lines show the corresponding average model IVs. Moneyness $(S / K)$ is between 0.95 and 1.05 . 
Figure 10.B: Market- (solid) and Model-Implied (dashed) Term Structures for At-the-Money Implied Volatility. Upward-Sloping (grey) and Downward-Sloping (black) Days
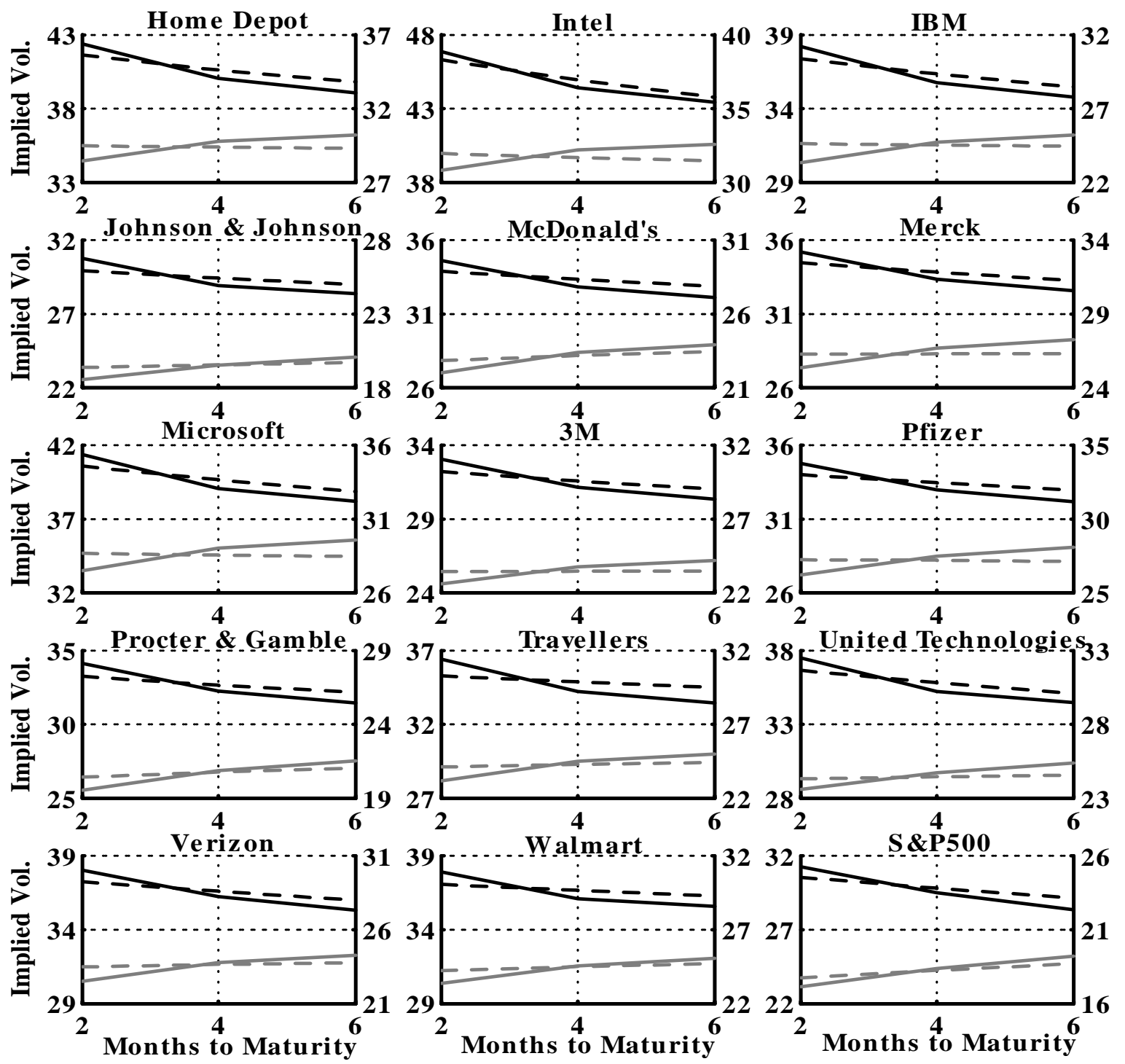

Notes to Figure: The solid black line (left axis) shows the average market IV on days with steeperthan-median downward-sloping term structures and the grey line (right axis) shows the average market IV on days with steeper-than-median upward-sloping term structures. The dashed lines show the corresponding average model IVs. Moneyness $(S / K)$ is between 0.95 and 1.05 . 
Figure 11: Implied Volatility Levels, Moneyness Slopes, and Term Structure Slopes Scatter Plotted Against Beta. 29 Firms
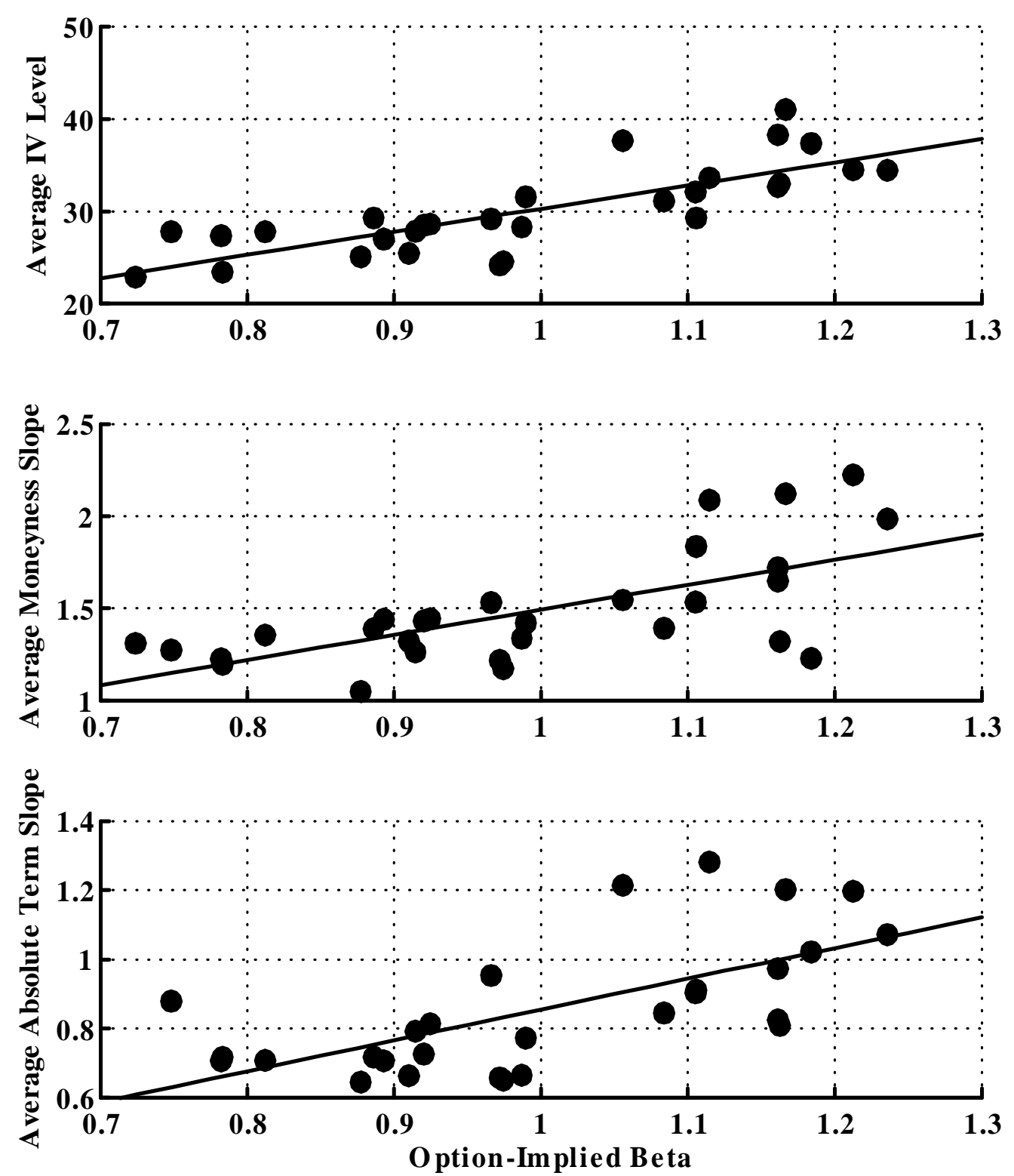

Notes to Figure: We plot the average implied volatility (IV) levels (top panel), the average moneyness slopes (middle panel), and the average absolute value of the term-structure slopes (bottom panel) against the estimated betas from Table 6 . 
Figure 12: Historical Beta versus Option-Implied Beta. 29 Firms

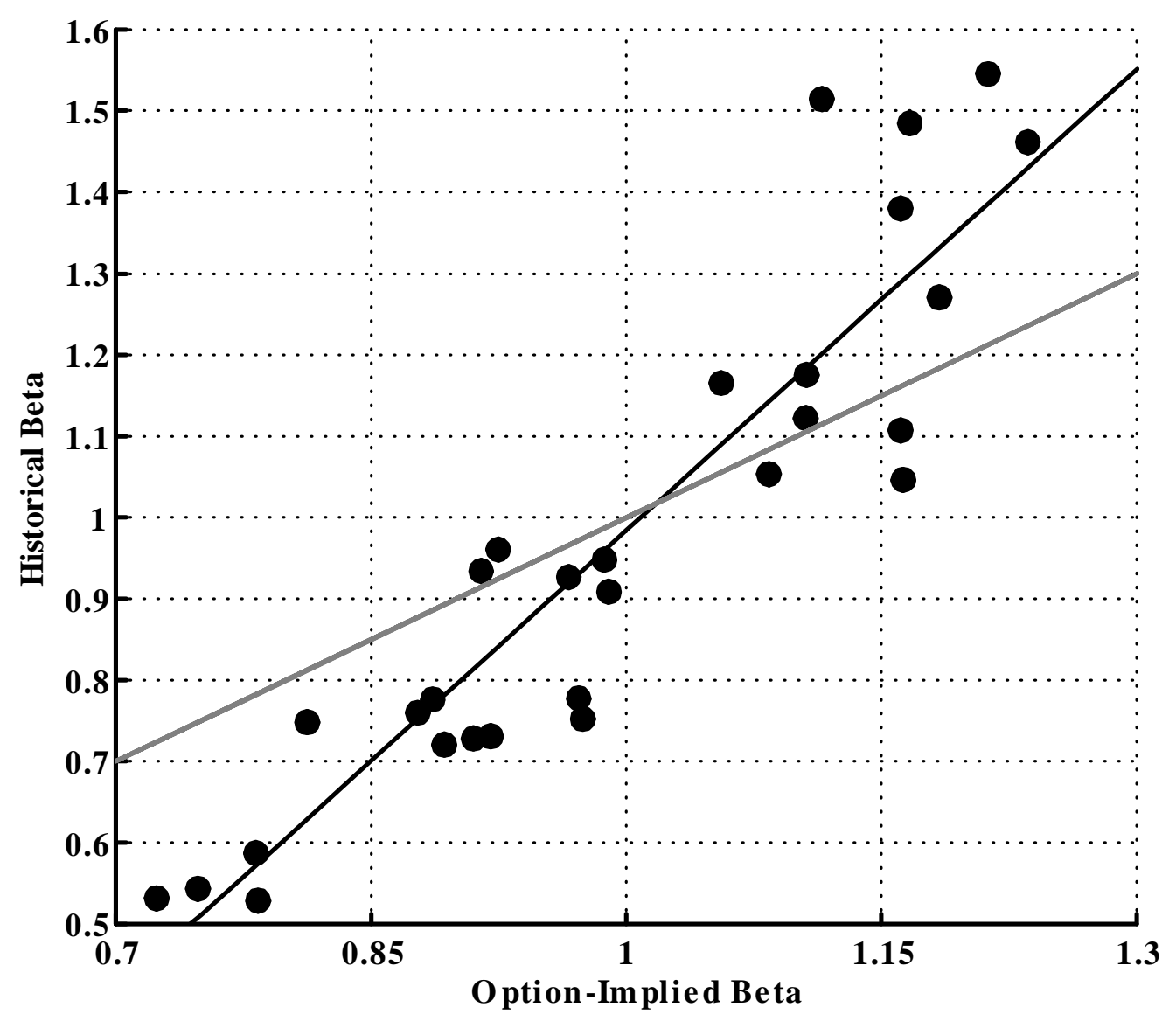

Notes to Figure: We plot the historical beta estimates against option-implied betas for 29 firms. The historical betas are obtained from a CAPM regression using daily returns from the CRSP database during the period from January 4, 1996 to October 29, 2010. The fitted line from the regression is displayed in black while the grey line represents the $45^{\circ}$ line. 
Table 1: Companies, Tickers and Option Contracts

\begin{tabular}{|c|c|c|c|c|c|c|}
\hline \multirow[t]{2}{*}{ Company } & \multirow[t]{2}{*}{$\underline{\text { Ticker }}$} & \multicolumn{3}{|c|}{ Total Number of Options } & \multirow{3}{*}{$\begin{array}{c}\text { Average } \\
\frac{\text { DTM }}{159}\end{array}$} & \multirow{3}{*}{$\begin{array}{c}\text { Average } \\
\underline{\text { IV }} \\
20.65 \%\end{array}$} \\
\hline & & $\underline{\text { All }}$ & $\underline{\text { Puts }}$ & Calls & & \\
\hline S\&P500 Index & SPX & 775,670 & 387,909 & 387,761 & & \\
\hline $\begin{array}{c}\text { Alcoa } \\
\end{array}$ & $\overline{\mathrm{AA}}$ & 758,967 & 380,239 & 378,728 & 157 & $37.00 \%$ \\
\hline American Express & AXP & 761,928 & 381,811 & 380,117 & 157 & $33.98 \%$ \\
\hline Bank of America & $\mathrm{BAC}$ & 714,269 & 357,297 & 356,972 & 146 & $32.51 \%$ \\
\hline Boeing & BA & 769,658 & 385,083 & 384,575 & 158 & $31.46 \%$ \\
\hline Caterpillar & CAT & 765,370 & 382,874 & 382,496 & 157 & $32.87 \%$ \\
\hline JP Morgan & JPM & 752,609 & 376,652 & 375,957 & 155 & $34.05 \%$ \\
\hline Chevron & CVX & 766,139 & 382,958 & 383,181 & 156 & $24.99 \%$ \\
\hline Cisco & $\mathrm{CSCO}$ & 746,456 & 375,550 & 370,906 & 155 & $40.68 \%$ \\
\hline $\mathrm{AT} \& \mathrm{~T}$ & $\mathrm{~T}$ & 709,773 & 355,171 & 354,602 & 141 & $27.60 \%$ \\
\hline Coca Cola & $\mathrm{KO}$ & 775,364 & 387,793 & 387,571 & 159 & $24.10 \%$ \\
\hline Disney & DIS & 752,050 & 376,921 & 375,129 & 155 & $31.16 \%$ \\
\hline Dupont & DD & 760,468 & 380,354 & 380,114 & 155 & $28.22 \%$ \\
\hline Exxon Mobil & XOM & 775,676 & 387,785 & 387,891 & 159 & $24.48 \%$ \\
\hline General Electric & GE & 764,490 & 382,297 & 382,193 & 157 & $29.04 \%$ \\
\hline Hewlett-Packard & HPQ & 762,219 & 382,709 & 379,510 & 156 & $37.42 \%$ \\
\hline Home Depot & HD & 762,287 & 382,159 & 380,128 & 156 & $32.50 \%$ \\
\hline Intel & INTC & 760,016 & 381,699 & 378,317 & 156 & $37.97 \%$ \\
\hline IBM & IBM & 773,831 & 387,616 & 386,215 & 159 & $29.01 \%$ \\
\hline Johnson \& Johnson & JNJ & 775,875 & 387,971 & 387,904 & 159 & $22.79 \%$ \\
\hline McDonald's & MCD & 770,684 & 385,569 & 385,115 & 158 & $27.22 \%$ \\
\hline Merck & MRK & 743,529 & 371,847 & 371,682 & 151 & $28.41 \%$ \\
\hline Microsoft & MSFT & 770,432 & 386,374 & 384,058 & 158 & $31.96 \%$ \\
\hline $3 \mathrm{M}$ & MMM & 771,606 & 385,877 & 385,729 & 158 & $25.40 \%$ \\
\hline Pfizer & PFE & 744,401 & 372,863 & 371,538 & 151 & $29.26 \%$ \\
\hline Procter \& Gamble & PG & 775,170 & 387,716 & 387,454 & 159 & $23.36 \%$ \\
\hline Travellers & TRV & 767,999 & 384,070 & 383,929 & 157 & $28.42 \%$ \\
\hline United Technologies & UTX & 773,903 & 387,166 & 386,737 & 159 & $27.77 \%$ \\
\hline Verizon & $\mathrm{VZ}$ & 711,920 & 356,057 & 355,863 & 141 & $26.85 \%$ \\
\hline Walmart & WMT & 773,220 & 387,497 & 385,723 & 158 & $27.67 \%$ \\
\hline Average & & 758,976 & 379,999 & 378,977 & 155 & $29.94 \%$ \\
\hline
\end{tabular}

Note to Table: For each firm, we report the total number of options, and the number of puts and calls during the sample period 1996-2010. DTM refers to the average number of days-to-maturity in the option sample. Finally, IV denotes the average implied volatility in the sample. 
Table 2: Summary Statistics on Implied Volatility 1996-2010

$\underline{\text { Call Options }}$

$\underline{\text { Ticker }} \underline{\text { Avg IV }} \underline{\max (I V)} \underline{\min (I V)} \underline{\text { Avg Vega }} \underline{\text { Avg IV }} \underline{\max (I V)} \underline{\min (I V)} \underline{\text { Avg Vega }}$

\begin{tabular}{|c|c|c|c|c|c|c|c|c|}
\hline SPX & $20.5 \%$ & $88.6 \%$ & $7.3 \%$ & 246.20 & $20.8 \%$ & $91.1 \%$ & $6.9 \%$ & 246.19 \\
\hline$\overline{\mathrm{AA}}$ & $36.2 \%$ & $149.8 \%$ & $15.8 \%$ & 8.74 & $36.8 \%$ & $149.7 \%$ & $15.7 \%$ & 8.88 \\
\hline AXP & $33.5 \%$ & $149.3 \%$ & $12.6 \%$ & 12.92 & $33.8 \%$ & $149.7 \%$ & $11.6 \%$ & 13.18 \\
\hline BAC & $31.6 \%$ & $150.0 \%$ & $9.9 \%$ & 11.79 & $32.0 \%$ & $150.0 \%$ & $9.4 \%$ & 11.85 \\
\hline BA & $31.3 \%$ & $111.0 \%$ & $16.1 \%$ & 12.87 & $31.4 \%$ & $105.8 \%$ & $15.1 \%$ & 13.03 \\
\hline CAT & $32.4 \%$ & $127.5 \%$ & $16.0 \%$ & 13.29 & $33.0 \%$ & $116.4 \%$ & $15.9 \%$ & 13.40 \\
\hline JPM & $33.5 \%$ & $149.7 \%$ & $11.2 \%$ & 11.69 & $33.9 \%$ & $149.3 \%$ & $11.7 \%$ & 11.83 \\
\hline CVX & $24.6 \%$ & $110.3 \%$ & $11.2 \%$ & 16.55 & $25.4 \%$ & $106.7 \%$ & $9.8 \%$ & 16.63 \\
\hline CSCO & $40.1 \%$ & $133.9 \%$ & $15.9 \%$ & 8.30 & $40.5 \%$ & $129.6 \%$ & $16.2 \%$ & 8.55 \\
\hline $\mathrm{T}$ & $27.4 \%$ & $102.6 \%$ & $10.0 \%$ & 8.11 & $28.0 \%$ & $95.1 \%$ & $8.9 \%$ & 8.17 \\
\hline $\mathrm{KO}$ & $23.9 \%$ & $93.6 \%$ & $8.3 \%$ & 11.66 & $24.4 \%$ & $85.1 \%$ & $8.5 \%$ & 11.79 \\
\hline DIS & $30.5 \%$ & $105.7 \%$ & $6.7 \%$ & 8.10 & $31.3 \%$ & $130.2 \%$ & $14.2 \%$ & 8.25 \\
\hline DD & $27.7 \%$ & $100.9 \%$ & $12.2 \%$ & 11.13 & $28.2 \%$ & $114.5 \%$ & $12.8 \%$ & 11.22 \\
\hline XOM & $24.1 \%$ & $106.8 \%$ & $12.4 \%$ & 14.50 & $24.8 \%$ & $101.9 \%$ & $8.2 \%$ & 14.65 \\
\hline GE & $28.6 \%$ & $149.3 \%$ & $6.9 \%$ & 11.13 & $28.9 \%$ & $149.6 \%$ & $6.1 \%$ & 11.32 \\
\hline HPQ & $37.2 \%$ & $119.4 \%$ & $15.2 \%$ & 10.21 & $37.4 \%$ & $104.4 \%$ & $14.0 \%$ & 10.44 \\
\hline HD & $32.2 \%$ & $121.5 \%$ & $14.7 \%$ & 9.21 & $32.6 \%$ & $115.8 \%$ & $13.1 \%$ & 9.38 \\
\hline INTC & $37.8 \%$ & $136.0 \%$ & $17.3 \%$ & 10.08 & $37.9 \%$ & $98.7 \%$ & $13.1 \%$ & 10.36 \\
\hline IBM & $28.9 \%$ & $118.5 \%$ & $11.9 \%$ & 23.42 & $29.3 \%$ & $100.4 \%$ & $10.4 \%$ & 23.76 \\
\hline $\mathrm{JNJ}$ & $22.5 \%$ & $77.2 \%$ & $9.6 \%$ & 14.63 & $23.2 \%$ & $108.2 \%$ & $8.2 \%$ & 14.81 \\
\hline MCD & $26.9 \%$ & $100.1 \%$ & $10.9 \%$ & 9.33 & $27.7 \%$ & $94.5 \%$ & $11.7 \%$ & 9.43 \\
\hline MRK & $28.2 \%$ & $115.0 \%$ & $14.6 \%$ & 13.14 & $28.5 \%$ & $91.8 \%$ & $9.1 \%$ & 13.29 \\
\hline MSFT & $31.8 \%$ & $103.6 \%$ & $11.2 \%$ & 12.61 & $32.1 \%$ & $106.6 \%$ & $11.1 \%$ & 12.91 \\
\hline MMM & $25.2 \%$ & $96.2 \%$ & $12.3 \%$ & 19.13 & $25.6 \%$ & $97.2 \%$ & $12.0 \%$ & 19.31 \\
\hline PFE & $29.2 \%$ & $134.9 \%$ & $14.2 \%$ & 9.55 & $29.4 \%$ & $110.5 \%$ & $12.1 \%$ & 9.71 \\
\hline PG & $23.0 \%$ & $89.0 \%$ & $9.1 \%$ & 16.75 & $23.8 \%$ & $104.6 \%$ & $6.7 \%$ & 16.93 \\
\hline TRV & $28.1 \%$ & $146.2 \%$ & $10.2 \%$ & 10.06 & $28.7 \%$ & $131.8 \%$ & $9.8 \%$ & 10.16 \\
\hline UTX & $27.3 \%$ & $102.2 \%$ & $13.2 \%$ & 16.41 & $28.2 \%$ & $100.2 \%$ & $12.5 \%$ & 16.61 \\
\hline $\mathrm{VZ}$ & $26.6 \%$ & $105.6 \%$ & $8.2 \%$ & 9.84 & $27.4 \%$ & $90.6 \%$ & $8.9 \%$ & 9.88 \\
\hline WMT & $27.5 \%$ & $85.0 \%$ & $11.7 \%$ & 10.90 & $28.0 \%$ & $121.3 \%$ & $10.6 \%$ & 11.05 \\
\hline Average & $29.6 \%$ & $116.9 \%$ & $12.0 \%$ & 12.28 & $30.1 \%$ & $114.1 \%$ & $11.3 \%$ & 12.44 \\
\hline
\end{tabular}

Note to Table: For each firm, we report the average, maximum, and minimum of implied volatility using the IV surfaces from OptionMetrics. Option vega is computed using Black-Scholes. 
Table 3: Principal Component Analysis of Equity Implied Volatility Levels.

Component Loadings and Properties

\begin{tabular}{|c|c|c|c|}
\hline Company & $\underline{1 \mathrm{st} \text { Component }}$ & $\underline{\text { 2nd Component }}$ & $\underline{\text { 3rd Component }}$ \\
\hline Alcoa & $24.57 \%$ & $30.87 \%$ & $-20.02 \%$ \\
\hline American Express & $38.44 \%$ & $50.96 \%$ & $47.44 \%$ \\
\hline Bank of America & $15.63 \%$ & $-0.71 \%$ & $-5.85 \%$ \\
\hline Boeing & $13.05 \%$ & $-13.72 \%$ & $14.28 \%$ \\
\hline Caterpillar & $17.19 \%$ & $-13.35 \%$ & $-33.30 \%$ \\
\hline JP Morgan & $16.75 \%$ & $1.33 \%$ & $-1.39 \%$ \\
\hline Chevron & $10.96 \%$ & $3.45 \%$ & $-19.29 \%$ \\
\hline Cisco & $24.29 \%$ & $11.76 \%$ & $10.47 \%$ \\
\hline AT\&T & $15.89 \%$ & $-19.77 \%$ & $12.98 \%$ \\
\hline Coca Cola & $10.24 \%$ & $-14.91 \%$ & $9.94 \%$ \\
\hline Disney & $9.78 \%$ & $-12.05 \%$ & $-18.07 \%$ \\
\hline Dupont & $18.24 \%$ & $-18.97 \%$ & $17.29 \%$ \\
\hline Exxon Mobil & $19.47 \%$ & $2.09 \%$ & $-36.25 \%$ \\
\hline General Electric & $15.34 \%$ & $-7.85 \%$ & $-9.45 \%$ \\
\hline Hewlett-Packard & $14.58 \%$ & $-20.13 \%$ & $3.14 \%$ \\
\hline Home Depot & $29.43 \%$ & $18.73 \%$ & $0.72 \%$ \\
\hline Intel & $17.45 \%$ & $-7.70 \%$ & $-15.78 \%$ \\
\hline IBM & $18.41 \%$ & $-24.94 \%$ & $1.40 \%$ \\
\hline Johnson \& Johnson & $12.41 \%$ & $2.69 \%$ & $-8.32 \%$ \\
\hline McDonald's & $16.67 \%$ & $9.16 \%$ & $-3.35 \%$ \\
\hline Merck & $11.82 \%$ & $7.82 \%$ & $-19.85 \%$ \\
\hline Microsoft & $13.01 \%$ & $-4.05 \%$ & $-0.78 \%$ \\
\hline $3 \mathrm{M}$ & $12.09 \%$ & $-6.66 \%$ & $7.07 \%$ \\
\hline Pfizer & $12.55 \%$ & $-11.60 \%$ & $13.40 \%$ \\
\hline Procter \& Gamble & $28.44 \%$ & $11.51 \%$ & $-5.68 \%$ \\
\hline Travellers & $16.22 \%$ & $-29.44 \%$ & $8.50 \%$ \\
\hline United Technologies & $19.32 \%$ & $-7.70 \%$ & $-16.68 \%$ \\
\hline Verizon & $15.39 \%$ & $-12.61 \%$ & $-27.83 \%$ \\
\hline Walmart & $19.24 \%$ & $-41.77 \%$ & $33.13 \%$ \\
\hline age & $17.48 \%$ & $-4.05 \%$ & $-2.14 \%$ \\
\hline num & $9.78 \%$ & $-41.77 \%$ & $-36.25 \%$ \\
\hline mum & $38.44 \%$ & $50.96 \%$ & $47.44 \%$ \\
\hline $\begin{array}{l}\text { tion Captured } \\
\text { lation with S\&P500 }\end{array}$ & $77.18 \%$ & $13.43 \%$ & $2.47 \%$ \\
\hline age Implied Volatility & $91.94 \%$ & $14.88 \%$ & $-6.58 \%$ \\
\hline
\end{tabular}

Note to Table: For the first three principal components of the equity implied volatility (IV) levels we report the loadings of each firm as well as the average, minimum and maximum loading across firms. We also report the total cross-sectional variation captured by each of the first three components as well as their correlation with the S\&P500 IV levels. 
Table 4: Principal Component Analysis of Equity IV Moneyness Slopes.

Component Loadings and Properties

\begin{tabular}{|c|c|c|c|}
\hline Company & $\underline{1 \mathrm{st} \text { Component }}$ & 2nd Component & $\underline{\text { 3rd Component }}$ \\
\hline Alcoa & $19.40 \%$ & $-14.18 \%$ & $-6.86 \%$ \\
\hline American Express & $26.14 \%$ & $-9.89 \%$ & $50.00 \%$ \\
\hline Bank of America & $15.46 \%$ & $-6.14 \%$ & $-4.64 \%$ \\
\hline Boeing & $11.71 \%$ & $10.72 \%$ & $-1.07 \%$ \\
\hline Caterpillar & $18.22 \%$ & $1.25 \%$ & $-17.08 \%$ \\
\hline JP Morgan & $17.32 \%$ & $-3.05 \%$ & $-10.04 \%$ \\
\hline Chevron & $15.12 \%$ & $-5.56 \%$ & $-4.72 \%$ \\
\hline Cisco & $25.40 \%$ & $18.20 \%$ & $41.16 \%$ \\
\hline AT\&T & $17.34 \%$ & $18.98 \%$ & $-4.31 \%$ \\
\hline Coca Cola & $12.12 \%$ & $18.16 \%$ & $-19.15 \%$ \\
\hline Disney & $14.44 \%$ & $-10.47 \%$ & $-8.27 \%$ \\
\hline Dupont & $18.84 \%$ & $32.62 \%$ & $-5.51 \%$ \\
\hline Exxon Mobil & $19.99 \%$ & $-35.30 \%$ & $-7.49 \%$ \\
\hline General Electric & $19.45 \%$ & $-11.75 \%$ & $-21.89 \%$ \\
\hline Hewlett-Packard & $15.98 \%$ & $5.41 \%$ & $-14.49 \%$ \\
\hline Home Depot & $30.31 \%$ & $-20.67 \%$ & $33.50 \%$ \\
\hline Intel & $16.56 \%$ & $-4.77 \%$ & $-8.16 \%$ \\
\hline IBM & $16.62 \%$ & $21.62 \%$ & $-13.12 \%$ \\
\hline Johnson \& Johnson & $13.12 \%$ & $-1.95 \%$ & $-9.65 \%$ \\
\hline McDonald's & $20.11 \%$ & $-15.94 \%$ & $-8.08 \%$ \\
\hline Merck & $16.24 \%$ & $-9.38 \%$ & $-5.24 \%$ \\
\hline Microsoft & $15.47 \%$ & $1.71 \%$ & $-12.90 \%$ \\
\hline $3 \mathrm{M}$ & $13.86 \%$ & $9.98 \%$ & $-13.53 \%$ \\
\hline Pfizer & $15.89 \%$ & $3.67 \%$ & $-12.87 \%$ \\
\hline Procter \& Gamble & $29.96 \%$ & $-10.19 \%$ & $18.81 \%$ \\
\hline Travellers & $15.40 \%$ & $0.87 \%$ & $-2.62 \%$ \\
\hline United Technologies & $20.60 \%$ & $-6.86 \%$ & $-4.11 \%$ \\
\hline Verizon & $17.73 \%$ & $14.90 \%$ & $-35.19 \%$ \\
\hline Walmart & $12.12 \%$ & $64.38 \%$ & $20.35 \%$ \\
\hline ge & $17.96 \%$ & $1.94 \%$ & $-3.00 \%$ \\
\hline lum & $11.71 \%$ & $-35.30 \%$ & $-35.19 \%$ \\
\hline num & $30.31 \%$ & $64.38 \%$ & $50.00 \%$ \\
\hline $\begin{array}{l}\text { ion Captured } \\
\text { ation with S\&P500 }\end{array}$ & $76.67 \%$ & $5.57 \%$ & $3.72 \%$ \\
\hline yness Slope & $63.71 \%$ & $5.32 \%$ & $31.42 \%$ \\
\hline
\end{tabular}

Note to Table: For the first three principal components of equity implied volatility (IV) moneyness slope we report the loadings of each firm as well as the average, minimum and maximum loading across firms. We also report the total cross sectional variation captured by each of the first three components as well as their correlation with the S\&P500 moneyness slope. 
Table 5: Principal Component Analysis of Equity IV Term Structure Slopes.

Component Loadings and Properties

\begin{tabular}{|c|c|c|c|}
\hline Company & $\underline{1 \text { st Component }}$ & 2nd Component & $\underline{\text { 3rd Component }}$ \\
\hline Alcoa & $18.53 \%$ & $21.29 \%$ & $-21.80 \%$ \\
\hline American Express & $35.89 \%$ & $67.42 \%$ & $30.07 \%$ \\
\hline Bank of America & $18.75 \%$ & $-7.41 \%$ & $-2.74 \%$ \\
\hline Boeing & $13.07 \%$ & $-9.36 \%$ & $-5.24 \%$ \\
\hline Caterpillar & $17.77 \%$ & $-16.56 \%$ & $-10.04 \%$ \\
\hline JP Morgan & $15.37 \%$ & $-0.45 \%$ & $-15.07 \%$ \\
\hline Chevron & $14.62 \%$ & $-8.90 \%$ & $-22.02 \%$ \\
\hline Cisco & $21.19 \%$ & $15.42 \%$ & $21.43 \%$ \\
\hline AT\&T & $18.36 \%$ & $-17.78 \%$ & $4.29 \%$ \\
\hline Coca Cola & $12.05 \%$ & $-8.02 \%$ & $-10.52 \%$ \\
\hline Disney & $11.55 \%$ & $-10.75 \%$ & $-13.28 \%$ \\
\hline Dupont & $16.62 \%$ & $-19.56 \%$ & $10.45 \%$ \\
\hline Exxon Mobil & $17.31 \%$ & $-1.34 \%$ & $-21.94 \%$ \\
\hline General Electric & $17.79 \%$ & $-4.65 \%$ & $-15.76 \%$ \\
\hline Hewlett-Packard & $12.30 \%$ & $-10.64 \%$ & $-5.14 \%$ \\
\hline Home Depot & $27.37 \%$ & $18.40 \%$ & $-3.93 \%$ \\
\hline Intel & $19.57 \%$ & $-8.35 \%$ & $-6.20 \%$ \\
\hline IBM & $17.06 \%$ & $-15.23 \%$ & $18.99 \%$ \\
\hline Johnson \& Johnson & $15.66 \%$ & $-4.05 \%$ & $-14.15 \%$ \\
\hline McDonald's & $18.25 \%$ & $2.19 \%$ & $-18.20 \%$ \\
\hline Merck & $15.02 \%$ & $-5.77 \%$ & $-26.27 \%$ \\
\hline Microsoft & $15.52 \%$ & $-4.77 \%$ & $-6.75 \%$ \\
\hline $3 \mathrm{M}$ & $12.24 \%$ & $-5.21 \%$ & $-14.54 \%$ \\
\hline Pfizer & $13.01 \%$ & $-9.51 \%$ & $-6.59 \%$ \\
\hline Procter \& Gamble & $28.31 \%$ & $18.41 \%$ & $5.07 \%$ \\
\hline Travellers & $18.97 \%$ & $-29.79 \%$ & $31.85 \%$ \\
\hline United Technologies & $18.24 \%$ & $-10.81 \%$ & $-1.90 \%$ \\
\hline Verizon & $15.82 \%$ & $-9.27 \%$ & $-11.05 \%$ \\
\hline Walmart & $21.00 \%$ & $-31.43 \%$ & $55.14 \%$ \\
\hline Average & $17.83 \%$ & $-3.67 \%$ & $-2.62 \%$ \\
\hline Minimum & $11.55 \%$ & $-31.43 \%$ & $-26.27 \%$ \\
\hline Maximum & $35.89 \%$ & $67.42 \%$ & $55.14 \%$ \\
\hline Variation Captured & $59.55 \%$ & $13.57 \%$ & $4.87 \%$ \\
\hline Correlation with S\&P500 & & & \\
\hline Term Structure Slope & $79.87 \%$ & $9.03 \%$ & $-8.59 \%$ \\
\hline
\end{tabular}

Note to Table: For the first three principal components of implied volatility (IV) term structure slope we report the loadings of each firm as well as the average, minimum and maximum loading across firms. We also report the total cross sectional variation captured by each of the first three components as well as their correlation with the S\&P500 term structure slope. 
Table 6: Model Parameters and Properties. Index and Equity Options

\begin{tabular}{|c|c|c|c|c|c|c|c|}
\hline$\underline{\text { Ticker }}$ & $\underline{\text { Kappa }}$ & Theta & $\underline{\text { Delta }}$ & $\underline{\text { Rho }}$ & $\underline{\text { Beta }}$ & $\begin{array}{l}\text { Average Total } \\
\text { Spot Volatility } \\
\end{array}$ & $\begin{array}{l}\text { Systematic } \\
\text { Risk Ratio } \\
\text { (R-Squared) }\end{array}$ \\
\hline SPX & 1.13 & 0.0610 & 0.371 & -0.855 & & $22.23 \%$ & \\
\hline$\overline{\mathrm{AA}}$ & 1.04 & 0.0135 & 0.140 & "-0.370 & 1.18 & $42.23 \%$ & $38.85 \%$ \\
\hline AXP & 0.81 & 0.0018 & 0.054 & -0.600 & 1.24 & $39.57 \%$ & $48.23 \%$ \\
\hline BAC & 0.15 & 0.0159 & 0.068 & -0.724 & 1.11 & $40.05 \%$ & $38.29 \%$ \\
\hline BA & 1.07 & 0.0323 & 0.263 & -0.523 & 0.99 & $33.64 \%$ & $42.78 \%$ \\
\hline CAT & 0.87 & 0.0060 & 0.102 & -0.466 & 1.16 & $35.80 \%$ & $52.12 \%$ \\
\hline JPM & 1.14 & 0.0072 & 0.128 & -0.656 & 1.21 & $39.72 \%$ & $46.06 \%$ \\
\hline CVX & 0.84 & 0.0272 & 0.078 & -0.458 & 0.88 & $26.53 \%$ & $54.03 \%$ \\
\hline $\mathrm{CSCO}$ & 0.96 & 0.0586 & 0.333 & -0.529 & 1.17 & $44.98 \%$ & $33.24 \%$ \\
\hline $\mathrm{T}$ & 0.52 & 0.0229 & 0.055 & -0.434 & 0.97 & $30.22 \%$ & $51.11 \%$ \\
\hline $\mathrm{KO}$ & 0.90 & 0.0252 & 0.213 & -0.571 & 0.75 & $26.02 \%$ & $40.86 \%$ \\
\hline DIS & 0.95 & 0.0119 & 0.150 & -0.496 & 1.08 & $33.98 \%$ & $50.28 \%$ \\
\hline DD & 0.76 & 0.0113 & 0.126 & -0.542 & 0.99 & $30.58 \%$ & $51.50 \%$ \\
\hline XOM & 0.50 & 0.0267 & 0.008 & 0.297 & 0.97 & $25.83 \%$ & $70.32 \%$ \\
\hline GE & 0.99 & 0.0022 & 0.029 & -0.561 & 1.11 & $33.31 \%$ & $54.48 \%$ \\
\hline HPQ & 1.29 & 0.0420 & 0.329 & -0.474 & 1.06 & $41.30 \%$ & $32.29 \%$ \\
\hline HD & 1.04 & 0.0142 & 0.171 & -0.611 & 1.16 & $35.73 \%$ & $52.21 \%$ \\
\hline INTC & 1.24 & 0.0230 & 0.237 & -0.492 & 1.16 & $41.99 \%$ & $37.80 \%$ \\
\hline IBM & 1.24 & 0.0126 & 0.177 & -0.598 & 0.97 & $32.20 \%$ & $44.48 \%$ \\
\hline JNJ & 0.80 & 0.0219 & 0.187 & -0.566 & 0.72 & $24.35 \%$ & $43.67 \%$ \\
\hline MCD & 1.01 & 0.0451 & 0.302 & -0.426 & 0.78 & $28.81 \%$ & $36.44 \%$ \\
\hline MRK & 1.28 & 0.0330 & 0.291 & -0.495 & 0.92 & $30.11 \%$ & $46.17 \%$ \\
\hline MSFT & 0.99 & 0.0131 & 0.141 & -0.523 & 1.11 & $35.09 \%$ & $49.05 \%$ \\
\hline MMM & 0.99 & 0.0153 & 0.174 & -0.478 & 0.91 & $27.10 \%$ & $55.74 \%$ \\
\hline PFE & 0.96 & 0.0323 & 0.248 & -0.574 & 0.89 & $30.82 \%$ & $40.84 \%$ \\
\hline$P G$ & 0.85 & 0.0317 & 0.233 & -0.346 & 0.78 & $24.80 \%$ & $49.32 \%$ \\
\hline TRV & 0.54 & 0.0256 & 0.166 & -0.565 & 0.92 & $31.29 \%$ & $43.15 \%$ \\
\hline UTX & 1.04 & 0.0247 & 0.226 & -0.376 & 0.91 & $30.11 \%$ & $45.62 \%$ \\
\hline $\mathrm{VZ}$ & 0.73 & 0.0323 & 0.217 & -0.545 & 0.89 & $29.18 \%$ & $46.30 \%$ \\
\hline WMT & 0.54 & 0.0494 & 0.231 & -0.549 & 0.81 & $29.58 \%$ & $37.25 \%$ \\
\hline Average & 0.90 & 0.0234 & 0.18 & -0.49 & 0.99 & $32.93 \%$ & $45.95 \%$ \\
\hline
\end{tabular}

Note to Table: We use option data from 1996 to 2010 to estimate risk-neutral parameter values for the market index as well as the 29 individual equities. The individual equity parameters are estimated taking the market index parameter values as given. The last two columns report the average spot volatility through the sample and the proportion of total variance accounted for by the systematic market risk factor. 
Table 7: Model Fit for Index and Equity Put Options

\begin{tabular}{|c|c|c|c|c|c|c|c|}
\hline & \multicolumn{3}{|c|}{ All Put Options } & \multicolumn{3}{|r|}{ 2-month } & \multirow{2}{*}{$\begin{array}{c}\text { 6-month } \\
\text { ATM }\end{array}$} \\
\hline & Vega & & "IVRMSE / & ITM & OTM & ATM & \\
\hline$\underline{\text { Ticker }}$ & $\underline{\mathrm{RMSE}}$ & $\underline{\text { IVRMSE }}$ & Average IV & $\underline{\text { IVRMSE }}$ & $\underline{\text { IVRMSE }}$ & $\underline{\text { IVRMSE }}$ & $\underline{\text { IVRMSE }}$ \\
\hline SPX & $1.00 \%$ & $0.99 \%$ & $4.81 \%$ & $0.94 \%$ & $1.08 \%$ & $0.72 \%$ & $0.91 \%$ \\
\hline$\overline{\mathrm{AA}}$ & $1.36 \%$ & $1.36 \%$ & $3.68 \%$ & $1.33 \%$ & $\overline{~ 1.40 \%}$ & $1.32 \%$ & $1.22 \%$ \\
\hline AXP & $1.33 \%$ & $1.34 \%$ & $3.94 \%$ & $1.28 \%$ & $1.41 \%$ & $1.16 \%$ & $1.26 \%$ \\
\hline BAC & $1.58 \%$ & $1.59 \%$ & $4.88 \%$ & $1.53 \%$ & $1.65 \%$ & $1.43 \%$ & $1.39 \%$ \\
\hline BA & $1.03 \%$ & $1.03 \%$ & $3.27 \%$ & $0.98 \%$ & $1.08 \%$ & $0.93 \%$ & $0.98 \%$ \\
\hline CAT & $1.05 \%$ & $1.05 \%$ & $3.20 \%$ & $1.00 \%$ & $1.12 \%$ & $0.96 \%$ & $0.95 \%$ \\
\hline JPM & $1.38 \%$ & $1.38 \%$ & $4.06 \%$ & $1.31 \%$ & $1.47 \%$ & $1.12 \%$ & $1.29 \%$ \\
\hline CVX & $0.96 \%$ & $0.97 \%$ & $3.86 \%$ & $0.93 \%$ & $1.01 \%$ & $0.86 \%$ & $0.93 \%$ \\
\hline $\mathrm{CSCO}$ & $1.46 \%$ & $1.46 \%$ & $3.60 \%$ & $1.45 \%$ & $1.48 \%$ & $1.39 \%$ & $1.46 \%$ \\
\hline $\mathrm{T}$ & $1.50 \%$ & $1.51 \%$ & $5.48 \%$ & $1.53 \%$ & $1.49 \%$ & $1.49 \%$ & $1.27 \%$ \\
\hline $\mathrm{KO}$ & $0.93 \%$ & $0.95 \%$ & $3.93 \%$ & $0.94 \%$ & $0.96 \%$ & $0.86 \%$ & $0.82 \%$ \\
\hline DIS & $1.12 \%$ & $1.13 \%$ & $3.62 \%$ & $1.13 \%$ & $1.12 \%$ & $1.03 \%$ & $1.05 \%$ \\
\hline $\mathrm{DD}$ & $0.98 \%$ & $0.99 \%$ & $3.49 \%$ & $0.95 \%$ & $1.03 \%$ & $0.87 \%$ & $0.94 \%$ \\
\hline $\mathrm{XOM}$ & $1.08 \%$ & $1.09 \%$ & $4.44 \%$ & $1.07 \%$ & $1.11 \%$ & $1.10 \%$ & $0.98 \%$ \\
\hline GE & $1.61 \%$ & $1.64 \%$ & $5.66 \%$ & $1.69 \%$ & $1.58 \%$ & $1.45 \%$ & $1.43 \%$ \\
\hline HPQ & $1.16 \%$ & $1.16 \%$ & $3.09 \%$ & $1.13 \%$ & $1.20 \%$ & $1.20 \%$ & $1.18 \%$ \\
\hline HD & $1.15 \%$ & $1.16 \%$ & $3.55 \%$ & $1.11 \%$ & $1.21 \%$ & $1.01 \%$ & $1.10 \%$ \\
\hline INTC & $1.10 \%$ & $1.10 \%$ & $2.90 \%$ & $1.08 \%$ & $1.12 \%$ & $1.01 \%$ & $1.10 \%$ \\
\hline IBM & $1.15 \%$ & $1.15 \%$ & $3.98 \%$ & $1.14 \%$ & $1.17 \%$ & $1.11 \%$ & $1.10 \%$ \\
\hline JNJ & $1.13 \%$ & $1.17 \%$ & $5.11 \%$ & $1.17 \%$ & $1.15 \%$ & $1.03 \%$ & $0.80 \%$ \\
\hline MCD & $1.01 \%$ & $1.02 \%$ & $3.75 \%$ & $1.00 \%$ & $1.05 \%$ & $0.98 \%$ & $0.81 \%$ \\
\hline MRK & $1.00 \%$ & $1.00 \%$ & $3.54 \%$ & $0.96 \%$ & $1.06 \%$ & $0.91 \%$ & $0.98 \%$ \\
\hline MSFT & $1.32 \%$ & $1.35 \%$ & $4.21 \%$ & $1.38 \%$ & $1.30 \%$ & $1.16 \%$ & $1.32 \%$ \\
\hline MMM & $0.99 \%$ & $1.00 \%$ & $3.92 \%$ & $0.97 \%$ & $1.03 \%$ & $0.87 \%$ & $0.87 \%$ \\
\hline PFE & $1.10 \%$ & $1.11 \%$ & $3.80 \%$ & $1.09 \%$ & $1.14 \%$ & $1.00 \%$ & $1.02 \%$ \\
\hline PG & $1.15 \%$ & $1.18 \%$ & $5.07 \%$ & $1.21 \%$ & $1.15 \%$ & $1.07 \%$ & $0.92 \%$ \\
\hline TRV & $1.54 \%$ & $1.55 \%$ & $5.44 \%$ & $1.41 \%$ & $1.71 \%$ & $1.43 \%$ & $1.28 \%$ \\
\hline UTX & $1.08 \%$ & $1.08 \%$ & $3.90 \%$ & $1.04 \%$ & $1.14 \%$ & $0.92 \%$ & $0.94 \%$ \\
\hline $\mathrm{VZ}$ & $1.10 \%$ & $1.11 \%$ & $4.12 \%$ & $1.07 \%$ & $1.15 \%$ & $1.04 \%$ & $0.92 \%$ \\
\hline WMT & $1.10 \%$ & $1.11 \%$ & $4.02 \%$ & $1.09 \%$ & $1.14 \%$ & $1.05 \%$ & $0.90 \%$ \\
\hline Average & $1.19 \%$ & $1.20 \%$ & $4.05 \%$ & $1.17 \%$ & $1.23 \%$ & $1.10 \%$ & $1.08 \%$ \\
\hline
\end{tabular}

Note to Table: For the S\&P500 index and for each firm we compute the implied volatility root mean squared error (IVRMSE) along with the vega-based approximation used in estimation and IVRMSE divided by the average market IV from Table 1. We also report IVRMSE for out-of-the-money (OTM) and in-the money (ITM) put options separately. Finally, we report IVRMSE for at-the-money (ATM) 2 month and 6 month to maturity options. At the money is defined by $0.975<\mathrm{S} / \mathrm{K}<1.025$. 


\section{Table 8: Idiosyncratic Variance Correlation Matrix}

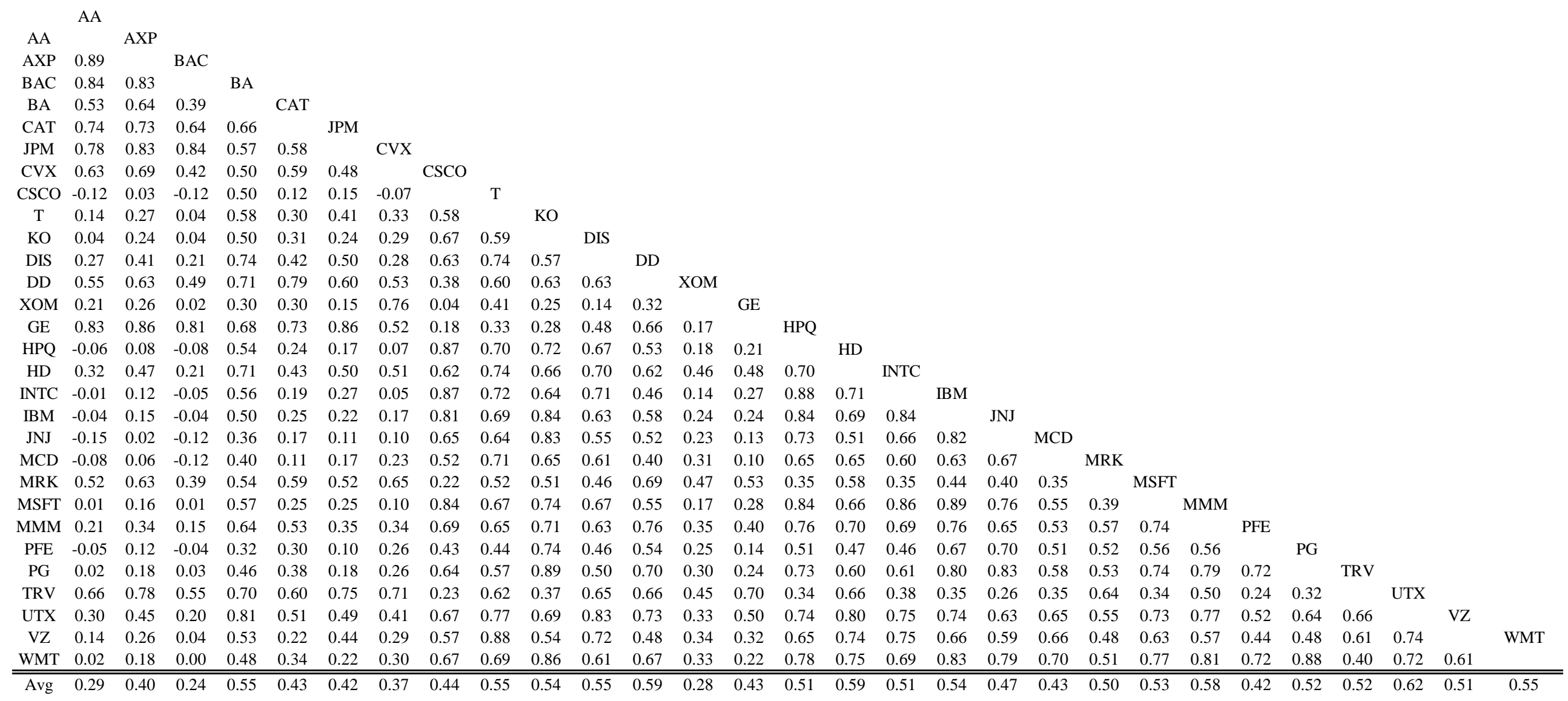

Note to Table: We report the sample correlation matrix of the time-series of idiosyncratic spot variances. 1996-2010. 
2013-29: Jiti Gao, Shin Kanaya, Degui Li and Dag Tjøstheim: Uniform Consistency for Nonparametric Estimators in Null Recurrent Time Series

2013-30: Ulrich Hounyo: Bootstrapping realized volatility and realized beta under a local Gaussianity assumption

2013-31: Nektarios Aslanidis, Charlotte Christiansen and Christos S. Savva: Risk-Return Trade-Off for European Stock Markets

2013-32: Emilio Zanetti Chini: Generalizing smooth transition autoregressions

2013-33: Mark Podolskij and Nakahiro Yoshida: Edgeworth expansion for functionals of continuous diffusion processes

2013-34: Tommaso Proietti and Alessandra Luati: The Exponential Model for the Spectrum of a Time Series: Extensions and Applications

2013-35: Bent Jesper Christensen, Robinson Kruse and Philipp Sibbertsen: A unified framework for testing in the linear regression model under unknown order of fractional integration

2013-36: Niels S. Hansen and Asger Lunde: Analyzing Oil Futures with a Dynamic Nelson-Siegel Model

2013-37: Charlotte Christiansen: Classifying Returns as Extreme: European Stock and Bond Markets

2013-38: $\quad$ Christian Bender, Mikko S. Pakkanen and Hasanjan Sayit: Sticky continuous processes have consistent price systems

2013-39: Juan Carlos Parra-Alvarez: A comparison of numerical methods for the solution of continuous-time DSGE models

2013-40: Daniel Ventosa-Santaulària and Carlos Vladimir Rodríguez-Caballero: Polynomial Regressions and Nonsense Inference

2013-41: $\quad$ Diego Amaya, Peter Christoffersen, Kris Jacobs and Aurelio Vasquez: Does Realized Skewness Predict the Cross-Section of Equity Returns?

2013-42: Torben G. Andersen and Oleg Bondarenko: Reflecting on the VPN Dispute

2013-43: $\quad$ Torben G. Andersen and Oleg Bondarenko: Assessing Measures of Order Flow Toxicity via Perfect Trade Classification

2013-44: Federico Carlini and Paolo Santucci de Magistris: On the identification of fractionally cointegrated VAR models with the $F(d)$ condition

2013-45: $\quad$ Peter Christoffersen, Du Du and Redouane Elkamhi: Rare Disasters and Credit Market Puzzles

2013-46: $\quad$ Peter Christoffersen, Kris Jacobs, Xisong Jin and Hugues Langlois: Dynamic Diversification in Corporate Credit

2013-47: Peter Christoffersen, Mathieu Fournier and Kris Jacobs: The Factor Structure in Equity Options 